\title{
LABORATORY MEASUREMENT OF ELECTRICAL AND HYDRAULIC \\ PROPERTIES OF REGOLITH OVER GRANITIC BEDROCK
}

by

Taylor James Bienvenue

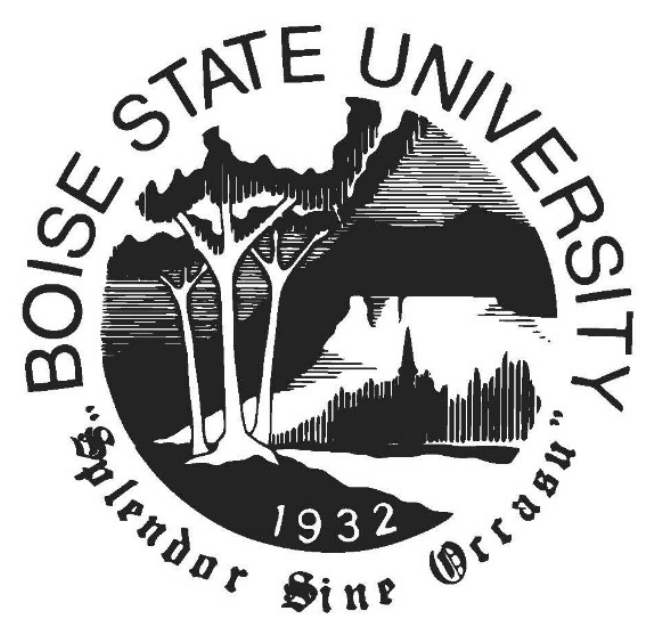

\author{
A thesis \\ submitted in partial fulfillment \\ of the requirements for the degree of \\ Master of Science in Hydrologic Sciences \\ Boise State University
}

August 2021 
(C) 2021

Taylor James Bienvenue

\section{ALL RIGHTS RESERVED}




\title{
BOISE STATE UNIVERSITY GRADUATE COLLEGE
}

\section{DEFENSE COMMITTEE AND FINAL READING APPROVALS}

\author{
of the thesis submitted by
}

Taylor James Bienvenue

Thesis Title: Laboratory Measurement of Electrical and Hydraulic Properties of Regolith Over Granitic Bedrock

Date of Final Oral Examination: $\quad 18$ June 2021

The following individuals read and discussed the thesis submitted by student Taylor James Bienvenue, and they evaluated the student's presentation and response to questions during the final oral examination. They found that the student passed the final oral examination.

Qifei Niu, Ph.D.

James P. McNamara, Ph.D.

Jacob Anderson, Ph.D.
Chair, Supervisory Committee

Member, Supervisory Committee

Member, Supervisory Committee

The final reading approval of the thesis was granted by Qifei Niu, Ph.D., Chair of the Supervisory Committee. The thesis was approved by the Graduate College. 


\section{ACKNOWLEDGMENTS}

I would like to recognize and thank the faculty within the Department of Geosciences at Boise State University. I specifically want to thank my advisor Dr. Qifei Niu for allowing me the opportunity to continue my intellectual and academic development at Boise State University. It has been an honor to work with him and I am forever grateful. Moreover, I would like to thank my committee members, Dr. James McNamara and Dr. Jake Anderson, for taking the time to serve on my thesis committee. Their help and guidance throughout this project have been greatly appreciated. Lastly, I would like to acknowledge the financial support provided by the Boise State University. 


\begin{abstract}
Characterizing water flux within the critical zone $(\mathrm{CZ})$ is essential for a multitude of studies and applications related to irrigation, drainage, water management, and contaminant transport. Trying to measure water flux in the critical zone, specifically in the subsurface, is difficult due to the associated structural heterogeneity and complex interactions taking place between biological, chemical, and physical processes. Current methods (i.e., inferred from soil suction and soil moisture measurements) to characterize water flux within the critical zone can be time consuming and are not directly related to water flux. Recent literature has provided evidence that self-potential (SP) is a promising tool to characterize water flux within the vadose zone. In hydrological settings, SP is the electric potential signal generated mainly by water-flux within a porous medium through the electrokinetic phenomenon. By combining SP with more established methods, such as soil suction measurements, it is possible to efficiently and completely describe water flux within the subsurface.

The use of SP for field CZ hydrological applications has been halted by a lack of understanding of the relationship between the hydraulic and electrical properties of earth materials in the CZ. Thus, the aim of this study is to improve the measurement technique and understanding of the electrical properties and hydraulic properties of CZ soils. Samples from the regolith overlying a granitic bedrock at the Treeline study site within the greater Dry Creek Experimental Watershed (Boise, ID) are used in this study. The central hypothesis is that, in addition to texture, mineralogical composition has a
\end{abstract}


significant effect on the hydraulic and electrical properties of $\mathrm{CZ}$ soils. In order to evaluate this hypothesis, a novel soil column system has been built to measure the electrical and hydrological properties of soils at both saturated and unsaturated conditions. For saturated tests, the soil column system mirrors that of a constant-head setup for permeability tests. The soil column system includes two newly designed hydrogeophysical probes that can make SP and pressure head measurements simultaneously. In this study, the design, fabrication, and evaluation of the proposed experimental setup is presented. Moreover, the regolith samples, and a sand sample (for reference), are evaluated via saturated testing (to measure the saturated soil properties) and unsaturated testing (to measure the unsaturated soil properties).

Experimental results demonstrate both the vertical heterogeneity in the regolith and the significant impact of the mineralogy (specifically clay minerals) on both the electrical and hydrological properties of $\mathrm{CZ}$ soils. Within the subsurface of the $\mathrm{CZ}$, clay mineral content tends to increase with distance from the bedrock due to chemical weathering. The associated increase in clay minerals is matched by a proportional decrease in saturated hydraulic conductivity, streaming potential coupling coefficient, and increase in surface conduction. Moreover, it was found that in addition to permeability (textural influence), the zeta potential at the mineral-water interface (i.e., mineralogical influence) also controls the magnitude of the streaming potential coupling coefficient, and therefore the SP response relative to changes in pore water pressure head.

The quality of experimental data suggests the proposed experimental setup, at its current state, is ideal for evaluating the electrical and hydrological properties of coarsegrained soils. The measured response of the electrical and hydrological properties of the 
coarse-grained soils were closely aligned with the theoretical expectations. The measured response for soils with a greater quantity of clay minerals identified some limitations of the experimental setup. However, with some minor modifications, the experimental setup may become a preferred method for measuring both clay-bearing soils and coarse-grained soils. Moreover, the results of the unsaturated tests produce unsaturated soil properties in line with theoretical trends. The quality of parameters obtained from the unsaturated tests indicate the ability of the test setup to obtain useful information regarding the unsaturated portion of the critical zone. 


\section{TABLE OF CONTENTS}

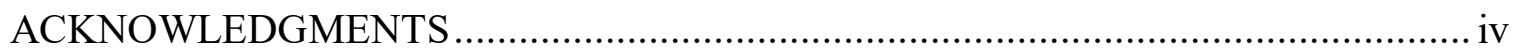

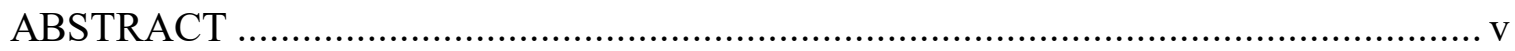

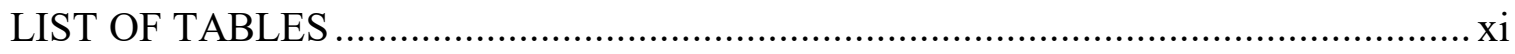

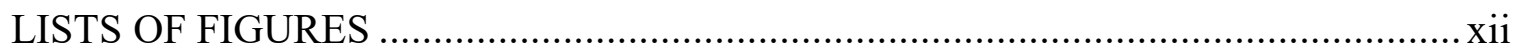

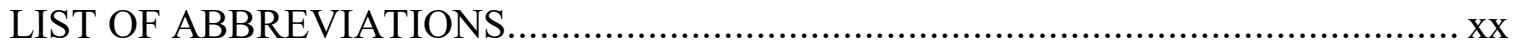

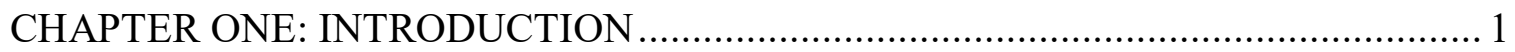

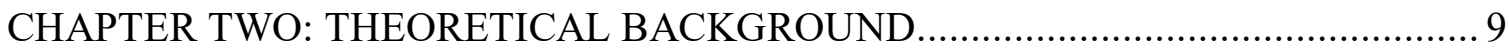

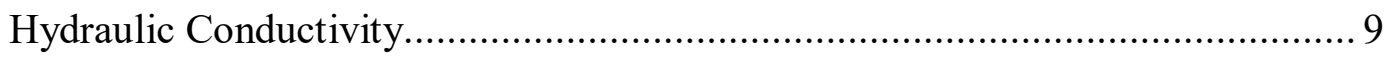

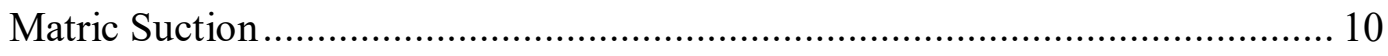

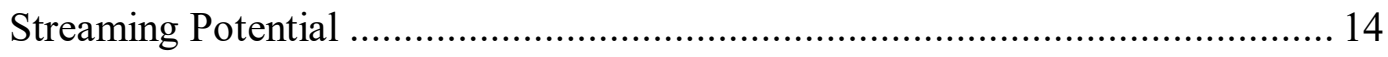

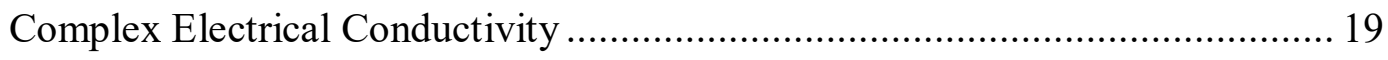

CHAPTER THREE: DEVELOPMENT OF A LABORATORY SOIL COLUMN SYSTEM FOR SIMULTANEOUSLY MEASUING ELECTRICAL AND HYRAULIC

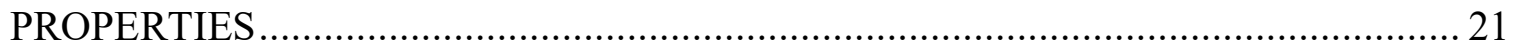

Design and Fabrication of the Soil Column System ……………...................... 21

An Integrated Hydrogeophysical Probe ................................................. 21

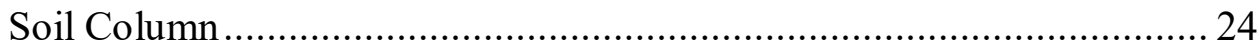

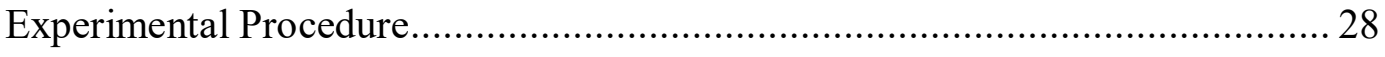

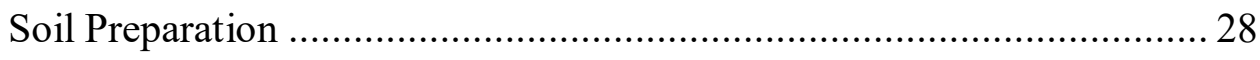

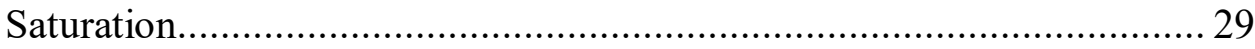


Constant Head Test.............................................................................

Characterization of Soil Samples ……………………….........................

Performance of the Hydrogeophysical Probe........................................................32

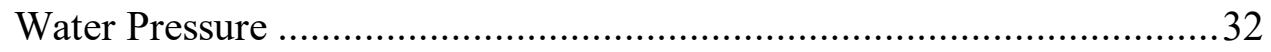

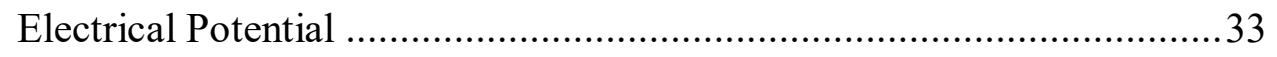

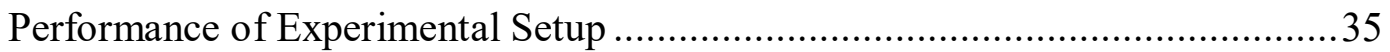

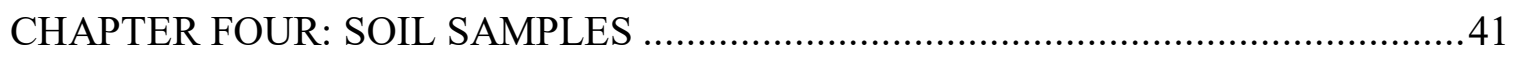

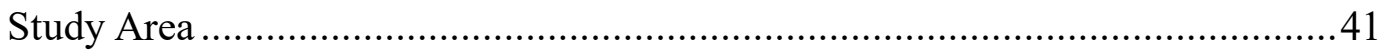

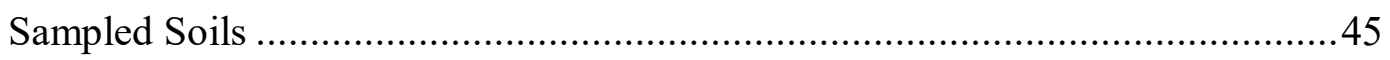

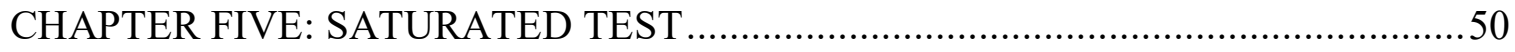

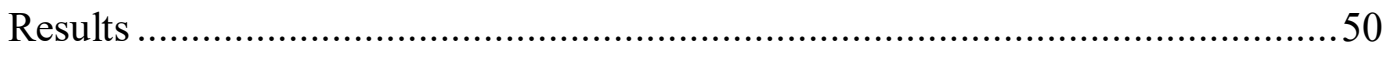

Performance of Experimental Setup ………..................................................5

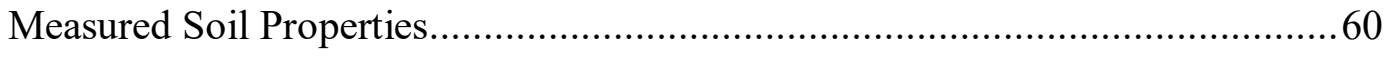

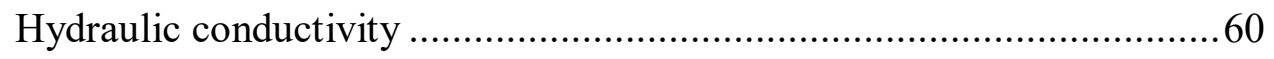

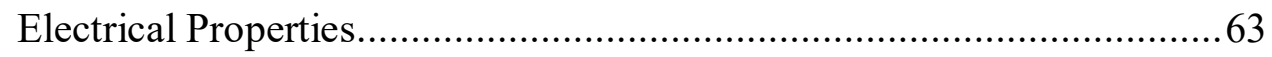

Streaming Potential Coupling Coefficient ...............................................66

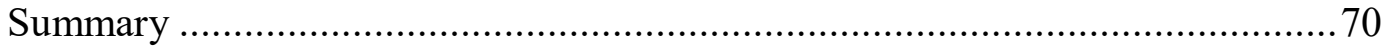

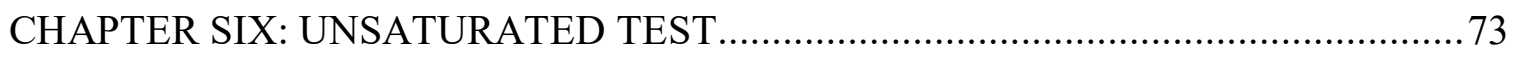

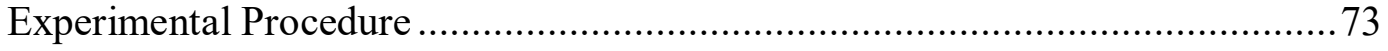

Hydraulic and Electrical Modeling of the Unsaturated Response.........................75

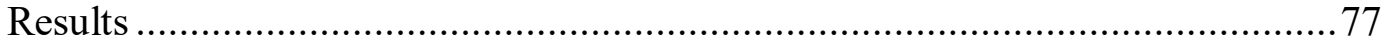

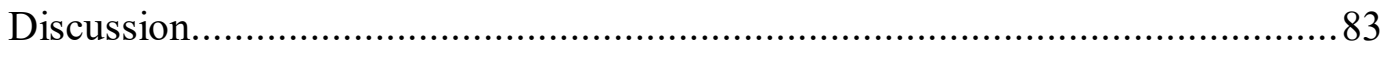

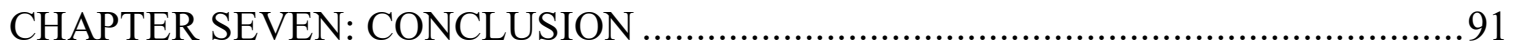




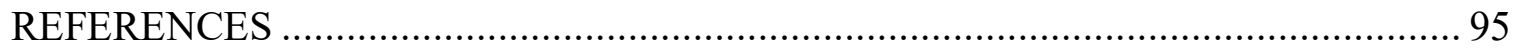




\section{LIST OF TABLES}

Table 1 XRD results of the silica sand used in the validation of the experimental setup. The sample is made up of no clays and only three mineral types. .39

Table 2 Summary of the silica sand's petrophysical properties. The real electrical conductivity and imaginary conductivity were measured at a frequency of

Table 3 XRD analysis of the three Treeline samples and RS -1 . Values represent the normalized weight percent a given mineral for its respective soil sample.

Table 4 Summary of the measured petrophysical properties of five for soil samples. The real electrical conductivity and imaginary conductivity were measured at a frequency of $0.077 \mathrm{~Hz}$. The formation factor $F$ was found using Equation 16 where the contribution for surface conductivity was accounted for. The apparent formation factor $F_{a}$ does not account for surface conduction and is simply calculated as fluid conductivity $\sigma_{f}$ divided by the real electrical conductivity $\sigma^{\prime}$. The water conductivity $\sigma_{f}$ at which the complex conductivity was measured is also reported in the table.

Table 5 Calculated formation factor $F$ values based on Archie's law (Equation 15) with a constant cementation factor $m$ (1.4). Using Equation 17, the surface conduction $\sigma_{s}$ was calculated. .66

Table 6: $\quad$ The Brooks-Corey parameters and electrical properties of each soil used to model the drainage process in COMSOL. For reference, published Brooks-Corey values of a sand (Del Monte Sand), to compare with the sand sample RS - 1, and a sandy loam (Columbia Sandy Loam), to compare with the sandy loam samples $\mathrm{TL}-1, \mathrm{TL}-2$, and $\mathrm{TL}-3$, have been included in the table. 


\section{LISTS OF FIGURES}

Figure 1 A representative stratigraphic profile of the critical zone with associated mechanisms of weathering. The regolith includes the soil and saprolite layers. The profile shown here represents a system pre-dominantly formed via in-situ processes. The black dashed line represents residual particle trajectory. The blue line represents a water flow path. Not all layers presented here may be present in all systems. Figure is modified from Anderson et al. (2007).....

Figure 2 Diagram showing the electric double layer formed around a grain, which is negatively charged on the surface. The inner Stern layer is in direct contact with the grain. The diffuse layer is outside the Stern layer and is only connected to the grain via Coulombic interactions. Figure is from Revil et al. (2014).

Figure 3 This diagram represents the mineral-water interface of a saturated porous medium with an applied hydraulic gradient driving water flow. Water is moving from left to right. The flow of water drags the excess cations in the diffuse layer in the direction of fluid flow. The resulting streaming current $J_{s}$ and counterbalancing conduction current $J_{c}$ give rise to the electrical potential distribution along the flow path (i.e., streaming potential). In the figure, streaming current $J_{s}$, which is contributed from excess cations in the diffuse layer, moves from left to right; conduction current $J_{c}$, a net effect of $J_{c(+)}$ and $J_{c(-)}$ in the bulk water, moves from right to left.

Figure 4 (a) Schematic of the proposed probe design. The proposed schematic resembles that of a traditional tensiometer. The obvious difference is the inclusion of a silver/silver chloride electrode. (b) A prototype of the integrated hydrogeophysical probe developed in this project. Location 1 represents the pressure transducer that is be used to measure soil water pressure. 2 is an air release point. 3 is a non-polarizable silver/silver chloride electrode. 4 is a porous ceramic cup with an air entry value of 1 bar. The porous ceramic cup ensures air will not enter probe's reservoir and the electrode and pressure transducer remain in constant contact with

water. 
Figure 5 The Advanced Tensiometer sensor (pressure transducer) used to measure the water pressure in the probe. The probe is equipped with a beveled fitting that is compatible with the beveled rubber stopper, seen here, to allow a secure, airtight connection. Figure is modified from Aishlin et al.

Figure 6 The soil column to be used for testing. Seen here are the designed probes inserted into the soil column, as well as, factory-built $\mathrm{Ag} / \mathrm{AgCl}$ nonpolarized electrodes. Both sets of electrodes are connected to the data logger via coaxial cables. .25

$\begin{array}{ll}\text { Figure } 7 & \text { (a) Schematic of the saturated testing setup and (b) view of the saturated }\end{array}$ experimental setup in the lab. In (a), black arrows indicate the direction of flow and in (b), red arrows indicate the direction of flow. For both (a) and (b), water moves from (1) the upper constant head reservoir to the soil column, then to (2) the lower constant head reservoir, and then to (3) the storage reservoir before it is finally (4) pumped back to the upper constant head reservoir. The hydraulic gradient may be adjusted by opening or closing the valve at the bottom of the soil column or by adjusting the elevation of the lower constant head reservoir. .26

Figure 8 A bird's eye view of the soil column during preparation of a soil sample. At this point, the hydrogeophysical probe is installed by inserting the porous ceramic cup into the soil column.

Figure 9 Results from pre-emplacement calibration of the pressure transducers used in the soil column tests. Both sensors had a nearly linear relationship with very minimal offset.

Figure 10 (a) represents the real conductivity measured using three different nonpolarizable electrodes. Real conductivity values represent the bulk conductivity of the entire sample. (b) represents the imaginary conductivity associated with the EDL polarization. The complex conductivity measured from these three electrodes are nearly identical...35

Figure 11 Plots representing (a) total head (expressed as $\mathrm{kPa}$ ) and (b) electrical potential difference (SP signal) measured between two probes during testing. Vertical black lines represent changes in the hydraulic gradient. The first interval is representative of a hydrostatic state, the next five intervals represent increases in hydraulic gradients, and the last interval is again a hydrostatic state. The first hydrostatic interval is zero because the initial voltage has been removed. The grey lines in (b) represent the raw, unprocessed electrical potential. The blue line is a 60 -period moving average of the raw signal. 
Figure 12 The average SP response to changes in total head. Error bars represent the standard deviation from average values. $C_{\text {sat }}$ represents the streaming potential coupling coefficient (Equation 11). 38

Figure 13 Specific discharge $q$ at different hydraulic gradients. A linear relationship between $q$ and the hydraulic gradient is consistent with the prediction of Darcy's Law, which usually holds for granular sands. ........................ 38

Figure 14 Results from the complex conductivity tests for the silica sand 39

Figure 15 Aeriel photograph of the Treeline study site. The estimated boundary of the Treeline catchment is indicated by the white dashed line. The red line is the location of the ERT survey line. The star represents the location of the sampled soils.

Figure 16 The two-dimensional distribution of electrical resistivity of the subsurface under a ridgeline at the Treeline site. The soil sample location is indicated by the star symbol. The variation of the electrical resistivity values, both laterally and vertically, demonstrate the heterogeneous structure of the CZ. The test was conducted during the summer. 44

Figure 17 Soil pit with representative sample locations. TL - 1 lies directly beneath the organically abundant $\mathrm{A}$ and $\mathrm{O}$ soil horizons. TL - 2 contains no organic material and is predominately coarse sands. However, there are some pebbles of poorly cemented bedrock material within this layer. TL-3 is directly overlying the bedrock. The total soil pit depth is about $80 \mathrm{~cm}$. Samples collected represent a vertical depth of $10 \mathrm{~cm}$.

Figure 18 Grainsize distribution of sampled soils. RS - 1, sampled from a nearby creek, is a well sorted sand, containing almost no silts or clay sized minerals. The Treeline samples represent an overall fining upwards sequence. All samples, however, contain less than $10 \%$ silt or clay sized minerals. The Treeline samples can be classified as loamy sand.

Figure 19 The saturated testing results for $\mathrm{RS}-1$ : a) total head (expressed as $\mathrm{kPa}$ ) measured from the two probes, b) the measured self-potential (voltage difference between the top probe and bottom probe), c) specific discharge versus applied hydraulic gradient, and d) self-potential versus change in total head. Different flow intervals are separated by the vertical black lines in a) and b). The data points in c) and d) represent the average value for each interval and the associated error bars indicate one standard deviation. In b) the grey line represents the raw data and the blue line is the 60 second moving average value. Both (c) and (d) demonstrate an almost perfect linear relationship. 
Figure 20 The saturated testing results from the deepest sampled $\mathrm{CZ}$ soil $(70 \mathrm{~cm}$ below the surface), TL - 3: a) total head (expressed as $\mathrm{kPa}$ ) measured from the two probes, b) the measured self-potential (voltage difference between the top probe and bottom probe), c) specific discharge versus applied hydraulic gradient, and d) self-potential versus change in total head. Different flow intervals are separated by the vertical black lines in a) and b). The data points in c) and d) represent the average value for each interval and the associated error bars indicate one standard deviation. In b) the grey line represents the raw data and the blue line is the 60 second moving average value. Relative to $\mathrm{RS}-1$ and $\mathrm{S}-1$, the change in total head is similar, but the flow rate is significantly lower. As a result, the calculated hydraulic conductivity (c) is about three magnitudes lower than RS -1 and S -1 . Both (c) and (d) demonstrate an almost perfect linear relationship, but there is a relatively large standard deviation associated with each point which may be a point of concern for future interpretations.

Figure 21 The saturated testing results for the sample taken $40 \mathrm{~cm}$ below the surface, $\mathrm{TL}-2$ : a) total head (expressed as $\mathrm{kPa}$ ) measured from the two probes, b) the measured self-potential (voltage difference between the top probe and bottom probe), c) specific discharge versus applied hydraulic gradient, and d) self-potential versus change in total head. Different flow intervals are separated by the vertical black lines in a) and b). The data points in c) and d) represent the average value for each interval and the associated error bars indicate one standard deviation. In b) the grey line represents the raw data and the blue line is the 60 second moving average value. In d), a slope that does not pass through an origin is shown due to the improved fit.

Figure 22 The saturated testing results for the sample taken $10 \mathrm{~cm}$ from the surface, $\mathrm{TL}$ - 1: a) total head (expressed as $\mathrm{kPa}$ ) measured from the two probes, $\mathrm{b}$ ) the measured self-potential (voltage difference between the top probe and bottom probe),c) shows each electrodes SP response relative to an external ground, d) specific discharge versus applied hydraulic gradient, and e) self-potential versus change in total head. Different flow intervals are separated by the vertical black lines in a), b), and c). The data points in d) and e) represent the average value for each interval and the associated error bars indicate one standard deviation. In b) the grey line represents the raw data and the blue line is the 60 second moving average value. Through observation of the electrode's absolute values in c), there is an observed SP signal change relative to changes in the hydraulic gradient that is not observed in b). With respect to the other soil samples, TL -1 has the lowest coefficient of determination observed for plots d) and e)..56 
Figure 23 Measured hydraulic conductivity plotted against porosity. S - 1 represents the silica sand sample used to validate the experimental setup (see Chapter Three). The lines on the graph represent the Kozeny-Carman equation (Equation 3) with different effective grain/pore sizes $(1 \mathrm{~mm}, 0.1 \mathrm{~mm}$, and $0.01 \mathrm{~mm})$. The Kozeny-Carman equation does well to predict the measured $K$ relative to the $\mathrm{d}_{10}$ values for RS-1 $(0.21 \mathrm{~mm})$ and $\mathrm{S}-1(0.31$ $\mathrm{mm})$. The measured hydraulic conductivity values for $\mathrm{TL}-1, \mathrm{TL}-2$, and $\mathrm{TL}-3$, which have $d_{10}$ values equal to $0.09 \mathrm{~mm}, 0.1 \mathrm{~mm}$, and $0.13 \mathrm{~mm}$ respectively, are underestimated relative to the values of the KozenyCarman equation.

Figure 24 Formation factor plotted relative to porosity. The formation factor can be predicted from porosity and a cementation factor $(m)$ as demonstrated in Archie's Law (Equation 15). Lines represent the predicted formation factor as a function of porosity, with a constant cementation factor. Expected $m$ for unconsolidated soils range from 1.3 to 2.3 . TL -1 and TL -2 fall below the minimum expected value. This is not completely unexpected since Archie's Law is developed to interpret samples made up of predominantly clean sands (Glover et al., 2000). TL -1 and TL -2 are made up of more silt/clay then the other samples and may not be applicable to Archie's Law. 65

Figure 25 Saturated Streaming potential coupling coefficient $C_{\text {sat }}$ plotted relative to the permeability $k$. The lines represent the predicted permeability using Equation 18) with the zeta potentials $-0.019 \mathrm{~V}$ (orange), $-0.009 \mathrm{~V}$ (blue), and $-0.001 \mathrm{~V}$ (green). The fluid conductivity $\boldsymbol{\sigma} \boldsymbol{f}$ is assumed constant at $1.92 \times 10^{-3} \mathrm{~S} / \mathrm{m}$, a reasonable assumption considered the relatively small variation in fluid conductivity between samples (Table 4). Moreover, the formation factor $F$ is assumed constant at 2.87 based on the lack of variability between the samples (Table 5). Based on the plotted functions, the zeta potential plays a significant role in the magnitude of coupling coefficient values. Coupling coefficient values are reported as absolute values. 
Figure 26 Saturated Streaming potential coupling coefficient $C_{\text {sat }}$ plotted with average grain diameter using Equation 19. The fluid conductivity $\boldsymbol{\sigma} \boldsymbol{f}$ is assumed constant at $1.92 \times 10^{-3} \mathrm{~S} / \mathrm{m}$, a reasonable assumption considered the relatively small variation in fluid conductivity between samples (Table 4). Moreover, the formation factor $F$ is assumed constant at 2.87 based on the lack of variability between the samples (Table 5).With relatively similar average grain diameters, it is apparent that the zeta potential has a significant impact on the streaming potential coupling coefficient values. The predicted zeta potentials seem to be a reflection of the mineralogy. TL -1 has the highest clay content (i.e., highest CEC) and lowest predicted zeta potential. RS -1 and $\mathrm{S}-1$ have the lowest clay content (i.e., lowest CEC) and highest predicted zeta potentials. Coupling coefficient values are reported as absolute values.

Figure 27 The distribution of petrophysical properties with depth for the regolith samples. RS - 1 is included to be a representative sample of the bedrock. The effective grain size and electrical properties (i.e., $F_{a}, \sigma_{\text {sur }}, C_{\text {sat }}, \zeta$, and $\left.\boldsymbol{\sigma}^{\prime \prime}\right)$ reflect the fining upward sequence and increase in clay mineral content with decreasing soil depth. .72

Figure 28 The experimental setup for unsaturated testing. (1) represents the height of the water level during the pre-drainage hydrostatic period. Once drainage commences, water flows from the soil column to the lower constant head reservoir (2). From the lower constant head reservoir, water flows into the container atop the scale (3). The weight of water in the container is recorded every second. The rate at which water is draining from the soil column can be calculated based on weight in the container for a given time.

Figure 29 The measured and modeled electrical and hydraulic responses during the drainage process for RS - 1 . The shaded area represents the measured response at a hydrostatic state. (a) is the total head difference between the two probes. The overall measured trend is in good agreement with the modeled signal. The measured pressure starts to approach zero at $120 \mathrm{~s}$. The modeled pressure, however, consolidates at about one kilopascal, indicating some hydraulic gradient still inducing fluid flow. (b) and (c) represents the SP response and the total volume of drained water. The measured SP signal is a 60 - period moving average of the raw signal. Both (b) and (c) are show promising results for the proposed method to measure the drained response in sand samples. 
Figure 30 The measured and modeled electrical and hydraulic responses during the drainage process for $\mathrm{TL}-3$. The shaded area represents the measured response at a hydrostatic state. (a) is the total head difference between the two probes. Although the two signals show the same trend, the magnitude between the measured and modeled results are significantly different. (b) and (c) represents the SP response and the total volume of drained water. The measured SP signal is a 60 - period moving average of the raw signal. The measured and experimental SP signal both show a similar trend, but the measured signal is associated with some obvious noise. (c) represents a good relationship between the modeled and experimental cumulative flow

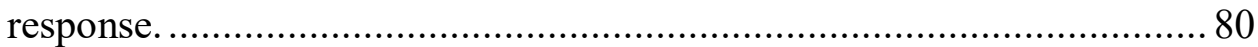

Figure 31 The measured and modeled electrical and hydraulic responses during the drainage process for TL -2 . The shaded area represents the measured response at a hydrostatic state. (a) is the total head difference between the two probes. Like TL -3 , the two signals show a parallel trend, but the magnitude between the measured and modeled results are significantly different. (b) shows the SP response. The measured SP signal is a $60-$ period moving average of the raw signal. The experimental signal for the first $\sim 5500$ s of testing is similar to the modeled response. After this point, experimental SP signal increases. This response is not associated with an observed hydraulic gradient increase, indicating it is most likely a result of some external influence. (c) represents an agreeable relationship between the modeled and experimental cumulative outflow response.

Figure 32 The measured and modeled electrical and hydraulic responses during the drainage process for $\mathrm{TL}-1$. The shaded area represents the measured response at a hydrostatic state. (a) is the total head difference between the two probes. For this sample, there is again a similar signal produced by the modeled and experimental measurements. (b) shows the SP response. The measured SP signal is a 60 - period moving average of the raw signal. The experimental signal seems to follow the same trend as the modeled results, but the associated noise with the experimental signal make it difficult to make any definitive conclusions about response. (c) shows the total volume of water drained and again, both signals are in good agreement. 82 
Figure 33 (a) represents the soil water pressure (tension) versus the effective saturation. Both the sand samples (RS-1 and Del Monte Sand), red and pink lines, are in good agreement with one another. The regolith samples have a similar shape to their sandy loam counterpart (the Columbia Sandy Loam), but they have a lower air-entry pressure head $\left(\psi_{b}\right)$ relative to the Columbia Sandy Loam, and therefore, become unsaturated $(\Theta<1)$ at a lower pressure head. The air-entry pressure head values, however, seem to reflect their relative grainsize distribution. The sand samples have the lowest air-entry pressure head, while the sandy-loam samples have the highest. (b) represents the change in unsaturated hydraulic conductivity with increasing pressure head. Here, the sand samples show a steep decrease in hydraulic conductivity with increasing pressure, while the sandy loam samples have a more gradual change in hydraulic conductivity with increasing pressure. * Samples are from Lappala et al., 1983. 


\section{LIST OF ABBREVIATIONS}

CEC

$\mathrm{CZ}$

$\mathrm{BC}$

EDL

ERT

GPR

$\mathrm{KC}$

SP

SWRC

XRD
Cation Exchange Capacity

Critical Zone

Brooks-Corey

Electric Double Layer

Electrical Resistivity

Ground Penetrating Radar

Kozeny-Carman

Self-Potential

Soil Water Retention Curve

X-Ray Diffraction 


\section{CHAPTER ONE: INTRODUCTION}

Nearly all the variables necessary for sustaining life on Earth exist between the top of the trees and the bottom of active groundwater circulation (Brantley et al., 2007). Because of its relative importance, this outermost layer of Earth's surface has been labeled by scientists as the Critical Zone $(\mathrm{CZ})$ and was deemed one of the most compelling research areas in the Earth sciences in the $21^{\text {st }}$ century by the US National Research Council (NRC, 2001). The CZ contains all the resources to sustain terrestrial life and is therefore inherently complex. The $\mathrm{CZ}$ is shaped by processes taking place between rock, soil, water, air, and living organisms. It is the interactions between all these systems that cause tremendous spatial heterogeneity within the CZ (Anderson et al., 2007). The complexity of the $\mathrm{CZ}$ is brought to light when trying to quantify and understand the storage and movement of water within the CZ.

The subsurface of the $\mathrm{CZ}$ can be parsed into distinguishable layers identifiable as (from top to bottom) regolith, fractured rock, and bedrock. The regolith is defined in The Regolith Glossary (Eggleton, 2001) as: "The entire unconsolidated or secondarily recemented cover that overlies more coherent bedrock, that has been formed by weathering, erosion, transport and/or deposition of the older material." The uppermost portion of the regolith is simply referred to as "soil". Soil represents the interface between earth materials and the atmosphere, surface water, and biosphere. Soil is identifiable by its biotic components and genetic horizon organization (Pope, 2015). Regolith that has not been transported (i.e., formed in-situ) is referred to as saprolite 
(Anderson et al., 2007). Saprolite typically exists at the bedrock interface of the regolith. Both the formation and extent of soil and saprolite layers are a direct result of mechanical and/or chemical weathering processes (Anderson et al., 2007) (Figure 1).

Mechanical weathering is the physical breakdown of a material. Conversely, chemical weathering involves breaking down a material by changing its chemical composition. Although traditionally seen as separate processes, mechanical and chemical weathering often occur in parallel with positive feedback between the processes (Pope, 2015). The extent of each weathering process, however, is often determined by three variables: (1) time, (2) availability of rock and mineral decay agents, and (3) efficacy of rock and mineral decay agents (Pope, 2015). The factors that control these variables will vary based on climate, geology, aspect, soil depth, and elevation. For example, warm and wet climates will have significantly faster weathering rates relative to drier and colder climates (White \& Blum, 1995). Additionally, high temperature and/or high precipitation climates will generally have a deeper regolith (Migoń, 2013). Regarding aspect, Anderson et al. (2011) found the weathering front, within the northern hemisphere, to be deeper and saprolite more decayed on north-facing slopes than south-facing slopes. Moreover, areas with dense vegetation, low slopes angles, and high infiltration rates will have a greater regolith depth than contrasting minimal vegetation, high angle, and high surface runoff slopes (Pope, 2015). Bedrock that is susceptible to solution or dissolution (i.e., bedrock that contains minerals such as calcite, dolomite, and potassium feldspar), bedrock that is poorly cemented, and bedrock that has a high porosity and/or is highly fractured will often be associated with a thick regolith (Migoń, 2013; Pope, 2015). 


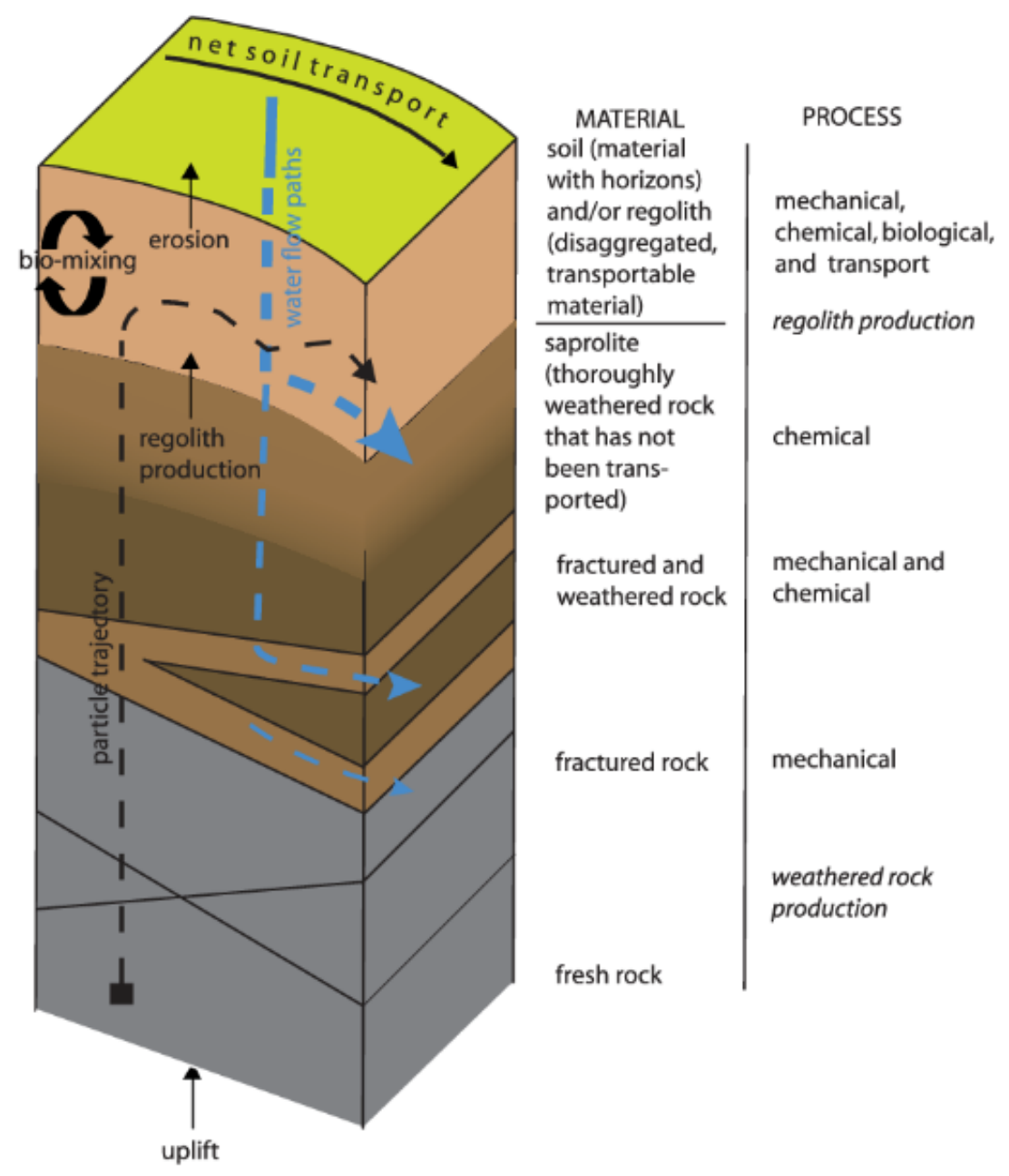

Figure 1 A representative stratigraphic profile of the critical zone with associated mechanisms of weathering. The regolith includes the soil and saprolite layers. The profile shown here represents a system pre-dominantly formed via insitu processes. The black dashed line represents residual particle trajectory. The blue line represents a water flow path. Not all layers presented here may be present in all systems. Figure is modified from Anderson et al. (2007).

It is imperative to characterize water movement and associated soil properties in the CZ. By understanding the hydrological properties and water flux within the subsurface, it is possible to generate important information regarding estimation of drainage, evapotranspiration, pollutant transport, aquifer recharge, and infiltration/runoff partition, each of which are essential for environmental, agronomical, and hydrological applications (Doussan et al., 2002). Characterizing water movement in the subsurface, 
however, is a difficult and time-consuming process. The vertical and lateral variations in the critical zone make it challenging to determine the subsurface properties necessary for quantifying and predicting water movement (e.g., hydraulic conductivity, hydraulic gradient, etc.). In addition to the difficulties associated with varying stratigraphy, the hydrological state in the CZ (e.g., water content, soil water tension or matric suction) is varying over space and time due to the heterogeneous $\mathrm{CZ}$ structure and subsurface interactions with the atmosphere and vegetation. Variations in the hydrological state of the $\mathrm{CZ}$ creates additional complications for the unsaturated portion of the $\mathrm{CZ}$ (i.e., vadose zone) where the pore space of geological materials is partially filled with water.

Important soil hydraulic properties in the vadose zone, such as hydraulic conductivity, are also dependent on the hydrological states and therefore more difficult to characterize in the vadose zone than in the saturated portion of the $\mathrm{CZ}$.

There are many techniques available for determining soil properties and hydrological characteristics (e.g., soil moisture and tension) in the subsurface. These measured soil properties and hydrological characteristics can be used to estimate or characterize the subsurface water movement (flux and direction). Currently, soil moisture can be measured using a variety of methods, such as neutron scattering, gamma ray attenuation, electrical conductivity probes, and time domain reflectometry (Gray \& Granger, 1986; Walker et al., 2004). An improved, slightly more direct approach to infer water movement is the use of tensiometers to measure differences in soil water pressure (Iwata \& Hirota, 2005). Tensiometers, however, only measure soil water pressure at point scale. When trying to quantify water movement in a medium as complex as the $\mathrm{CZ}$, point scale measurements alone may not be sufficient to completely describe the water flux and 
direction. Additionally, sensor sensitivity for both soil moisture and matric suction may be limited to periods when soil moisture is relatively high or when there is significant water movement (Voyteck et al., 2019).

Several geophysical methods exist that can offer spatially integrated monitoring of the subsurface properties. Examples include time-lapse electrical resistivity tomography (ERT) and ground penetrating radar (GPR). Both these methods provide a channel to image not only the subsurface properties over, for example, a hill-slope scale, but also dynamic changes in subsurface properties. Time-lapse ERT and GPR have been used extensively to characterize and monitor subsurface properties within the CZ (e.g., Doestsch et al., 2010; Klotzsche, 2019; Mangel et al., 2015; Miller et al., 2008; Robinson et al., 2012; Watlet et al., 2018). Although more spatially integrated than the previously mentioned point scale measurement methods, these geophysical imaging techniques are sensitive only to static or state variables (e.g. water content and mineralogy).

A more promising geophysical approach to quantify water movement (flux and flow direction) in the subsurface is to measure the self-potential (SP). This method directly measures the electrical signals generated by water flow in geological materials with a charged surface. The water flow generated SP signal (or streaming potential) may lead to improved interpretations relative to the measurement of hydraulic variables (e.g. soil moisture and matric suction) (Voytek et al., 2019). Currently, the SP method is predominantly associated with applications in the saturated zone. Relevant SP work includes monitoring pumping tests (Rizzo et al., 2004), mapping of contaminant plumes (Abbas et al., 2017), detecting dam leakage (Bolève et al., 2009), and sinkhole identification (Jardani et al., 2006). The number of hydrological studies using SP in the 
vadose zone, however, is relatively low (Jougnot et al., 2015). Of the studies that do exist, Jougnot et al. (2015) and Voytek et al. (2019) are the only two who have implemented field studies to measure the vertical SP distribution. The results from both these studies indicated that SP has the potential to provide spatially and temporally dense measurements of changes in subsurface water flow. The major factor hindering the use of SP to estimate water movement in the vadose zone is the quantitative interpretation of SP signals (Hu et al., 2020). Interpreting SP signals requires an understanding of the relationship between streaming potential and unsaturated/saturated water flow, as well as, the influence of basic soil properties, such as texture and mineralogy. Some laboratory work has been done to explore these relationships (e.g., Allègre et al., 2010, 2014; Chidichimo et al., 2015; Doussan et al., 2002; Jaafar et al., 2009; Revil et al., 2017a; Younes et al., 2018); however, continued exploration of these relationships must be done before meaningful hydrologic interpretations of SP signals can be made. In particular, more work is required before SP can be used for field CZ applications because the materials have not been systematically studied.

It is anticipated that by measuring SP and soil suction concurrently in the field, water flux estimation in the $\mathrm{CZ}$ can be better constrained relative to individual methods. By combining both hydrological and geophysical measurements, it is possible to have sufficient information to completely describe water movement in the CZ (Darnet \& Marquis, 2004). In addition, it is believed that hydraulic properties of the subsurface, such as water retention curves and the hydraulic conductivity function, can be estimated with less ambiguity if multiple datasets are used. There have been several attempts to jointly use SP and hydrological data. For example, Mboh et al. (2012) used a coupled 
hydrogeophysical inversion to estimate unsaturated soil properties from streaming potential signals; Straface et al. (2011) jointly inverted field hydraulic head and SP measurements to estimate the 3-D distribution of permeability in a shallow aquifer; and Jardani et al. (2013) used a stochastic joint inversion to reconstruct the hydraulic conductivity field between two wells from resistivity and SP data. In all these applications, it is apparent that we must better understand the linkage between SP signals and other soil properties (hydraulic conductivity, texture, mineralogy, etc.) to improve the interpretation of SP signals relative to water movement.

The hydraulic and electrical properties (and their relationships) of earth materials in the $\mathrm{CZ}$ have not been systematically studied. Thus, the aim of this study is to improve our understanding of the electrical properties and hydraulic properties of $\mathrm{CZ}$ soils. For the remainder of this paper, the term "soil" indicates the regolith layer of the $\mathrm{CZ}$ rather than the soil layer. The central hypothesis is that, in addition to texture, mineralogical composition has a significant effect on the hydraulic and electrical properties of CZ soils. A new hydrogeophysical soil column system was developed in this study. Using the novel soil column system, laboratory electrical and hydraulic experiments are performed on soil samples collected from the regolith over a granitic bedrock. The data collected in this study was used to analyze and test the hypothesis.

This thesis is organized as follows. First, the design and fabrication of the new laboratory setup is introduced. The experimental setup adopts the ideas of typical constant head measurements but has the added benefit of allowing the insertion of a newly designed hydrogeophysical probe in the soil column. The probe can be used to measure both the soil water pressure and electrical potential simultaneously in the soil. In 
addition, the proposed setup is made without any metal in order to accurately determine the electrical properties of a soil sample. There is no precedent for the experimental setup or probe, so tests have been performed to evaluate the performance of the new experimental setup and probe. After validation of the experimental system, three soil samples collected from the regolith above a granitic bedrock are tested to study the electrical and hydraulic properties of CZ soils. Two sand samples are also tested for a control. In addition, the usefulness and limitations of both the test setup and probe are also discussed. 


\section{CHAPTER TWO: THEORETICAL BACKGROUND}

In this section, background knowledge regarding some physical properties of soils are briefly reviewed. Soil properties discussed include hydraulic conductivity, matric suction, streaming potential, and complex electrical conductivity.

\section{Hydraulic Conductivity}

The hydraulic conductivity $K$ describes the ease at which fluid can travel through a porous medium (Schwartz \& Zhang, 2003). The equation describing fluid flow in a saturated medium is Darcy's Law:

$$
Q=-K_{\text {sat }} \frac{\Delta h}{\Delta x} A
$$

where $Q$ is the flow rate, $\frac{\Delta h}{\Delta x}$ is the hydraulic gradient (total head difference $\Delta h$ overflow distance $\Delta x$ ), and $A$ is the cross-sectional area. The magnitude of $K_{\text {sat }}$ is influenced by both the physical properties of the soil (e.g., grain size, grain distribution, grain shape, mineralogy, etc.) and the properties of the fluid (e.g., viscosity and fluid density) traveling through the medium. Therefore, each soil sample has a unique $K_{\text {sat }}$ value that is relative to the type of fluid traveling through it. To exclude the influence of the fluid, the intrinsic permeability $k$ of the sample can be calculated using the following equation (Schwartz \& Zhang, 2003):

$$
k=\frac{K_{\text {sat }} \mu}{\rho_{w} g}
$$


where $g$ is the gravitational acceleration and $\mu$ and $\rho_{w}$ represent the fluid viscosity and fluid density respectively.

To predict the hydraulic conductivity of soils, many theoretical and/or empirical models have been developed based on the physical properties of the soil and the fluid. One of the most popular models for granular materials is the Kozeny-Carman (KC) equation (Bear, 1972):

$$
K_{\text {sat }}=\frac{\rho_{w} g}{\mu}\left(\frac{\phi^{3}}{(1-\phi)^{2}}\right) \frac{d_{10}^{2}}{180}
$$

where $\phi$ is the porosity and $d_{10}$ is a representative grain size at which $10 \%$ of the sample is finer by weight. The KC model will be used in this study to guide the interpretation of the experimental data.

\section{Matric Suction}

Water in any medium moves because of an energy gradient. In the subsurface, spatial difference between total head values (i.e. the sum of elevation head and pressure head) represent the gradient that drives water flow (Schwartz \& Zhang, 2003). By measuring the pressure head (or water pressure) at multiple points, the gradient between these points may be calculated and the water movement can be estimated according to a governing groundwater flow equation, such as Darcy's Law (Equation 1). In a saturated porous medium, the water pressure is usually positive relative to atmospheric pressure. In an unsaturated medium, the pressure of pore water is usually negative (relative to atmospheric pressure) due to surface tension of capillary water formed between grains (Schwartz \& Zhang, 2003). Pressure head may refer to either positive or negative pore water pressure (i.e., saturated and unsaturated zone), and matric suction (or soil water 
suction) is typically reserved for describing negative pore water pressure values (i.e., unsaturated zone) (Chiorean, 2017).

One important aspect of matric suction is its influence on soil strength and stiffness (Leung et al., 2015; Mariappan et al., 2009). More relevant to water flow, however, is the association matric suction has with soil moisture. This relationship can be described by the soil water retention curve (SWRC), which is one of the most important hydraulic properties of soil (Shwetha \& Varija, 2015). The SWRC characterizes a soil's ability to store water, and therefore, is extremely useful when describing water flow in the unsaturated zone.

The SWRC of a soil can be measured in the lab with both static and transient tests. Static tests apply changes in matric suction to a saturated sample, either by decreasing the water pressure (e.g. hanging column test) or increasing the air pressure (e.g. pressure plate extractor), and then measuring the resulting water saturation when fluid flow has completely ceased and equilibrium has been established (Lo et al., 2017). Measurements via the static test method, however, are time consuming and may take weeks or, if the soil has a significant number of fines, months to reach an equilibrium. In addition, static tests typically yield a limited number of water retention data points (usually less than 10) per soil sample (Haghverdi et al., 2018).

To improve the efficiency of SWRC determination, transient measurements have been developed. These methods monitor water content, water pressure, and/or cumulative outflow volume during a one-step or multi-step drainage process. One example of a transient test is the evaporation method. This method produces many soil water retention data points by measuring the water content and matric potential at various heights of a 
soil sample exposed to evaporation, thus forming a SWRC (Haghverdi et al., 2018). In addition to experiments, the SWRC can also be predicted with the so-called pedotransfer functions that are based on some easy-to-measure soil properties, such as, soil texture, bulk density, and/or soil organic content (Wang et al., 2016).

A SWRC is influenced by the physical properties of a soil (e.g., grainsize, grain distribution, density, organic content, etc.) (Ng \& Pang, 2000). Ultimately, the most influential property on the shape of SWRC, however, is the grain/pore size distribution (Shwartz \& Zhang, 2003). When a soil is in unsaturated conditions, menisci can form between neighboring grains due to the interfacial tension between water and air. The shape of the curved meniscus is related to the pressure difference across the air-water interface (i.e., matric suction) and the pore size between grains. A higher matric suction corresponds to a smaller radius of curvature of the meniscus forming in small pore sizes (Mitchell \& Soga, 2005). Sands, for example, have a relatively uniform distribution of large pores, which in turn, will lead to relatively small matric suction values for a given water content. Conversely, a silt-loam, which has a larger portion of small pore sizes, will have significantly larger matric suction values at the same water content. In addition to capillary pressure (interfacial tension), clay bearing soils may hold extra water through electrical forces, and therefore, will have higher matric suction values than its coarser grained counterparts (Dingman, 2015). Additionally, a high organic content can increase the water retention in soils (Rawls et al., 2003).

Many equations/models have been proposed to describe the SWRC of various soils. Two of the most used models include the van Genuchten closed form equation (van Genuchten, 1980) and Brooks-Corey (Brooks \& Corey, 1964). For this study, the Brooks- 
Corey model will be used to interpret our unsaturated experimental results. According to the Brooks-Corey model, the SWRC is defined by the following relationship for effective saturation $\Theta$ and matric suction $\varphi$ (Brooks and Corey, 1964):

$$
\Theta=\left\{\begin{aligned}
\left(\frac{\psi_{b}}{\psi}\right)^{\lambda}, & \psi<\psi_{b} \\
1, & \psi \geq \psi_{b}
\end{aligned}\right.
$$

where $\psi_{b}$ is the air-entry pressure head and $\lambda$ is a pore size distribution index. Both $\psi_{b}$ and $\lambda$ can be used as fitting parameters to characterize the shape of a SWRC. The effective saturation is defined by:

$$
\Theta=\frac{\theta-\theta_{r}}{\theta_{s}-\theta_{r}}
$$

where $\theta$ is the measured volumetric water content, $\theta_{s}$ is the volumetric water at saturation, and $\theta_{r}$ is the residual water content.

The hydrological state (e.g., matric suction) also affects a soil's ability to transmit water. In general, as the matric suction increases, it becomes more difficult for water to flow through a soil. The hydraulic conductivity of unsaturated soils is therefore a function of matric suction (e.g., Mitchell \& Soga, 2005). Though some experimental setups are available [e.g., constant head method (Benson \& Gribb, 1997)], it is difficult to directly measure the unsaturated hydraulic conductivity. In practice, the SWRC can also be used to estimate the unsaturated $K$ because, much like $K$, the shape of a SWRC is determined by a soil's texture and structure. Models have been developed to predict $K$ as a function of suction based on a soil's SWRC. Considering the Brooks-Corey model (Equation 4), the relative hydraulic conductivity $K_{r}$ (ratio of unsaturated $K$ to saturated $K_{s a t}$ ) can be predicted (Brooks and Corey, 1964): 


$$
K_{r}=\left\{\begin{aligned}
\left(\frac{\psi_{b}}{\psi}\right)^{2+3 \lambda}, & \psi<\psi_{b} \\
1, & \psi \geq \psi_{b}
\end{aligned}\right.
$$

\section{Streaming Potential}

SP signals generated by water flow in porous geological materials are related to the electric double layer (EDL) (Figure 2) that forms at the mineral-water interface (Börner et al., 1996; Darnet \& Marquis, 2004; Doussan et al., 2002). Excess charges (ions) accumulate near the grain surface to balance the charged mineral surface, forming the EDL. As shown in Figure 2, the EDL is made up of the Stern layer and diffuse layer (Revil et al., 2012). The Stern layer represents the inner, strongly bonded ions. The diffuse layer is the outer layer of ions that are connected to the mineral surface through Coulombic interaction, which means the bonds are relatively weaker, and ion exchange can occur between the EDL and the bulk solution (Avena \& de Pauli, 1998). 


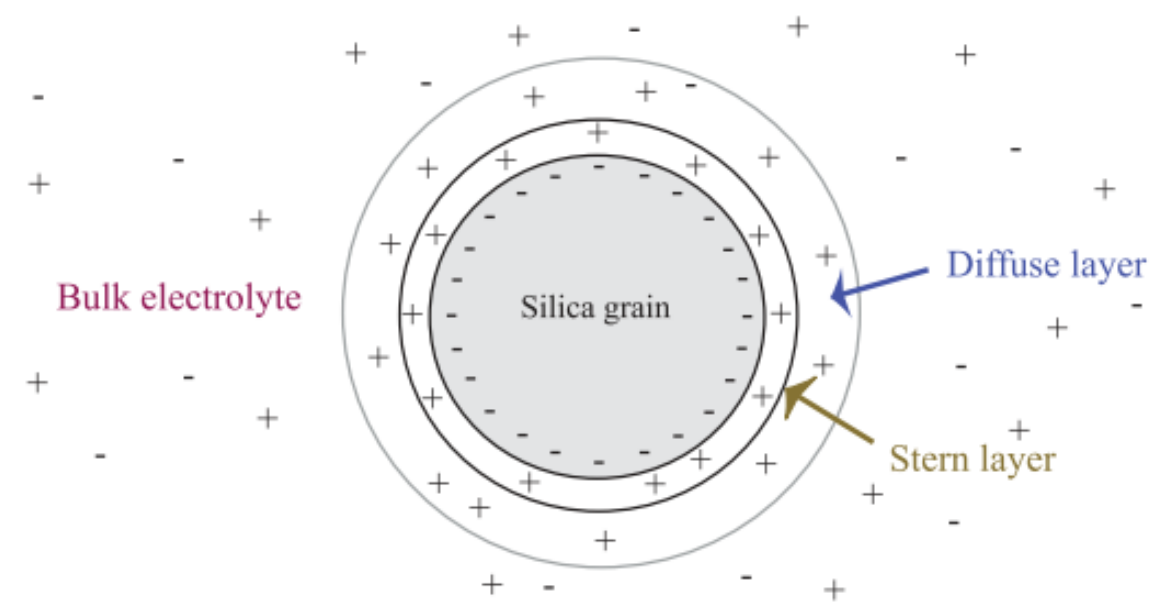

Figure 2 Diagram showing the electric double layer formed around a grain, which is negatively charged on the surface. The inner Stern layer is in direct contact with the grain. The diffuse layer is outside the Stern layer and is only connected to the grain via Coulombic interactions. Figure is from Revil et al. (2014).

When water moves through a porous medium, interactions between water and the EDL create what is known as the electrokinetic phenomena. As shown in Figure 3, the moving water drags a fraction of the excess charge in the diffuse layer, which gives rise to a measurable electric current termed as streaming current $J_{s}$ (Jougnot et al., 2015; Doussan et al., 2002; Voytek et al., 2019). In a porous medium, $J_{s}$ is balanced by the conduction current $J_{c}$ (Figure 3 ). The resulting electrical potential signal along the flow direction is termed as streaming potential, which is proportional to the water flux. 


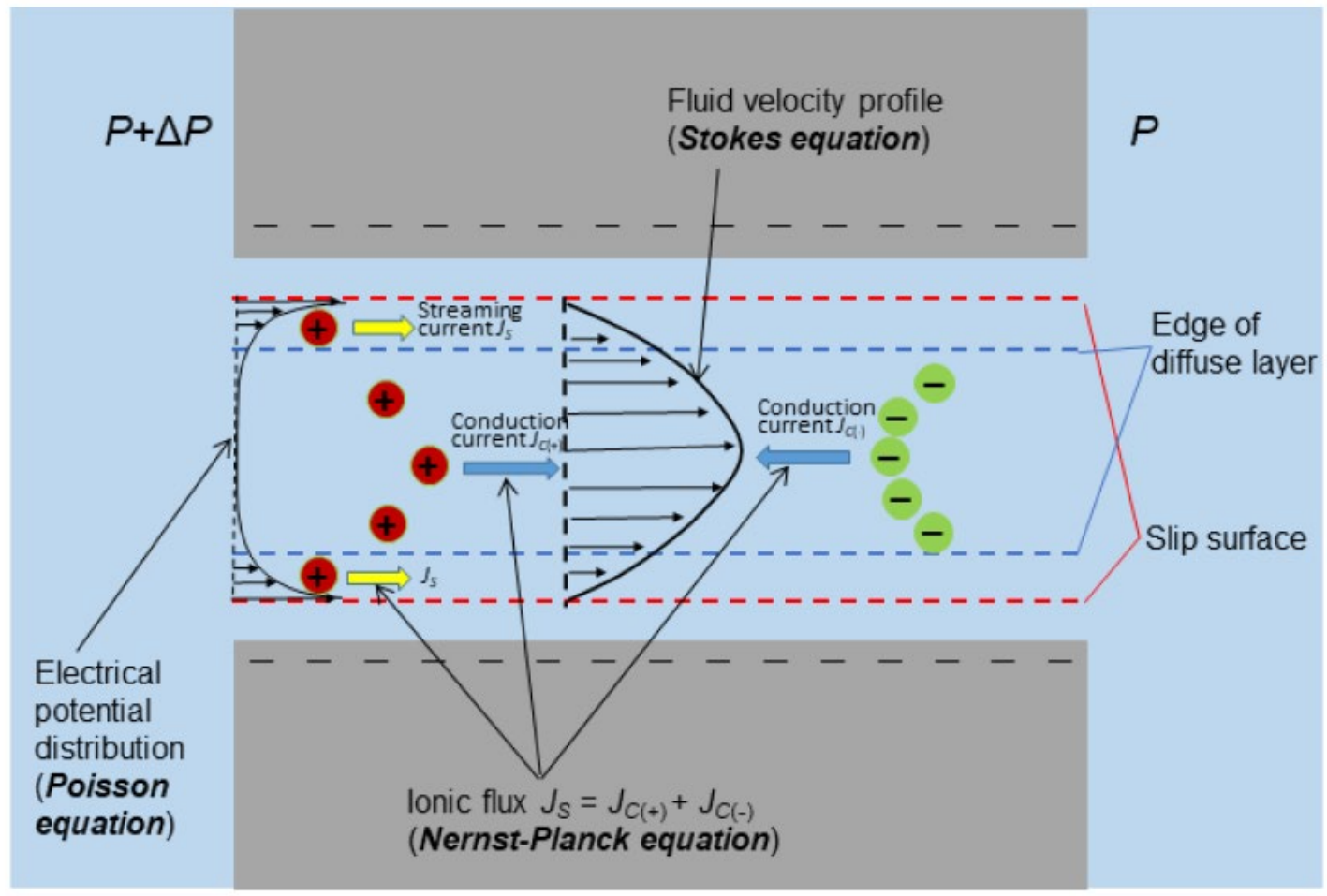

Figure 3 This diagram represents the mineral-water interface of a saturated porous medium with an applied hydraulic gradient driving water flow. Water is moving from left to right. The flow of water drags the excess cations in the diffuse

layer in the direction of fluid flow. The resulting streaming current $J_{s}$ and

counterbalancing conduction current $J_{c}$ give rise to the electrical potential distribution along the flow path (i.e., streaming potential). In the figure, streaming current $J_{s}$, which is contributed from excess cations in the diffuse layer, moves from left to right; conduction current $J_{c}$, a net effect of $J_{c(+)}$ and $J_{c_{(-)}}$in the bulk water, moves from right to left.

In addition to the streaming potential, there are other natural electric fields (e.g., thermoelectric, electroredox, and electrochemical potential) that exist on the surface and subsurface of the Earth. Therefore, a given SP signal may have more than one contributing source (Jardani et al., 2006; Mboh et al., 2012). In hydrological settings, the streaming potential is typically the dominant contribution to observed SP signals (Mboh et al., 2012). With that said, the observed streaming potential is a reflection of both the physical, electrical, and fluid properties of a soil. 
The streaming current $J_{s}$ generated by the flow of pore water in a partially saturated medium can be written as:

$$
J_{s}=-\frac{C\left(S_{w}\right) \sigma\left(S_{w}\right)}{K_{r}\left(S_{w}\right) K_{s a t}} u
$$

where $C$ is the streaming potential coupling coefficient $\left(\mathrm{V} \mathrm{m}^{-1}\right), \sigma$ is the effective electrical conductivity $\left(\mathrm{S} \mathrm{m}^{-1}\right), S_{w}\left(\theta / \theta_{s}\right)$ is the degree of saturation, and $u$ is the Darcy velocity $\left(\mathrm{m} \mathrm{s}^{-1}\right.$ ) (Revil et al., 2017a). Note that $C, \sigma$, and $K_{r}$ are dependent on the hydrological state of the soils and thus are functions of $S_{w}$. The Darcy velocity $u$ can be determined using Darcy's law as:

$$
u=-K \frac{\Delta h}{\Delta x}
$$

The streaming current is related to streaming potential $V$ through Poisson equation (Revil et al., 2017a):

$$
\nabla \cdot(\sigma \nabla V)=\nabla \cdot \mathrm{j}_{S}
$$

In an experiment, the SP can be measured using a reference and a potential electrode (usually non-polarizable electrodes) placed on the ground surface. The measured SP value $\Delta V$ is the electrical potential difference between the reference electrode $V_{\text {ref }}$ and potential electrode $V_{i}$ (Voytek et al., 2019):

$$
\Delta V=V_{i}-V_{r e f}
$$

SP electrodes are typically spaced within 1 meter of each other. The SP signals generated by water flow in the soil are of several millivolts and can be used to characterize water flux between two points. Negative values indicate water is flowing away from the potential electrodes and positive values mean water is moving towards the potential electrodes (given a negatively charged mineral surface) (Darnet \& Marquis, 2004). 
The SP signal $\Delta V$ produced from a fluid pressure gradient $\Delta P$ can be defined by the streaming potential coupling coefficient $(C)$, a key petrophysical property for soils (Jaafar et al., 2009). This definition is expressed as (Sill, 1983):

$$
C=\frac{\Delta V}{\Delta P}
$$

The pressure gradient $\Delta P$ considers the effect of elevation head and is therefore equivalent to the total head difference $\Delta h$ in Equations 1 and 8 . It is important to note that $C$ is a function of saturation $S_{w}$. See Chapter Six; Hydraulic and Electrical Modeling of the Unsaturated Response for more details.

The streaming potential coupling coefficient $C$ of soils at saturation $\left(C_{s a t}\right)$ may also be defined by using the Helmoltz-Smoluchowski relation (Smoluchowski, 1905):

$$
C_{s a t}=\frac{\varepsilon_{f} \zeta_{a}}{\eta_{f} \sigma_{f}}
$$

where $\varepsilon_{f}\left(\mathrm{~F} \mathrm{~m}^{-1}\right)$ is the dielectric permittivity of the fluid, $\eta_{f}(\mathrm{~Pa} \mathrm{~s})$ is the fluid dynamic viscosity, $\sigma_{f}\left(\mathrm{~S} \mathrm{~m}^{-1}\right)$ is the fluid electrical conductivity, and $\zeta_{a}(\mathrm{~V})$ is the apparent zeta potential. Equation 12 is based on the assumption that the surface conduction (i.e., electrical conduction contributed from the EDL) in porous medium is negligible. The zeta potential is a key parameter which characterizes the electrical potential of the shear plane at the mineral-fluid interface in the EDL (Crespy et al., 2007). Through observation of the variables in Equations 7, 9, and 12, one can see that the observed SP signal is dependent on the hydraulic properties $\left(K_{r}\right.$ and $\left.K_{s a t}\right)$ and electrical properties $(\sigma$ and $\zeta)$ of the soil as well as properties of the fluid $\left(\varepsilon_{f}, \eta_{f}\right.$, and $\left.\sigma_{f}\right)$. 


\section{Complex Electrical Conductivity}

The complex electrical conductivity of a material can be determined by applying a sinusoidal electrical current to a sample and measuring the induced electrical potential and phase shift (Revil et al., 2017b). For most saturated geological materials, the complex conductivity is a function of frequency $f$ and is expressed as:

$$
\sigma^{*}(f)=\sigma^{\prime}(f)+i \sigma^{\prime \prime}(f)
$$

where $\sigma^{\prime}$ and $\sigma^{\prime \prime}$ are the real and the imaginary (quadrature) parts of the conductivity respectively and $i=\sqrt{ }-1$ represents the imaginary number (Nordsiek et al., 2016). The real conductivity comes from the electromigration processes, i.e., the transport of the charge carriers driven by the electric field, both in the pore water and along the electrical double layer coating the surface of the grains (Revil et al., 2017b). The low frequency $(<$ $100 \mathrm{~Hz}$ ) real conductivity is almost identical to the conductivity derived from the traditional direct current resistivity methods and can be regarded as frequency independent. The low-frequency real conductivity of saturated geological materials can be described by:

$$
\sigma^{\prime}=\frac{\sigma_{f}}{F}+\sigma_{s}
$$

where $\sigma_{s}$ is the surface conductivity and $F$ is the dimensionless formation factor (Revil et al., 2017b). The surface conductivity $\sigma_{s}$ represents contributions from both the diffuse layer and the Stern layer (Revil et al., 2017b) (Figure 2). The formation factor $F$ can be linked to porosity $\phi$ via Archie's law:

$$
F=\phi^{-m}
$$

where the porosity exponent $m$ is usually called the cementation factor, which is mainly influenced by the grain shape and packing (e.g., Niu \& Zhang, 2018). The value of $m$ 
may range from 1.3-2.3 for unconsolidated sands and 1.87 to 3.28 for various clays

(Salem \& Chilingarian, 1999).

Traditional direct current resistivity measurements conducted with a single fluid salinity are unable to distinguish between bulk and surface conductivity (Revil et al., 2017b). If $\sigma^{\prime}$ is used to calculate $F$, unrealistic interpretations of $F$ in terms of porosity can occur (Revil et al., 2017b). Work has been done by Börner et al. (1996) and Weller et al. (2013) to estimate the surface conductivity from imaginary conductivity values and incorporate those values into Archie's law. The formation factor can be calculated via the complex conductivity values from the following equation (Börner et al., 1996):

$$
F=\frac{\sigma_{w}}{\sigma^{\prime}-\left(\frac{\sigma^{\prime \prime}}{l}\right)}
$$

where $l$ is the ratio between the imaginary conductivity $\sigma^{\prime \prime}$ and surface conductivity $\sigma_{s}$ and can be used to correct for the contribution of surface conduction to the bulk water conduction. A single representative value for $l$ has not been established, and published values vary between studies. Weller et al. (2013), for example, evaluated 63 sandstone and unconsolidated samples and determined $l$ equal to 0.042. Börner et al. (1996), however, suggested that $l$ may range from 0.01 to 0.15 , and deemed it appropriate that for unconsolidated silicate sediments, 0.1 can be used to represent $l$. In this study, $l$ will be equal to 0.1 . Equation 16 improves the determination of $F$ relative to using $F=\sigma_{w} / \sigma^{\prime}$ because this estimation assumes that the surface conduction is small, a questionable assumption even in relatively clean sands (Robinson et al., 2018). 


\section{CHAPTER THREE: DEVELOPMENT OF A LABORATORY SOIL COLUMN SYSTEM FOR SIMULTANEOUSLY MEASUING ELECTRICAL AND HYRAULIC PROPERTIES}

\section{Design and Fabrication of the Soil Column System}

The soil column system consists of a sample holder, hydrogeophysical probes for electrical and hydraulic measurements, and other accessories. In this section, the details of the design and fabrication will be presented.

\section{An Integrated Hydrogeophysical Probe}

In this project, an integrated hydrogeophysical probe is designed and built to simultaneously measure the electrical potential and soil water pressure (both positive and negative pressure) in the soil. Both aspects of traditional tensiometer and SP measurement techniques are integrated into this newly designed probe (Figure 4). As shown in Figure 4, attached to the probe's reservoir is a porous ceramic cup with a highair entry pressure (1 Bar). The porous ceramic cup allows only water to move in or out of the reservoir. Also connected to the reservoir is a pressure transducer (to measure the water pressure) and a non-polarizable electrode (to measure the electrical potential). The purpose of the high-air entry pressure porous cup is to stop air from entering the reservoir and ensure the pressure transducer and electrode are always fully immersed in water. Moreover, the porous cup allows the water pressure inside the probe's reservoir to remain in equilibrium with the pressure of the soil water. As the pressure of the soil water changes, the pressure of the water in the probe's reservoir will also change to reach 
equilibrium with the surrounding matrix. The porous cup end of the reservoir is threaded to allow insertion of the probe into the soil column to be used for testing. This design allows both electrical potential (e.g., SP) and soil water pressure to be measured at both saturated and unsaturated conditions.

a)

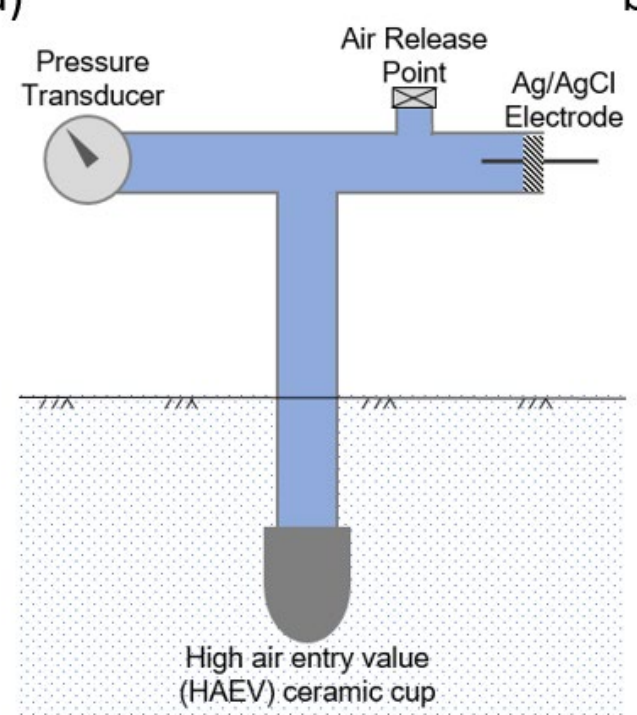

b)

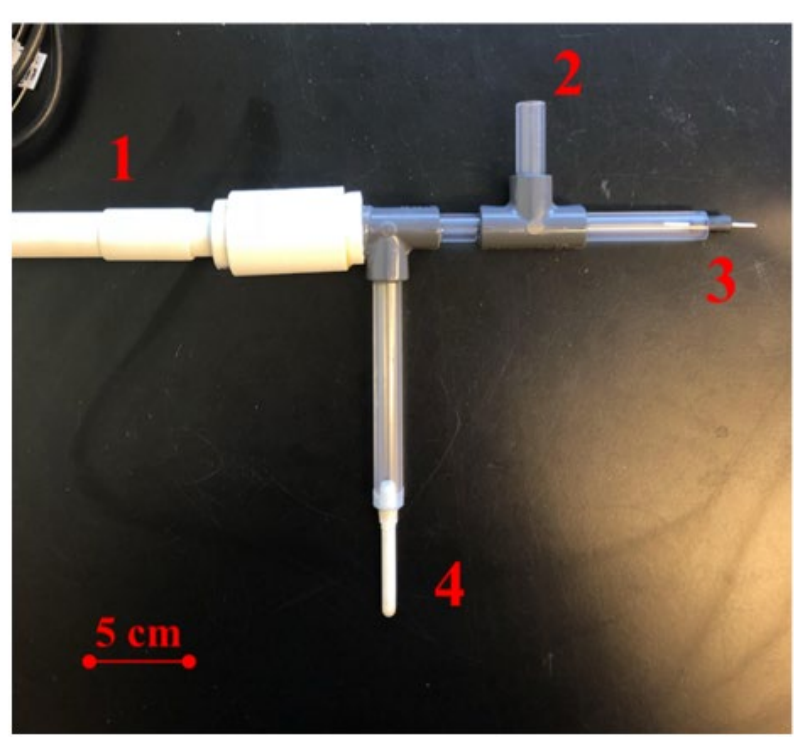

Figure 4 (a) Schematic of the proposed probe design. The proposed schematic resembles that of a traditional tensiometer. The obvious difference is the inclusion of a silver/silver chloride electrode. (b) A prototype of the integrated hydrogeophysical probe developed in this project. Location 1 represents the pressure transducer that

is be used to measure soil water pressure. 2 is an air release point. 3 is a nonpolarizable silver/silver chloride electrode. 4 is a porous ceramic cup with an air entry value of 1 bar. The porous ceramic cup ensures air will not enter probe's reservoir and the electrode and pressure transducer remain in constant contact with water.

The pressure transducers (Advanced Tensiometers, Electronic Engineering Innovations, Las Cruces, NM, USA) described in Aishlin et al. (2013) were used in this study (Figure 5). These sensors can detect pressure changes ranging from $\pm 39226.6 \mathrm{~Pa}$ ( $\pm 400 \mathrm{~cm}$-water) with a precision of $0.98 \mathrm{~Pa}(0.01 \mathrm{~cm}$-water $)$. In addition to pressure, the sensors can also record temperature. The probe is fitted with a beveled fitting that matches the beveled rubber stopper of the pressure transducer. The rubber stopper and 
matching fitting on the probe allow for a secure airtight connection. The temporary connection between the probe and the pressure transducer allows for water in the reservoir to be added/replaced. During dry periods, when matric suction values may become exceedingly high (e.g., higher than the high-air entry value of the ceramic cup), loss of water from the probe's reservoir to the soil through the ceramic cup can occur (Aishlin et al., 2013). Although exceedingly high matric suction values are not expected to be encountered during lab testing, as a precaution, the pressure transducer can be removed, and the reservoir can be refilled.

A non-polarizable $\mathrm{Ag} / \mathrm{AgCl}$ electrode is immersed in the reservoir to measure the electrical potential. The importance of the non-polarized electrode should be noted. Within the natural subsurface environment, electrical potential resulting from electrokinetic sources (i.e., streaming potential) are lower than those induced by other factors. These factors include redox reactions and mineral and geothermal anomalies, which are often associated with high noise polarization levels (Corwin, 1990; Jang et al., 2005). Additionally, stainless steel electrodes, which are often used in geophysical field applications (e.g. ERT), are not appropriate for SP testing. Stainless steel electrodes often have an electrode polarization which can produce electrical potential signals significantly higher than the streaming potential. Also, non-polarizable electrodes have more stability with time and lower noise values relative to stainless steel electrodes (Abdulsamad et. al., 2016; Dahlin et al., 2002). Of the traditional non-polarizable electrodes, the $\mathrm{Ag} / \mathrm{AgCl}$ electrodes show the lowest noise and the best stability over time (Abdulsamad et. al., 2016). In addition to measuring the streaming potential, non-polarizable electrodes can 
also be used to accurately determine the induced polarization of soils (e.g., Breede et al., 2012; Jougnot et al., 2010; Revil et al., 2017b).

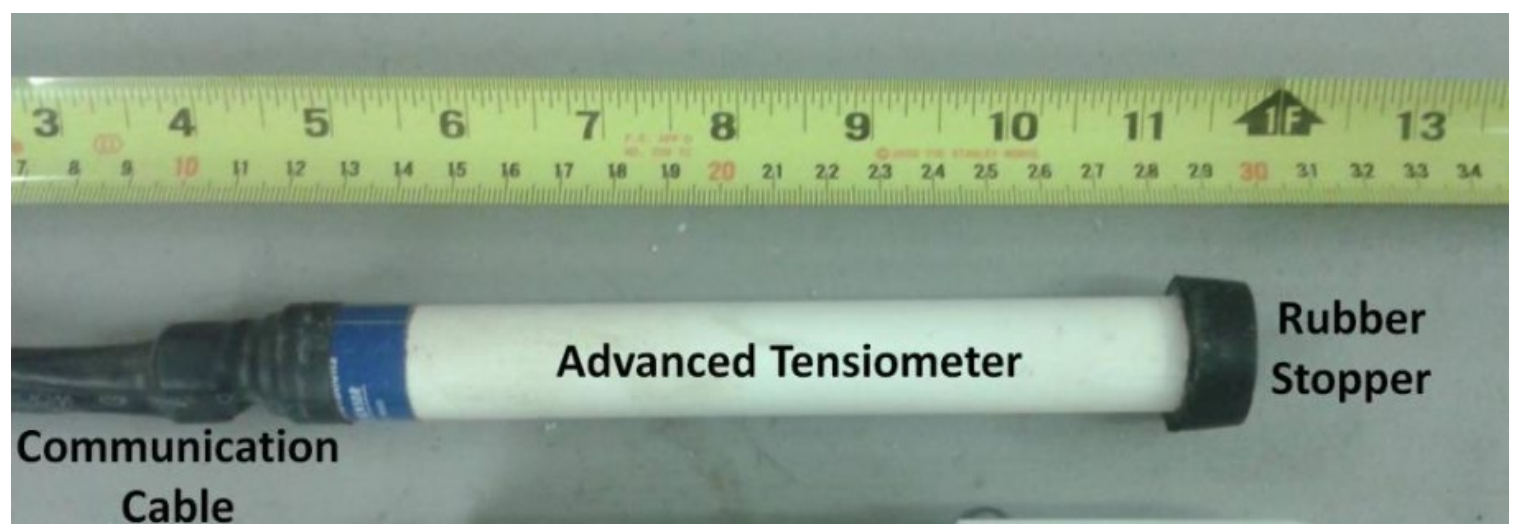

Figure 5 The Advanced Tensiometer sensor (pressure transducer) used to measure the water pressure in the probe. The probe is equipped with a beveled fitting that is compatible with the beveled rubber stopper, seen here, to allow a secure, airtight connection. Figure is modified from Aishlin et al. (2013).

\section{$\underline{\text { Soil Column }}$}

A soil column was created using 3-D printing technology (Figure 6). The developed hydrogeophysical probes are inserted into the soil column to measure the SP and soil water pressure in soils undergoing water flow. For saturated flow conditions, the testing apparatus (i.e., soil column, hydrogeophysical probes, and water reservoirs) is similar to traditional constant head permeability setups (Figure 7). Special care was taken to build the testing equipment with no metal in order to accurately measure the electrical properties of a given soil sample.

The developed soil column is $21 \mathrm{~cm}$ tall and has an inner diameter of $7.5 \mathrm{~cm}$. A valve at both the top and bottom of the soil column controls water in and/or out of the soil column. $\mathrm{Ag} / \mathrm{AgCl}$ non-polarizable electrodes were also placed at the inlet and outlet of the soil column to serve as reference points. At $4.5 \mathrm{~cm}$ and 16.5 from the bottom of the soil column are female pipe threads that allow the hydrogeophysical probe to be threaded 
into the side wall of the soil column. Adjacent to the insertion point for the probes, another point of insertion has been added for factory-built $\mathrm{Ag} / \mathrm{AgCl}$ electrodes (R0305, IDA HengShen Inc., Tianjin, China) to be in direct contact with the soil water (Figure 6). All pressure transducers and electrodes used in this setup are connected to a data logger (CR1000x, Campbell Scientific, Inc., Logan, UT, USA) via a coaxial cable. Through experimental investigations, it was found that making singled measurements, rather than differential measurements, with the data logger and using a coaxial cable, rather than an insulated copper wire, greatly improved the signal to noise ratio for electrical potential measurements.

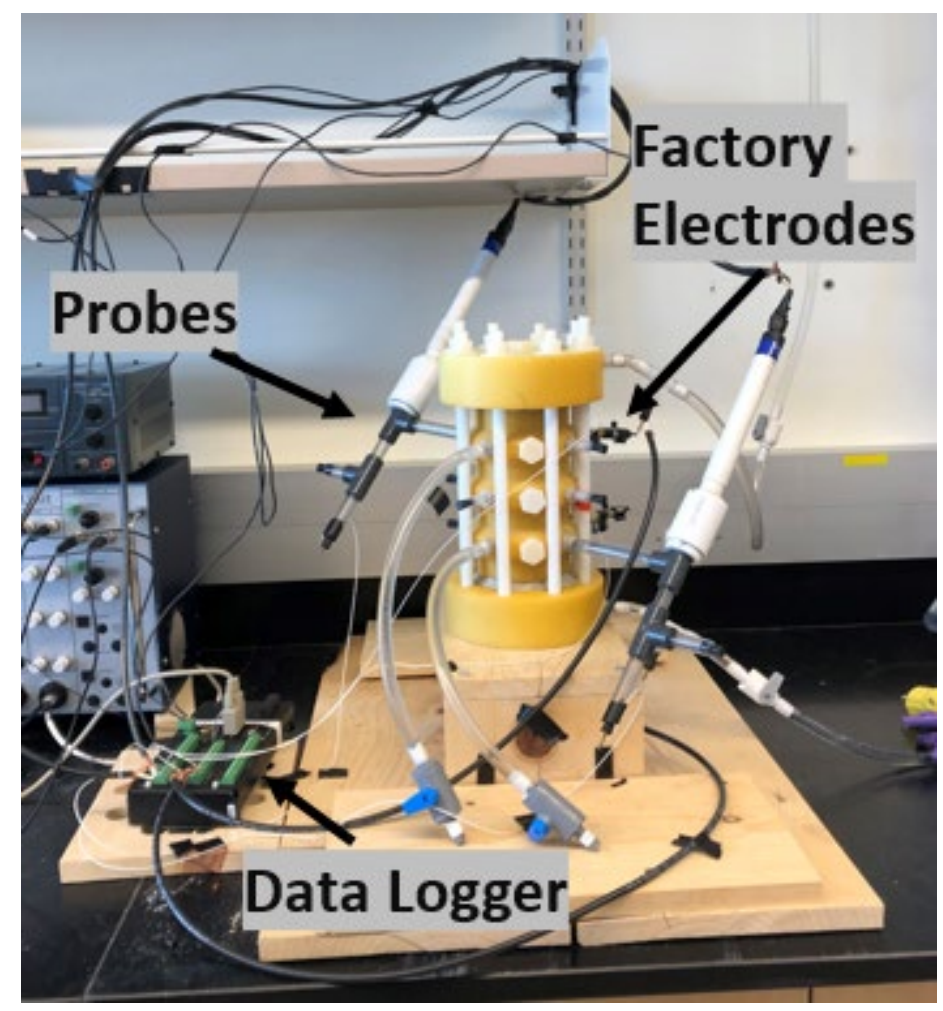

Figure 6 The soil column to be used for testing. Seen here are the designed probes inserted into the soil column, as well as, factory-built $\mathrm{Ag} / \mathrm{AgCl}$ non-polarized electrodes. Both sets of electrodes are connected to the data logger via coaxial cables. 

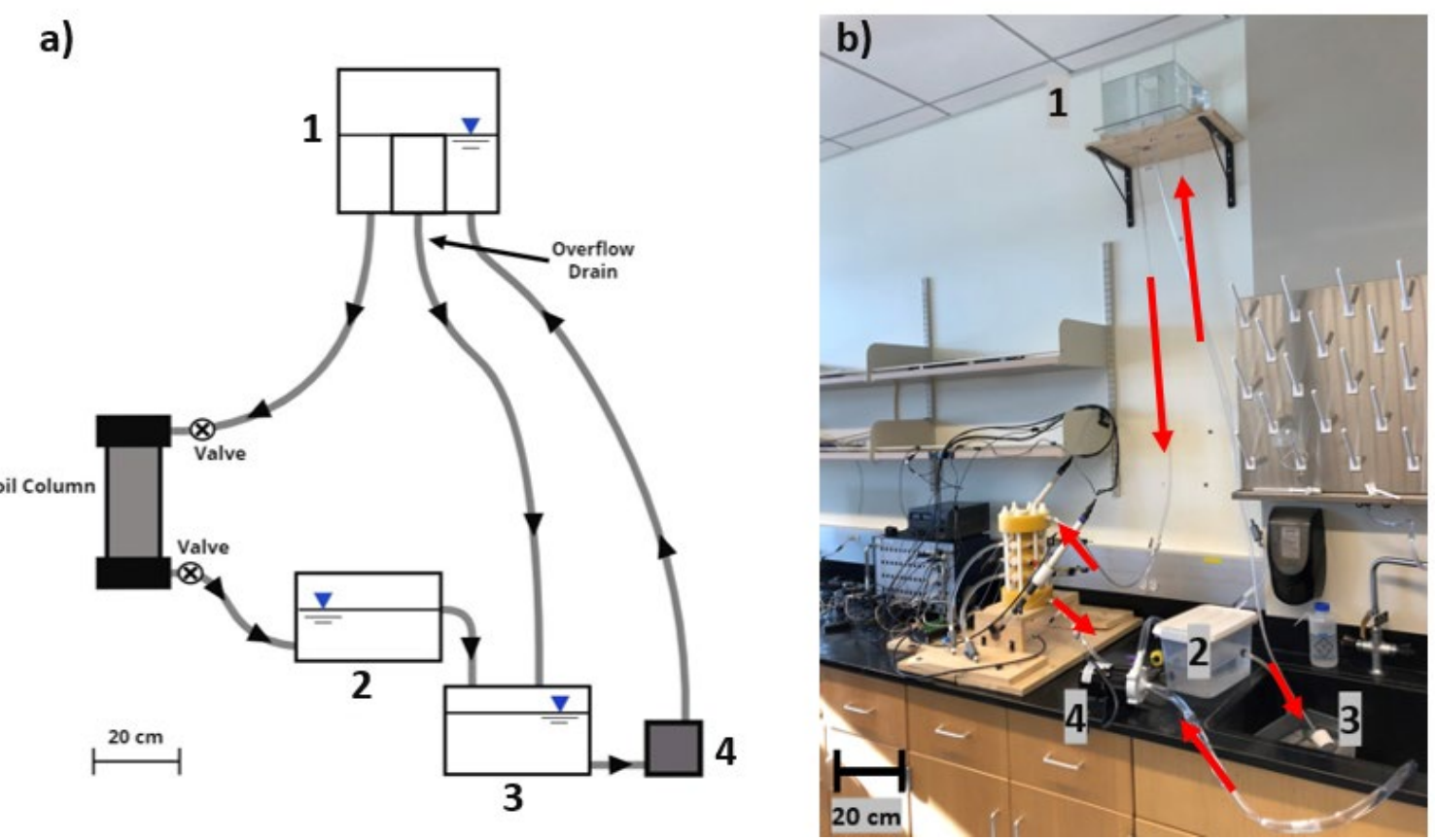

Figure 7 (a) Schematic of the saturated testing setup and (b) view of the saturated experimental setup in the lab. In (a), black arrows indicate the direction of flow and in (b), red arrows indicate the direction of flow. For both (a) and (b), water moves from (1) the upper constant head reservoir to the soil column, then to (2) the lower constant head reservoir, and then to (3) the storage reservoir before it is finally (4) pumped back to the upper constant head reservoir. The hydraulic gradient may be adjusted by opening or closing the valve at the bottom of the soil column or by adjusting the elevation of the lower constant head reservoir.

During a constant head test, water moves from the soil column and passes through three different reservoirs before once again reaching the soil column (Figure 7). The reservoirs are built using acrylic and plastic and are connected to one another via vinyl tubing. When water exits the soil column, it flows to a lower constant head reservoir (location 2 in Figure 7). This lower constant head reservoir serves as a point of access to collect water that is being cycled through the soil column. The volume of water collected at this point can be used to calculate the flow rate and make water chemistry measurements (e.g. pore-water conductivity and $\mathrm{pH}$ ). When water is not being collected from the lower reservoir, it drains into a storage reservoir (location 3 in Figure 7). Water from the storage reservoir is pumped to an upper constant head reservoir above the soil 
column (location 1 in Figure 7). Water is pumped using a magnetic drive pump (3XMDX, Little Giant, Fort Wayne, IN, USA). A magnetic drive pump eliminates water from having any contact with the pump motor and limits the risk of any water contamination during testing. The upper reservoir keeps water at a constant level of 136 $\mathrm{cm}$ above the top of the soil column. Water movement from the upper reservoir to the soil column is entirely gravity driven. The rate water moves through the soil column can either be adjusted via a valve at the bottom of the soil column, or by adjusting the height of the lower reservoir relative to the soil column.

In addition to saturated flow, the water pressure values and SP signal induced by unsaturated flow can also be measured with the hydrogeophysical probe during a drainage test. For unsaturated testing, the lower constant head reservoir is moved to a point $\sim 60 \mathrm{~cm}$ below the soil column. A high precision digital balance (OHAUS Scout SPX622, Parsippany, NJ, USA) is placed at the outlet of the lower constant head reservoir and the rate at which water is draining can be measured. The balance records the cumulative water drained from the soil column with $0.01 \mathrm{~g}$ precision. The balance is connected to a laptop which is programmed to record the reading at the scale every one second. The observed SP and pressure signal during drainage is later modeled with COMSOL Multiphysics 5.6. Using this program, the Brooks-Corey parameters $\left(\psi_{b}\right.$ and $\lambda$ ) of the soil sample can be estimated matching the observed signal to a simulated signal. The details of the unsaturated test and modeling will be presented in Chapter Six. 


\section{Experimental Procedure}

\section{$\underline{\text { Soil Preparation }}$}

Soil was packed into the soil column to ensure as uniform packing as possible. Special care is taken to ensure the arrangement of grains is consistent throughout the soil sample because any heterogeneities can significantly influence the hydrologic properties (Allégre et al., 2014). To prepare the sample, 200 grams of sample at its residual moisture content was weighed out and then placed in the soil column. The soil sample in the column was then tamped 30 times with a wooden tamp. This process was repeated until the soil sample reaches the height at which the bottom probe needs to be inserted (Figure 8). At this point, the ceramic cup side of the probe is threaded into the soil column. During preparation, the pressure transducer is not attached to the probe. The probe is considered secure when the tip of the porous cup is about a millimeter from the soil column wall (Figure 8). After the probe is installed, the process of adding soil to the column can be resumed until the next probe needs to be installed. Once the soil column is full, the end cap and silicone sealing rings may be put on and nuts tightened with a wrench (Figure 6). To ensure an air/water-tight seal, press to seal rope caulking is placed at the top and bottom edges of the soil column. 


\section{Figure 8 A bird's eye view of the soil column during preparation of a soil sample. At this point, the hydrogeophysical probe is installed by inserting the porous ceramic cup into the soil column.}

\section{Saturation}

Once the soil is prepared in the column, distilled water is used to saturate the sample with the following steps. First, a hose is put in place connecting the bottom of the soil column to the top reservoir. Water is pumped from the storage reservoir to the upper reservoir until a constant head is reached. Afterwards, the valve at the bottom of the soil column is opened to allow water to flow into the sample. The soil column is filled at a relatively slow flow rate (on the order of $\mathrm{mm} \mathrm{s}^{-1}$ ) from the bottom up to ensure no air will be trapped in the sample. Another hose is connected to the top of the soil column and attached to an empty reservoir that is higher than the top of the soil column. Attaching the top hose to a point higher than the soil column itself allows the user to visually verify the soil has been fully saturated.

During the saturation process, the pressure transducer is detached to allow water to enter the hydrogeophysical probes via the porous ceramic cups. When the probes are 
full of water and free of any air bubbles, the pressure transducer is attached to the probe. At this point during the saturation processes, the initial water conductivity in the soil column may be spatially heterogeneous due to soil water interactions. To ensure the water conductivity is homogeneous throughout the sample, water is cycled through the soil column until there are no significant changes in the electrical conductivity values within a ten-minute period. When the saturation is complete, the hoses are rearranged so that water enters the soil column from the top and exits through the bottom. A final check is made to ensure the upper and lower reservoirs are filled by water with a constant head and there are no air bubbles in the hoses.

\section{Constant Head Test}

After saturation, saturated testing may begin. During testing, water pressure, temperature, and the SP signal are recorded every 0.5 seconds. Every test begins with a hydrostatic period of at least 20 minutes. This hydrostatic period is to ensure there is no water moving in the soil column and to obtain the initial electrical potential, which is representative of the intrinsic characteristics of each non-polarizable electrode, measured by each probe. Following the hydrostatic period, five different hydraulic gradients, each lasting about 20 minutes, were applied to the sample sequentially. The hydraulic gradient may be adjusted by open/closing the valve at the bottom of the soil column, or by changing the vertical position of the lower reservoir. Water was collected for the final ten minutes of each interval from the lower constant head reservoir. From each water sample, the volume, $\mathrm{pH}$, and electrical conductivity were measured. Following completion of the five flow intervals, the sample was returned to a hydrostatic state for another 20 minutes. 
After completion of the saturated test, a complex conductivity test was performed. Both valves at the bottom and top of the column were closed to ensure no water movement. Electrical current was injected into the soil sample through the electrodes at the inlet and outlet of the soil sample. The induced electrical potential was measured at the two probe's position via the nonpolarizing electrodes. A complex impedance meter (PSIP, Ontash \& Ermac, Inc., River Edge, NJ, USA) was used to perform the test with a covered frequency from $0.01 \mathrm{~Hz}$ to $1 \mathrm{~Hz}$.

\section{Characterization of Soil Samples}

Once testing is complete, porosity, grainsize distribution, and mineral composition of the soil can be determined. Porosity of the sample in the soil column is calculated with the following equation:

$$
\phi=1-\left(\frac{\rho_{\text {samp }}}{\rho_{\text {grain }}}\right)
$$

where $\rho_{\text {samp }}$ is the dry density of the soil sample and $\rho_{\text {grain }}$ is the particle density. The dry density $\rho_{\text {samp }}$ is calculated as the ratio of the dry weight of the soil sample over the inner volume of the soil column. The average range of particle densities among soil samples is between 2.55 and $2.70 \mathrm{~g} / \mathrm{cm}^{3}$ depending on mineralogy. A value of $2.65 \mathrm{~g} / \mathrm{cm}^{3}$ is typical for soils abundant with silica (Blake, 2008). In this study, $2.65 \mathrm{~g} / \mathrm{cm}^{3}$ was used in the calculation of porosity.

The grain size distribution of the soil sample was determined through a mechanical sieving process. The maximum grain size was found with the $\# 4(4.75 \mathrm{~mm})$ sieve and a \#270 (0.053 mm) sieve was the smallest size used. Material that passed the \#270 sieve made up less than 5\% of the material for all soil samples tested. It was 
therefore deemed unnecessary to portion out the silts and clays passing through the $\# 270$ sieve.

All soil samples were subject to an X-ray diffraction (XRD) analysis to identify the mineral composition. Knowing the mineralogy helps to constrain some of the petrophysical properties that may be influencing the electric measurements. XRD analyses of all soil samples were carried out at the Boise State Center for Materials Characterization. The interpretation of the XRD data was made using RockJockML (Version 0.2; Brickmore, 2019), which is a MATLAB based program designed by Professor Barry R. Bickmore of the Department of Geological Sciences, Brigham Young University. RockJockML is adapted from the RockJock program created by Dennis Eberl at the U.S. Geological Survey (Eberl, 2003).

\section{Performance of the Hydrogeophysical Probe}

\section{$\underline{\text { Water Pressure }}$}

Before the probe was used to make any soil measurements, it was important to verify the pressure transducers and non-polarizable electrodes were working properly. The pressure transducers are factory calibrated and expected to have a linear relationship between the actual water pressure and the measured voltage. Ideally, calculated water pressure from the measured voltage using the factory calibration should have a 1:1 relationship with the actual water pressure, but Aishlin et al. (2013) found there may be some initial offset and each sensor should undergo pre-emplacement calibration. To validate each sensor and identify any off set, the sensors were recalibrated using a water column test. The test encompasses measuring the sensors reading under known heights of water. The actual water pressure and sensor measured water pressure (using factory 
calibrated equation) are shown in Figure 9. Both sensors used in the soil column had nearly perfect linear relationships, with minimal offset (Figure 9).
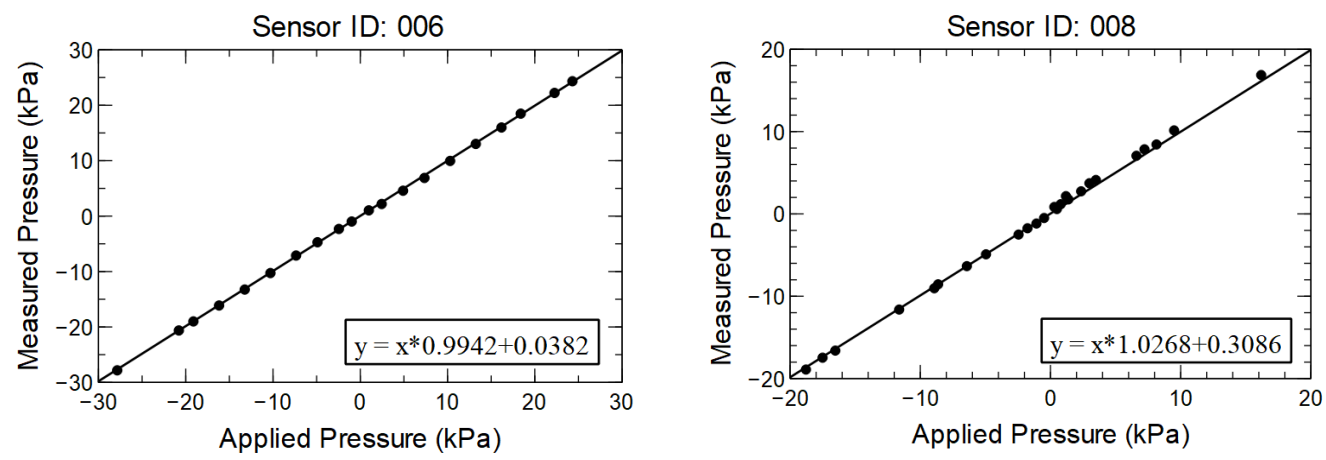

Figure 9 Results from pre-emplacement calibration of the pressure transducers used in the soil column tests. Both sensors had a nearly linear relationship with very minimal offset.

\section{Electrical Potential}

In addition to the pressure transducers, the performance of the lab-built $\mathrm{Ag} / \mathrm{AgCl}$ non-polarizable electrodes placed in the probe were also evaluated. The evaluation was conducted by comparing the measurements from the hydrogeophysical probes, commercial $\mathrm{Cu} / \mathrm{CuSO}_{4}$ electrodes (STELTH3, Borin Manufactiong, Inc., Culver City, CA, USA), and commercial Ag/AgCl electrodes (R0305, IDA HengShen Inc., Tianjin, China) in a conventional complex electrical conductivity measurement. As previously explained, the imaginary conductivity of saturated soil is associated with the polarization of the EDL, which is also responsible for the streaming potential in geological materials. If the designed probe's response to the complex conductivity measurements is on par with traditional electrodes, it stands to reason that the probe can be used to measure the SP signal.

Results from the complex conductivity tests prove the probe is capable of measuring weak electrical signals associated with the EDL (Figure 10). Each electrode 
used produced the same general shape and are all within the error of the complex conductivity test. Using Equation 16, the formation factor from each signal was calculated. For the probe, $\mathrm{Cu} / \mathrm{CuSO}_{4}$, and commercial $\mathrm{Ag} / \mathrm{AgCl}$ electrodes the formation factor was $5.71,5.91$, and 5.94 respectively. The imaginary conductivity signal is nearly identical for all electrodes (Figure 10b). As previously mentioned, the SP signal and imaginary conductivity are both associated with the EDL. Because all three electrodes measured a similar imaginary conductivity, it validates the accuracy of the probe in measuring the SP in the soil. In summary, both the complex conductivity tests and preemplacement calibration test for the newly developed hydrogeophysical probe indicate the hydraulic and electrical parts of the probe are working and may be used for soil testing. 

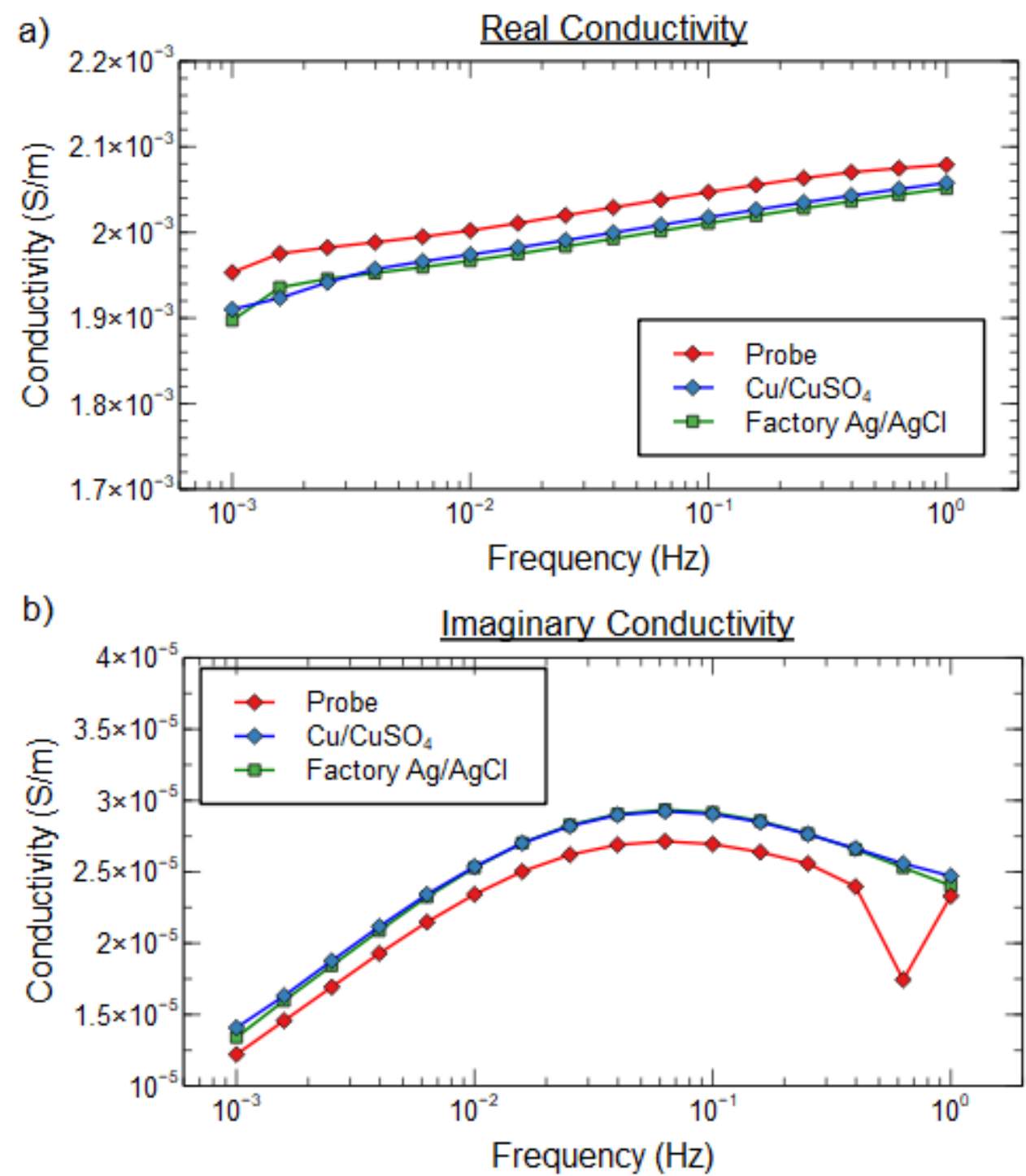

Figure 10 (a) represents the real conductivity measured using three different non-polarizable electrodes. Real conductivity values represent the bulk conductivity of the entire sample. (b) represents the imaginary conductivity associated with the EDL polarization. The complex conductivity measured from these three electrodes are nearly identical.

\section{Performance of Experimental Setup}

With no existing precedent for this test method, an initial constant head test was performed following the procedures outlined in the section titled Experimental Procedure Constant Head Test. In this chapter, only the details of the saturated test are discussed. Results of the unsaturated testing will be presented in Chapter Six. 
The initial saturated test was carried out with silica sand. Silica sand was chosen for its low surface conduction, which makes interpretation of the electrical properties more straightforward. Through XRD analysis, it was determined the silica sample contains only quartz, plagioclase, and potassium feldspar (Table 1). No clays, which have a high surface conduction, were found in the XRD results. Additionally, constant head measurements are typically applicable only to non-plastic, granular soils, so a coarse sand sample was chosen to ensure the initial test was within the limits of this testing method.

The electrical and hydraulic responses of the silica sand are shown in Figure 11. In Figure 11, the time series of the pore water pressure and the electrical potential difference between the two hydrogeophysical probes are shown. When calculating the difference, the measurement from the bottom probe was taken as the reference. Upon visual inspection, there is a clear relationship between the SP signal and hydraulic gradient (Figure 11). In order to confirm the relationship quantitatively, the average SP and hydraulic gradient for each flow interval were plotted against one another (Figure 12). With a coefficient of determination of 0.99 , there is a clear linear trend between SP and change in total head, which is to be expected based on Equation 11. Additionally, the relationship between the average hydraulic gradient for each interval and corresponding flow rate also showed a nearly perfect linear trend with a coefficient of determination of 0.99 (Figure 13). This is consistent with the prediction of Darcy's law (Equation 1). The results suggest that this is an appropriate method to use when characterizing the properties of coarse soils. 
a)

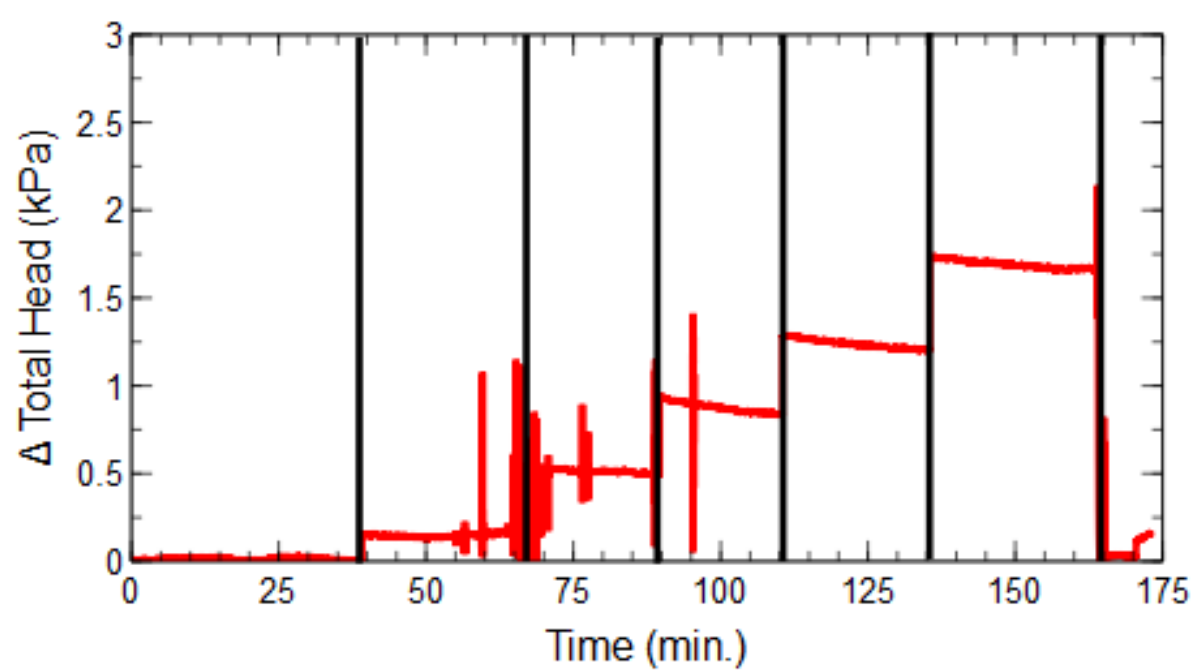

b)

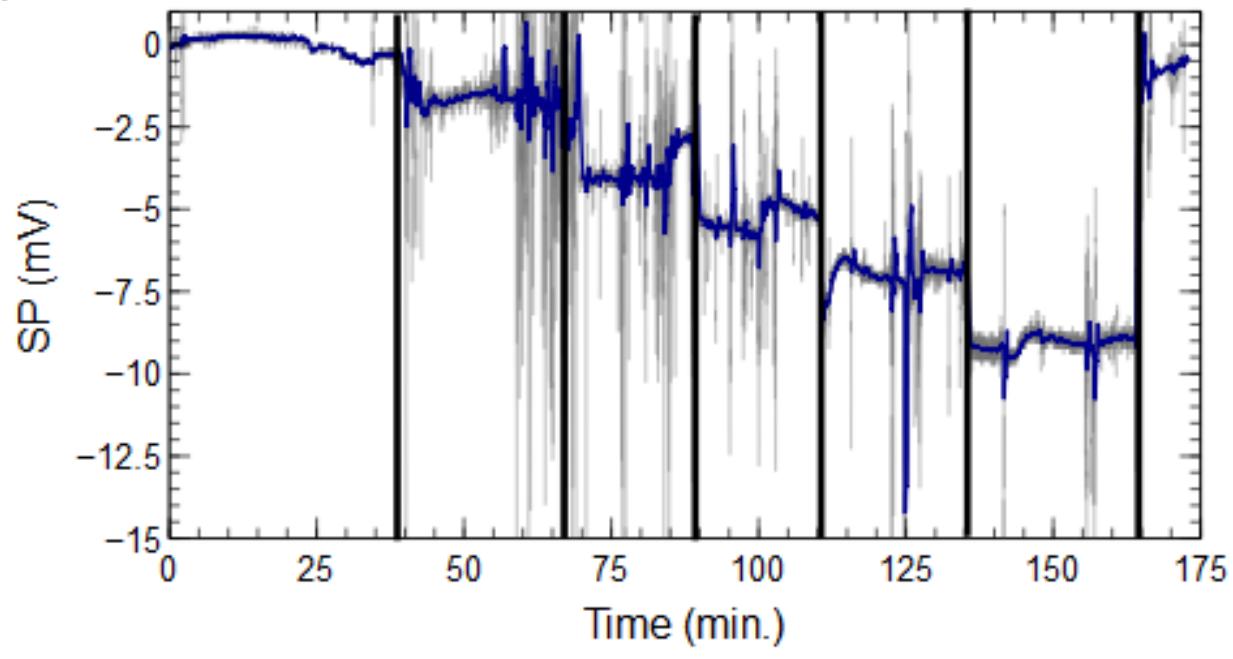

Figure 11 Plots representing (a) total head (expressed as kPa) and (b) electrical potential difference (SP signal) measured between two probes during testing. Vertical black lines represent changes in the hydraulic gradient. The first interval is representative of a hydrostatic state, the next five intervals represent increases in hydraulic gradients, and the last interval is again a hydrostatic state. The first hydrostatic interval is zero because the initial voltage has been removed. The grey lines in (b) represent the raw, unprocessed electrical potential. The blue line is a 60period moving average of the raw signal. 


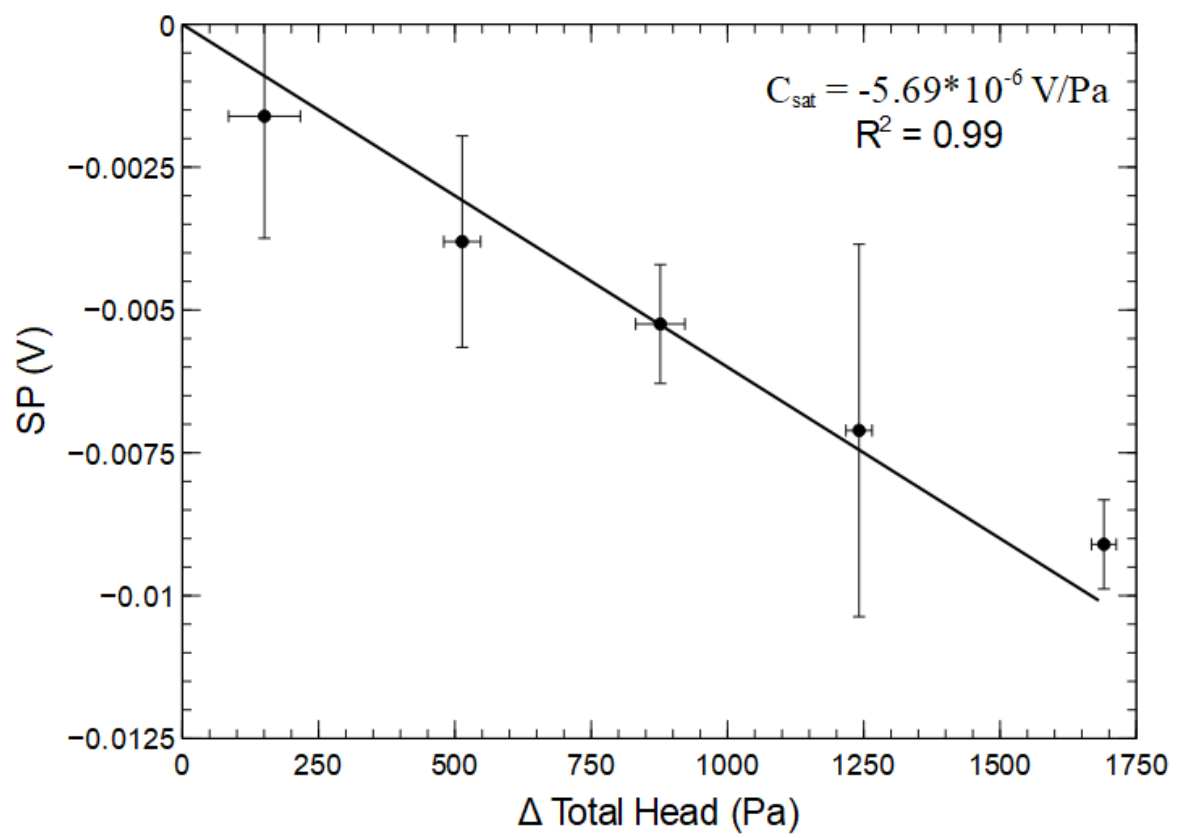

Figure 12 The average SP response to changes in total head. Error bars represent the standard deviation from average values. $C_{\text {sat }}$ represents the streaming potential coupling coefficient (Equation 11).

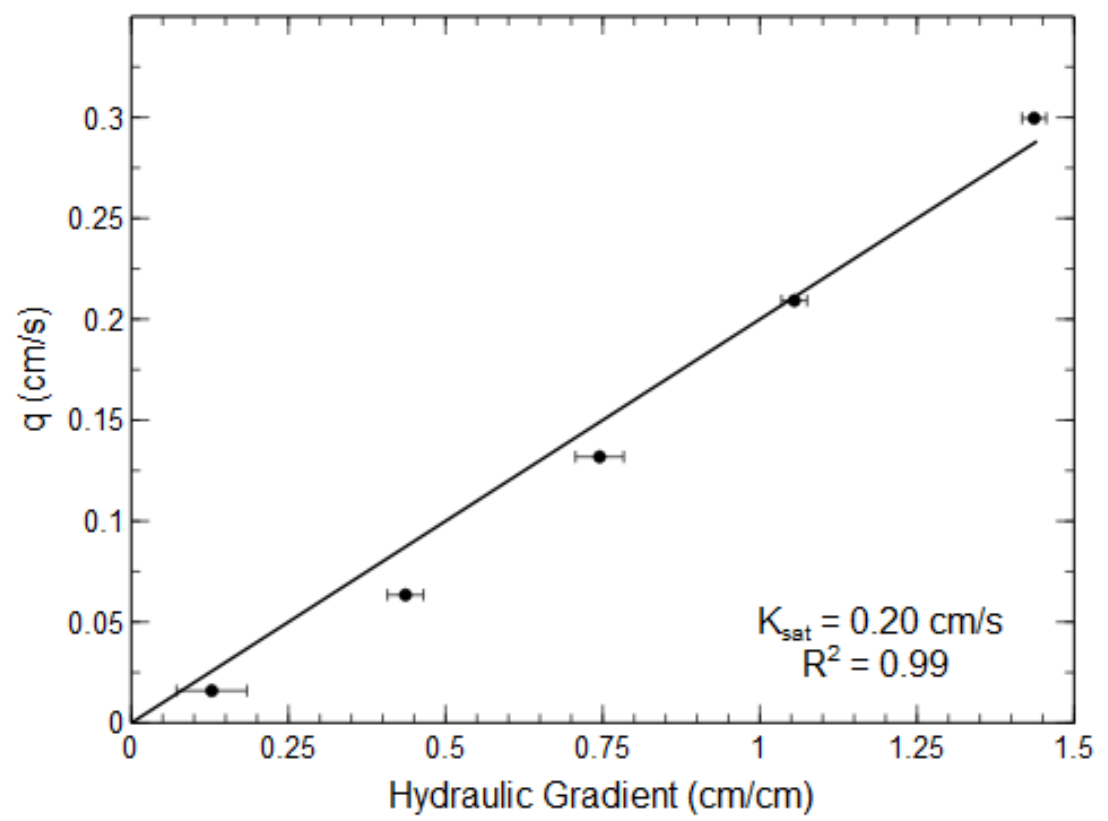

Figure 13 Specific discharge $q$ at different hydraulic gradients. A linear relationship between $q$ and the hydraulic gradient is consistent with the prediction of Darcy's Law, which usually holds for granular sands.

Results from the complex conductivity test are shown in Figure 14. Using Equation 16, the formation factor is calculated as 4.03, which is on par for typical 
formation factor values of clean sands (Garba, 2019). The remaining petrophysical properties of the sand can be found in Table 2. Overall, the results from the silica sand exhibit typical electrical and hydraulic responses of a granular sand. These results show that the developed experimental setup is capable of measuring the hydrogeophysical properties of coarse geological sediments.

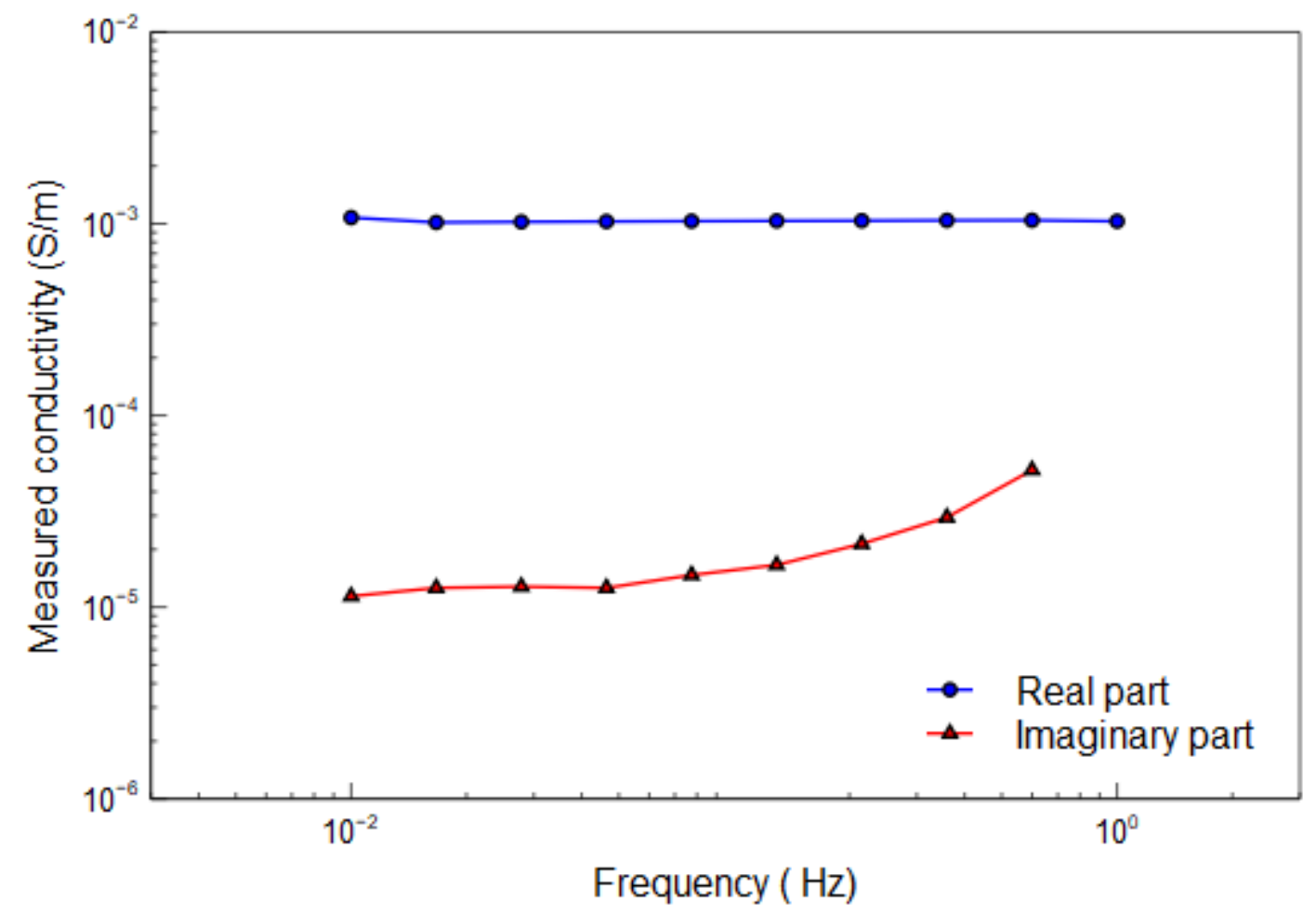

Figure 14 Results from the complex conductivity tests for the silica sand.

Table 1 XRD results of the silica sand used in the validation of the experimental setup. The sample is made up of no clays and only three mineral types.

\begin{tabular}{cc}
\hline Mineral & Weight \% \\
\hline Quartz & 50.76 \\
K-Feldspar & 30.08 \\
Plagioclase & 19.16 \\
\hline
\end{tabular}


Table 2 Summary of the silica sand's petrophysical properties. The real electrical conductivity and imaginary conductivity were measured at a frequency of $0.077 \mathrm{~Hz}$

\begin{tabular}{cc}
\hline $\begin{array}{c}\text { Petrophysical } \\
\text { Property }\end{array}$ & $\mathbf{S}-\mathbf{1}$ \\
\hline$\phi$ & 0.47 \\
$K_{\text {sat }}(\mathrm{m} / \mathrm{s})$ & $2.0 \times 10^{-3}$ \\
$k\left(\mathrm{~m}^{2}\right)$ & $1.77 \times 10^{-10}$ \\
$\mathrm{C}_{\text {sat }}(\mathrm{V} / \mathrm{Pa})$ & $5.69 \times 10^{-6}$ \\
$\mathrm{D}_{75}, \mathrm{D}_{50}, \mathrm{D}_{25}(\mathrm{~mm})$ & $0.53,0.42,0.31$ \\
$\left.\rho_{\text {samp }}(\mathrm{g} / \mathrm{cm})^{3}\right)$ & 1.4 \\
$\sigma^{\prime}\left(\sigma_{f}\right)(\mathrm{S} / \mathrm{m})$ & $1.03 \times 10^{-3}\left(3.65 \times 10^{-3}\right)$ \\
$\sigma^{\prime \prime}\left(\sigma_{f}\right)(\mathrm{S} / \mathrm{m})$ & $1.26 \times 10^{-5}$ \\
$F$ & 4.03 \\
\hline
\end{tabular}




\section{CHAPTER FOUR: SOIL SAMPLES}

\section{Study Area}

Three soil samples were collected from the Treeline study site within Dry Creek Experimental Watershed (DCEW) near Boise, ID. The DCEW is a semi-arid, snow melt driven mountain catchment occupying about $28 \mathrm{~km}^{2}$. The Treeline study site sits at an average elevation of about $1610 \mathrm{~m}$ and occupies $0.02 \mathrm{~km}^{2}$ of the greater DCEW. Average annual precipitation here is $57 \mathrm{~cm}$ with approximately half the precipitation falling as snow (McNamara et al., 2005). Cool winter temperatures $\left(5\right.$ to $\left.-10{ }^{\circ} \mathrm{C}\right)$ typically keep a persistent snowpack covering the site from December through March. Summers are generally hot $\left(20\right.$ to $\left.28^{\circ} \mathrm{C}\right)$ and dry with infrequent thunderstorms (McNamara et al., 2005). Rain-on-snow events are common in the late fall and early spring seasons. The primary vegetation includes sagebrush, forbs, grasses, and scattered trees with live canopy cover ranging from $9-11 \%$ in the fall and winter months and $35-45 \%$ in spring and summer seasons (Williams, 2005). The site drains into an ephemeral stream that typically begins flow soon after the onset of the seasonal snowpack each year (McNamara et al., 2005). Small hydrograph peaks are generated with early winter rain/melt events, but the annual peak hydrograph usually occurs in March or April depending on the duration of snowmelt (Williams, 2005). The surface of the Treeline site is far removed from a well-established aquifer. Nearby wells in the DCEW have been drilled to depths of $100 \mathrm{~m}$ before reaching an adequately producing groundwater aquifer 
(Miller et al., 2008). Additionally, Yenko (2003) indicated that deep regional groundwater does not contribute to the ephemeral streamflow in this catchment.

Soils in the Treeline study area are typically identifiable as sandy loam and vary in depth from a few centimeters to $\sim 1.3 \mathrm{~m}$ (Fullhart et al., 2018). Soils in this area are predominately sourced from a 75 to 85 -million-year-old granitic intrusion known as the Idaho Batholith (Kelleners et al., 2009). The Idaho Batholith itself is divided into two regions, the northern Bitterroot lobe and southern Atlanta lobe (King \& Valley, 2000). The DCEW is in the Atlanta lobe of the Idaho Batholith (Yenko, 2003). The portion of the Atlanta lobe within the DCEW is predominantly defined as biotite granodiorite. The biotite granodiorite is typically light gray in color, medium- to coarse-grained, and locally porphyritic with abundant potassium feldspar phenocrysts of up to $2.5 \mathrm{~cm}$ long. The mineralogic makeup of the biotite granodiorite is typically plagioclase, quartz, potassium feldspar, and $2-8 \%$ biotite (Johnson et al., 1988). 


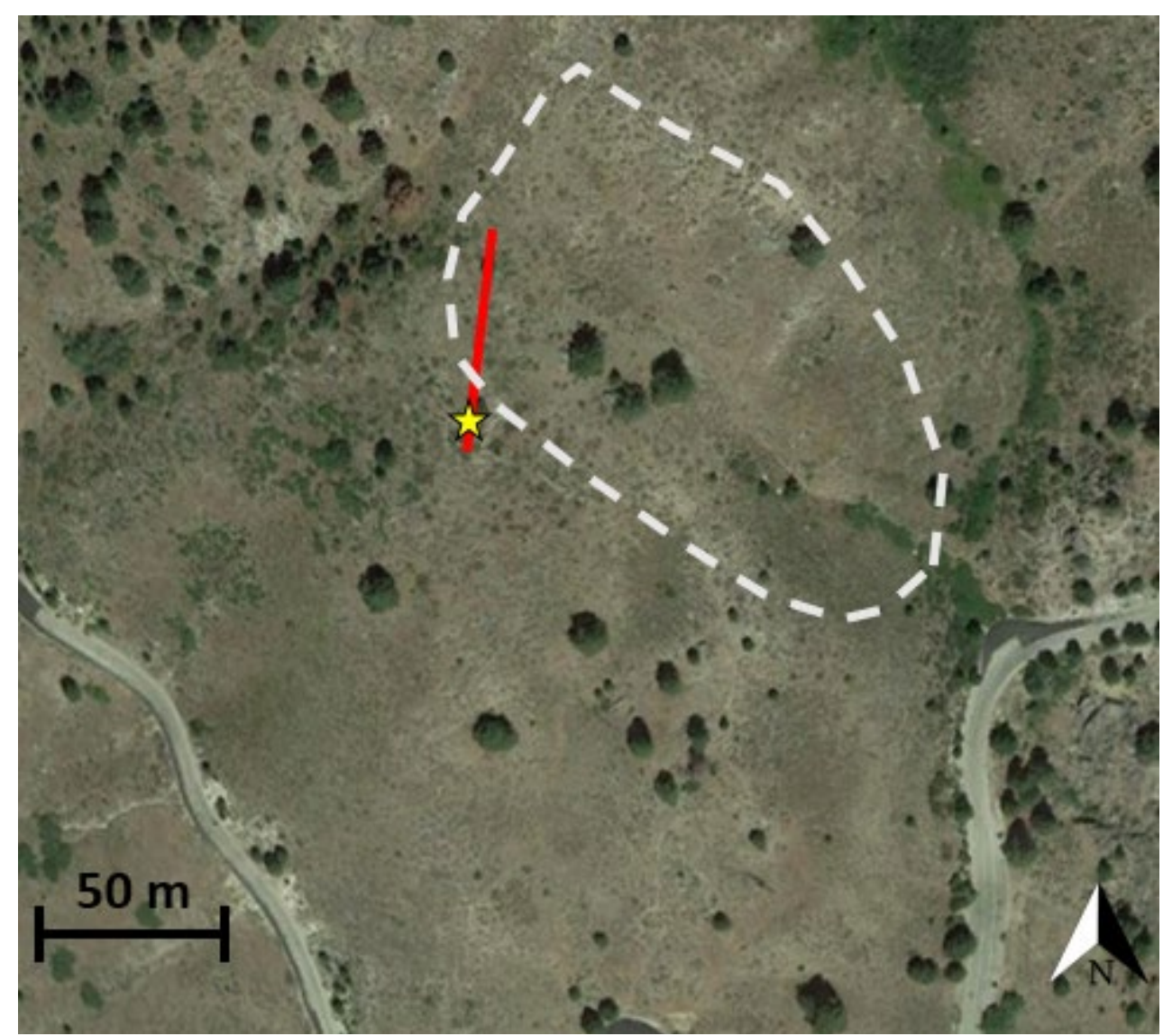

Figure 15 Aeriel photograph of the Treeline study site. The estimated boundary of the Treeline catchment is indicated by the white dashed line. The red line is the location of the ERT survey line. The star represents the location of the sampled soils.

A ridgeline at the Treeline site (Figure 15) was selected to collect the soil samples for this study. Samples collected near the ridgeline ensures the soils are mainly sourced from the bedrock via in-situ physical and chemical weathering. Downslope soils may experience significant erosion due to surface water flow and, at the valley bottom specifically, contain a significant amount of sediments deposited via water transport. These geomorphological factors associated with downslope soils are difficult to account for while analyzing a sample's mineralogical and textural properties.

Before digging a soil pit for sample collection, an electrical resistivity tomography (ERT) survey was conducted during the summer to characterize the 
subsurface of the ridgeline. In total, 72 electrodes spaced $1 \mathrm{~m}$ apart were installed along the $\sim 71 \mathrm{~m}$ survey line. The SYSCAL Pro 72 (IRIS Instruments, France) resistivity meter was used to collect apparent resistivity data via a Wenner array. The measurements were then inverted using the RES2DINV software (Geotomo Software, Malaysia) to obtain the 2D electrical resistivity distribution of the subsurface below the ridgeline (Figure 16).

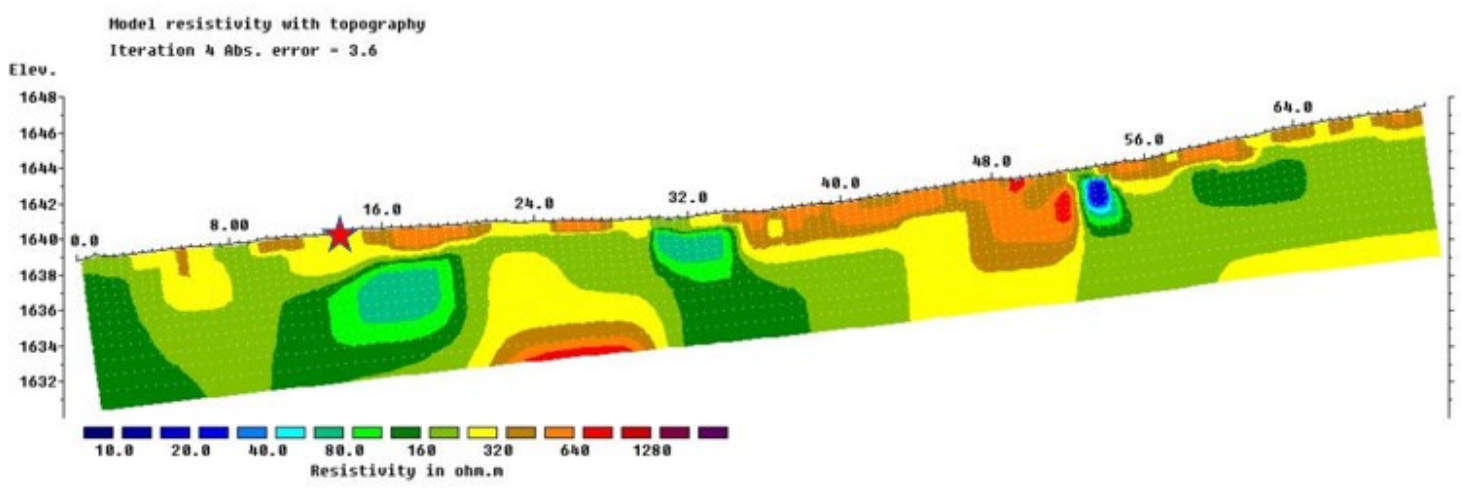

Figure 16 The two-dimensional distribution of electrical resistivity of the subsurface under a ridgeline at the Treeline site. The soil sample location is indicated by the star symbol. The variation of the electrical resistivity values, both laterally and vertically, demonstrate the heterogeneous structure of the $\mathrm{CZ}$. The test was conducted during the summer.

As shown in Figure 16, the subsurface is not homogeneous and clear layers can be identified. Near the surface ( $0 \mathrm{~m}$ to $\sim 1 \mathrm{~m})$, the resistivity is generally high $(\sim 300 \Omega \mathrm{m}$ to $\sim 600 \Omega \mathrm{m}$ ) and from $\sim 1 \mathrm{~m}$ to $\sim 5 \mathrm{~m}$ below the surface, the resistivity is generally low (< $200 \Omega \mathrm{m}$ ). This distinct resistivity contrast is mainly due the amount of water stored in the subsurface. Near the surface, the water in the soil has most likely evaporated or been consumed by vegetation (i.e., evapotranspiration) and as a result, the electrical resistivity is relatively high due to a low moisture content. In contrast, $\sim 1 \mathrm{~m}$ below the surface, there might be a significant amount of water stored in the soil and/or fractured rock, thus showing a relatively low electrical resistivity. A location for sample collection was 
identified where the resistivity of the soil is consistently around $300 \Omega \mathrm{m}$ up to $1 \mathrm{~m}$ below the surface (labeled with a star in Figure 16). At this location, several samples separated by at least $20 \mathrm{~cm}$ can be collected and observations about the different factors influencing weathering could be revealed.

\section{Sampled Soils}

Three samples were collected from a soil pit dug on a ridgeline at the Treeline study site (Figure 15). Samples were collected at $10 \mathrm{~cm}$ (TL-1), $40 \mathrm{~cm}$ (TL-2), and $70 \mathrm{~cm}$ (TL-3) below the ground surface (Figure 17). Because this study is not concerned with the structure of the samples, no attempt was made to preserve the in-situ physical properties (grain orientation, density, porosity, etc.) of the soil samples during collection. Through mechanical sieving, the grain size distribution of the three samples was determined and each sample was classified as a loamy sand (Figure 18).

For comparison, an additional soil sample was collected from a sand bar next to Mores Creek $\left(43.67716^{\circ} \mathrm{N}, 115.97874^{\circ} \mathrm{W}\right)$ and will be referred to as RS-1. Because Mores Creek flows through the Atlanta lobe of the Idaho Batholith, RS - 1 can be assumed to have a similar mineralogy as the intact bedrock. Based on a mechanical sieving analysis, RS-1 can be classified as a sand (Figure 18).

An XRD analysis was performed to determine the mineralogy of each sample (Table 3). Quartz, potassium feldspar, and plagioclase were determined to be the most abundant minerals (total mass larger than 50\%) for all four samples. In addition to the forementioned minerals, the Treeline samples also have a significant amount of clay minerals (i.e., mica, illite, kaolinite, and smectite) relative to RS-1, which has almost none. The clay minerals found at the Treeline site are consistent with the results from 
previous studies that show these clay minerals are expected to be seen within a low precipitation $(<60 \mathrm{~cm})$ area of the Idaho Batholith (e.g., Clayton, 1974).

For the Treeline samples, the clay mineral content is highest near the surface (i.e., $\mathrm{TL}-1$ ) and lowest near the bedrock (i.e., TL - 3). This implies, the material near the surface may be experiencing a higher degree of chemical weathering relative to material closer to the bedrock. This assessment is further supported by the increase in K-Feldspar content with increasing depth. Both illite and kaolinite are predominantly formed via the weathering of feldspars (Deer et al., 2013), and therefore, the relative decrease in K-spar as you move farther from the bedrock, indicates more weathering has taken place for soils closer to the surface. Moreover, smectite formation is also favored by high silica potential and availability of calcium, which may come from quartz and plagioclases respectively (which have the lowest concentrations at the surface (i.e., $\mathrm{TL}-1$ ), where smectite is highest) and dry conditions ( $<60 \mathrm{~cm}$ annual precipitation) that limit leaching away of ions needed to form smectite (Clayton, 1974; Deer et al., 2013). In conclusion, this means the difference in mineralogy of the Treeline samples is most likely caused by in-situ chemical weathering.

The mineralogy of the silt and sand grains have relatively little influence on a waters ability to move through the subsurface. The presence of clays, however, can drastically change how water moves in the subsurface (Lambe \& Whitman, 1969). Relative to the samples in this study, it is important to note the significant impact smectite can have on the hydraulic and electrical properties of the soil. Smectite is one of the least permeable clay minerals and has the ability to strongly influence the flow behavior of water (Lambe \& Whitman, 1969; Odom, 1984). Smectites ability to deter 
water flow has led to its use in several industrial and engineering applications aimed at impeding water movement (Odom, 1984). The high ion exchange capacity of smectite clays is responsible for its unique impermeable properties (Lambe \& Whitman, 1969). Also, the high surface charge of smectite could contribute considerably to the electrical contribution of the soil, resulting in a relatively high surface conductivity and high induced polarization (i.e., imaginary conductivity). The other clays found within the soil samples, illite and kaolinite, do not share the same high cation exchange capacity as smectite (Shaw et al., 1998). Therefore, illite and kaolinite may not have the same significant impact on hydraulic and electrical properties of soils as smectite. 


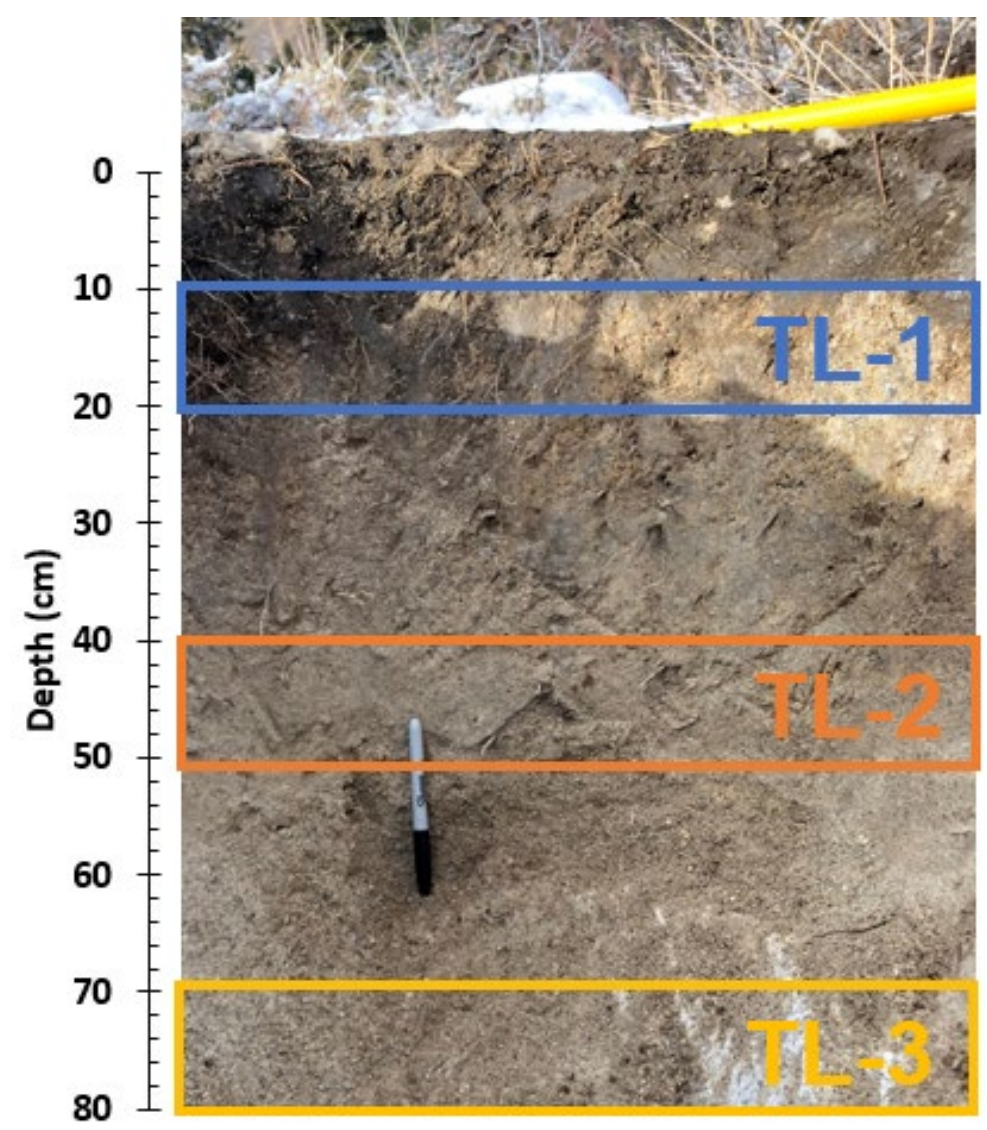

Figure 17 Soil pit with representative sample locations. TL - 1 lies directly beneath the organically abundant $A$ and $O$ soil horizons. TL - 2 contains no organic material and is predominately coarse sands. However, there are some pebbles of poorly cemented bedrock material within this layer. TL-3 is directly overlying the bedrock. The total soil pit depth is about $80 \mathrm{~cm}$. Samples collected represent a vertical depth of $10 \mathrm{~cm}$. 


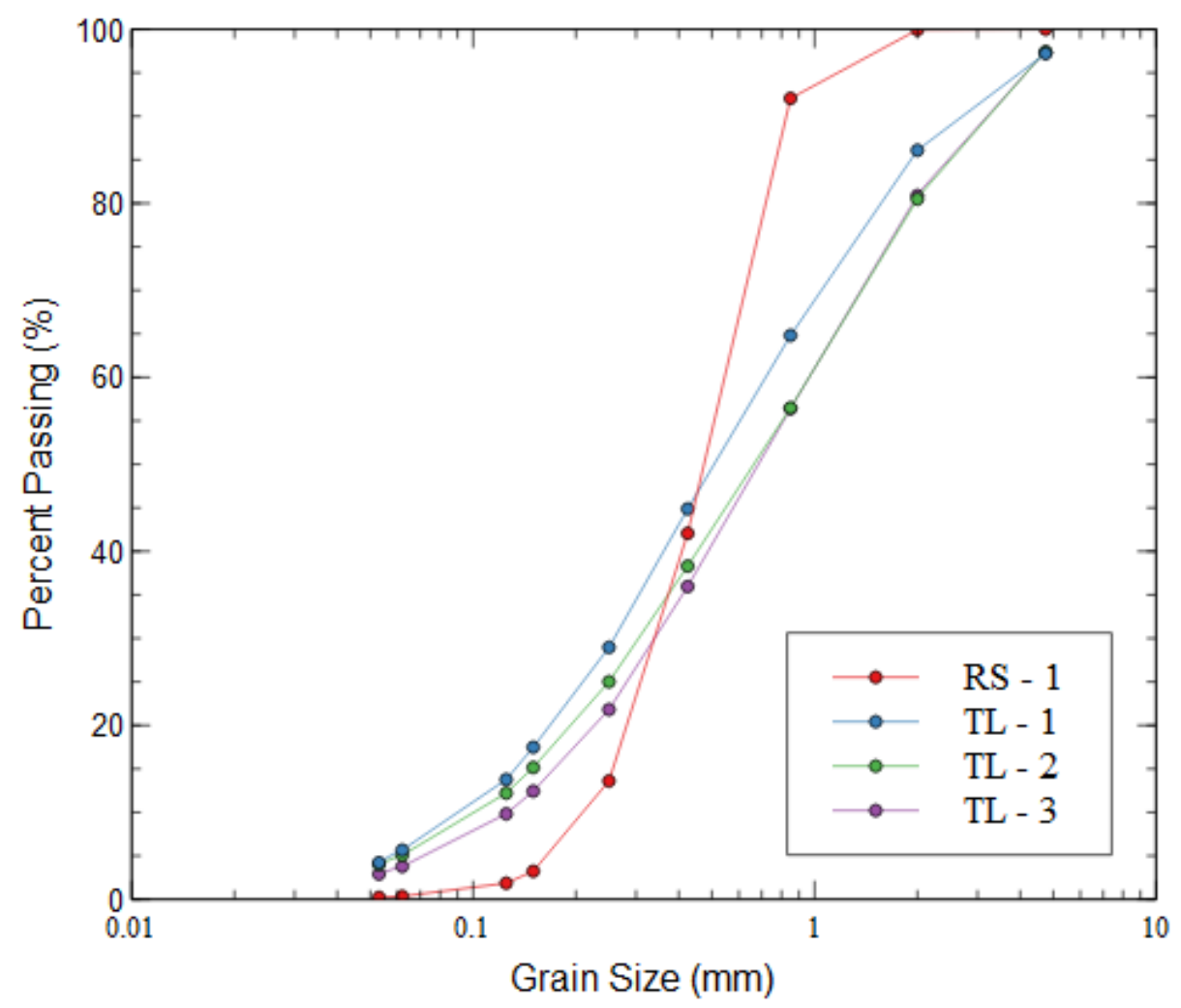

Figure 18 Grainsize distribution of sampled soils. RS - 1, sampled from a nearby creek, is a well sorted sand, containing almost no silts or clay sized minerals. The Treeline samples represent an overall fining upwards sequence. All samples, however, contain less than $10 \%$ silt or clay sized minerals. The Treeline samples can be classified as loamy sand.

Table 3 XRD analysis of the three Treeline samples and RS -1 . Values represent the normalized weight percent a given mineral for its respective soil sample.

\begin{tabular}{ccccc}
\hline Mineral & RS - 1 & TL - 1 & TL - 2 & TL - 3 \\
\hline Quartz & 12.67 & 11.72 & 13.42 & 12.88 \\
K-Feldspar & 25.48 & 6.70 & 7.70 & 10.11 \\
Plagioclase & 57.61 & 32.73 & 33.24 & 35.02 \\
Micas & 4.25 & 3.59 & 2.70 & 4.25 \\
Pyroxene & - & 4.56 & 2.94 & 2.78 \\
Illite & - & 21.61 & 32.78 & 31.78 \\
Kaolinite & - & 3.80 & 4.08 & 3.18 \\
Smectite & - & 15.3 & 3.17 & - \\
\hline
\end{tabular}




\section{CHAPTER FIVE: SATURATED TEST}

The four soil samples (RS - 1, TL - 3, TL - 2, TL - 1) were tested using the developed soil column and their electrical and hydraulic properties were determined. In this chapter, the results of the saturated tests are presented and the effects of texture and mineralogy are discussed.

\section{Results}

All four soil samples underwent the saturated test, which includes simultaneous measuring of SP and pore water pressure for five different hydraulic gradients. The results are shown in Figure 19 to 22. The sample RS - 1 produced exceptionally good pressure and electrical signals relative to the theoretical expectations of the test (Figure 19). The measured pressure shows proportional response with a stair-step pattern matching the gradual increases in hydraulic gradient (Figure 19a). The same stair step pattern is observed in the SP response to the increase in hydraulic gradient (Figure 19b). This observed relationship is quantified in Figure 19c and 19d where the relationship between specific discharge $q(q=Q / A$ where $Q$ is the flow rate and $A$ is the crosssectional area) and change in hydraulic gradient and the streaming potential coupling coefficient $C_{\text {sat }}$ and change in pressure were both almost perfectly linear with a coefficient of determination of 0.99 . Unless otherwise stated, the coefficient of determination values $\left(\mathrm{R}^{2}\right)$ are based on a linear fit with an intercept set to zero for all results presented in this section. When determining the quality of fit for the specific discharge and hydraulic gradient, assuming an intercept of zero is appropriate because 
based on the hydrostatic data, it is observed that periods of no flow have no pressure

difference. Moreover, an assumed intercept of zero is appropriate for the SP verse pressure data because initial SP offset has been adjusted to zero for periods of a hydrostatic state. Based on the fitted line values for RS -1 , the values of $K_{s a t}$ and $C_{s a t}$ are determined as $1.1 \times 10^{-3} \mathrm{~m} \mathrm{~s}^{-1}$ and $-7.5 \times 10^{-6} \mathrm{~V} \mathrm{~Pa}^{-1}$, respectively.

\section{$\underline{\text { RS - } 1}$}

a)

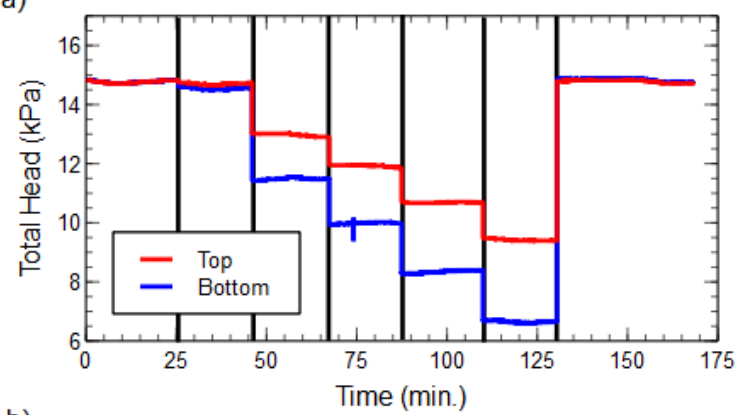

b)

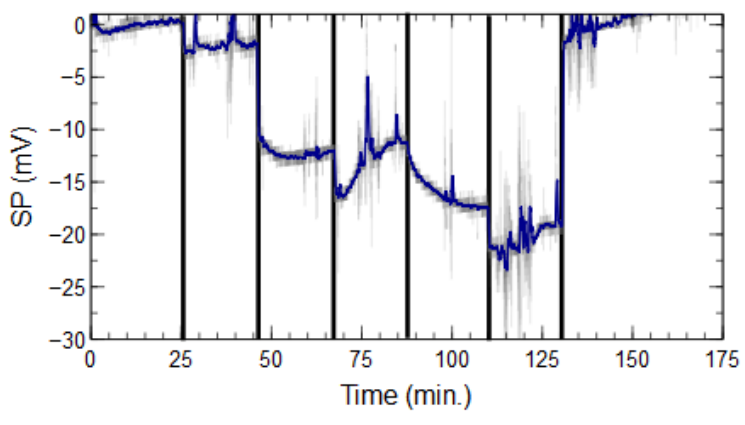

c)

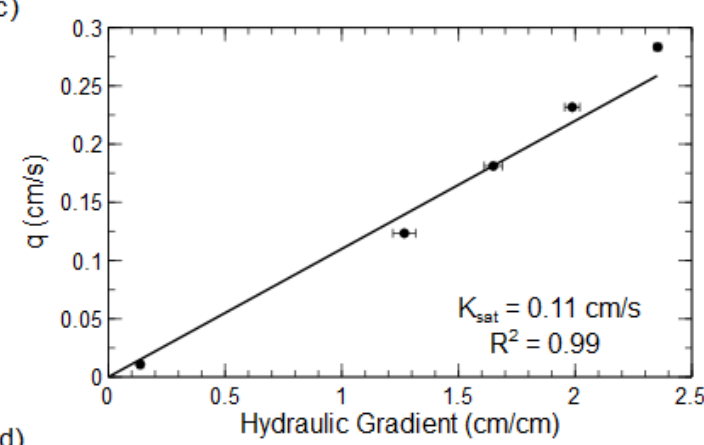

d)

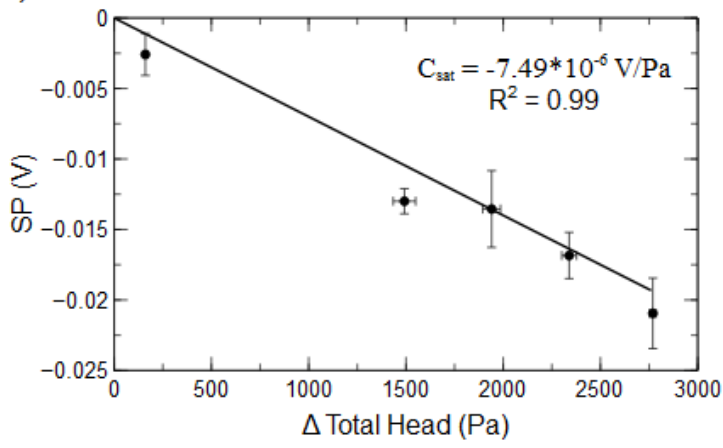

Figure 19 The saturated testing results for RS - 1: a) total head (expressed as kPa) measured from the two probes, b) the measured self-potential (voltage difference between the top probe and bottom probe), c) specific discharge versus applied hydraulic gradient, and d) self-potential versus change in total head. Different flow intervals are separated by the vertical black lines in a) and b). The data points in c) and d) represent the average value for each interval and the associated error bars indicate one standard deviation. In b) the grey line represents the raw data and the blue line is the 60 second moving average value. Both (c) and (d) demonstrate an almost perfect linear relationship.

The maximum achievable flow rate for $\mathrm{TL}-3\left(0.18 \mathrm{~cm}^{3} \mathrm{~s}^{-1}\right)$ is significantly smaller than the maximum flow rate achieved under the same conditions for RS - 1 $\left(12.51 \mathrm{~cm}^{3} \mathrm{~s}^{-1}\right)$. This indicates the soil sample collected from the $\mathrm{CZ}$ has a relatively 
lower hydraulic conductivity. The calculated $K_{\text {sat }}$ is $3.06 \times 10^{-4} \mathrm{~m} \mathrm{~s}^{-1}$ for TL -3 , which is about three orders of magnitude lower than RS - 1 . The reduction in $K_{\text {sat }}$ is mainly due to the increase in finer particles present and/or the mineralogy change in the regolith; the effect of compaction should be smaller because the porosity of these two samples are similar $(0.42$ for TL -3 and 0.45 for RS -1$)$. Comparing RS -1 to the water flowinduced SP signal in TL -3 , the magnitude of change in total head is significantly larger in TL - 3, but the SP signal is about an order of magnitude smaller (Figure 20d). A linear relationship between SP response and change in total head, however, is still observed and the coefficient of determination $\mathrm{R}^{2}$ is 0.99 (Figure 20d). The calculated saturated streaming potential coupling coefficient $C_{\text {sat }}$ is $2.06 \times 10^{-7} \mathrm{~V} \mathrm{~Pa}^{-1}$. It should be noted that although the SP signal shows an almost perfect linear relationship with the hydraulic gradient, the relatively high standard deviations may be of concern (Figure 20d). Using Equation 11, $C_{\text {sat }}$ can be calculated using the average SP and average change in pressure for each interval. Of the five different hydraulic gradients, the calculated maximum $C_{\text {sat }}$ is $2.48 \times 10^{-7} \mathrm{~V} \mathrm{~Pa}^{-1}$ and the calculated minimum is $1.75 \times 10^{-7} \mathrm{~V} \mathrm{~Pa}^{-1}$. 
$\underline{\text { TL }-3}$
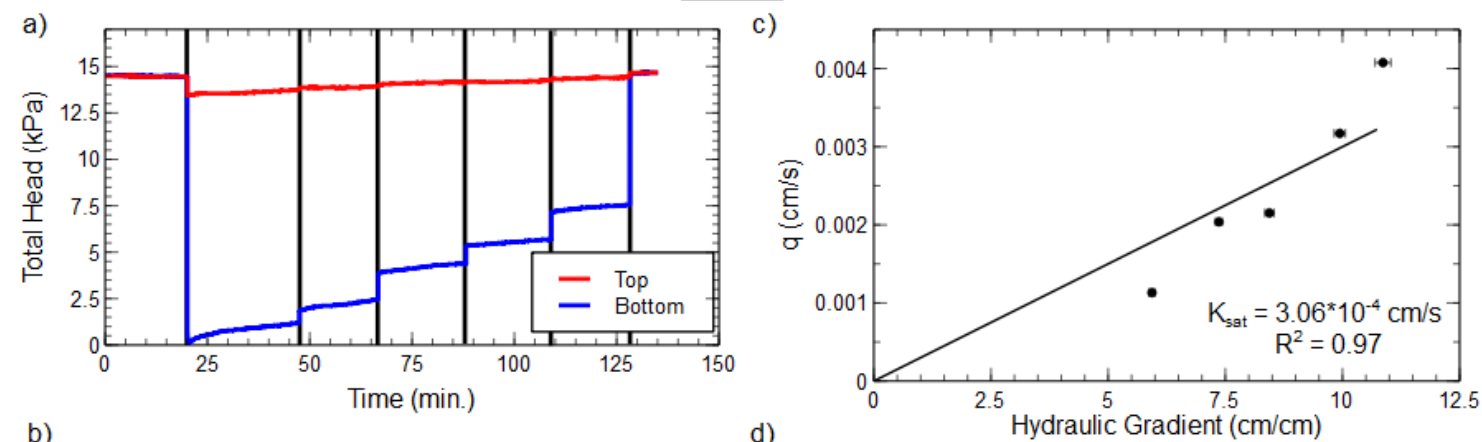

b)
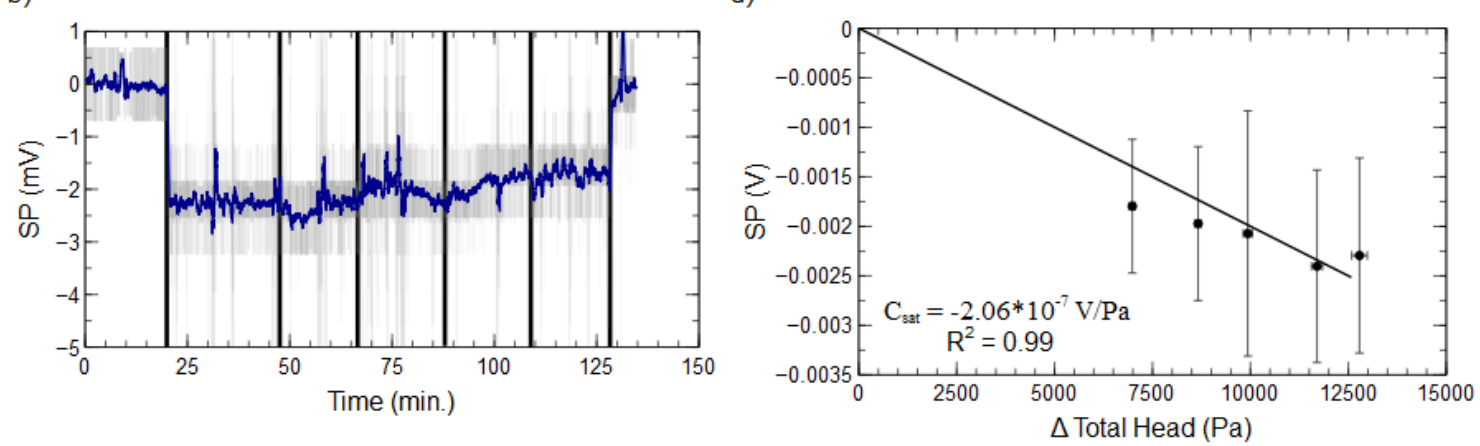

Figure 20 The saturated testing results from the deepest sampled $C Z$ soil $(70 \mathrm{~cm}$ below the surface), TL - 3: a) total head (expressed as kPa) measured from the two probes, b) the measured self-potential (voltage difference between the top probe and bottom probe), c) specific discharge versus applied hydraulic gradient, and d) selfpotential versus change in total head. Different flow intervals are separated by the vertical black lines in a) and b). The data points in c) and d) represent the average

value for each interval and the associated error bars indicate one standard

deviation. In b) the grey line represents the raw data and the blue line is the 60 second moving average value. Relative to $R S-1$ and $S-1$, the change in total head is similar, but the flow rate is significantly lower. As a result, the calculated hydraulic conductivity (c) is about three magnitudes lower than $R S-1$ and $S-1$. Both (c) and (d) demonstrate an almost perfect linear relationship, but there is a relatively large standard deviation associated with each point which may be a point of concern for future interpretations.

$\mathrm{TL}-2$ has a maximum achievable flow rate of $0.07 \mathrm{~cm}^{3} \mathrm{~s}^{-1}$, significantly smaller than the maximum flow rate for $\mathrm{TL}-3\left(0.18 \mathrm{~cm}^{3} \mathrm{~s}^{-1}\right)$ under the same applied hydraulic gradient. The flow rate at different hydraulic gradients is plotted in Figure 21c and shows a linear relationship between flow and change in hydraulic gradient. The calculated $K_{\text {sat }}$ is $5.05 \times 10^{-6} \mathrm{~m} \mathrm{~s}^{-1}$, however, is still at the same order as TL -3 . 
The SP response due to change in total head is still following a linear trend $\left(\mathrm{R}^{2}=\right.$ $0.89)$ but it appears that the best fitted line $\left(\mathrm{R}^{2}=0.96\right)$ does not pass through origin. The determined $C_{\text {sat }}$ for TL -2 is $6.35 \times 10^{-7} \mathrm{~m} \mathrm{~s}^{-1}$ and in the same order of magnitude as TL - 3. In Figure 21d, the error related to the SP signals is relatively large. Its influence on the $C_{\text {sat }}$ determination was estimated, and the calculated $C_{\text {sat }}$ range is from $1.94 \times 10^{-7}$ to $8.24 \times 10^{-7} \mathrm{~V} \mathrm{~Pa}^{-1}$. For the slope not passing through the origin, the $\mathrm{C}_{\text {sat }}$ is about two times larger at $1.29 \times 10^{-6} \mathrm{~V} \mathrm{~Pa}^{-1}$.
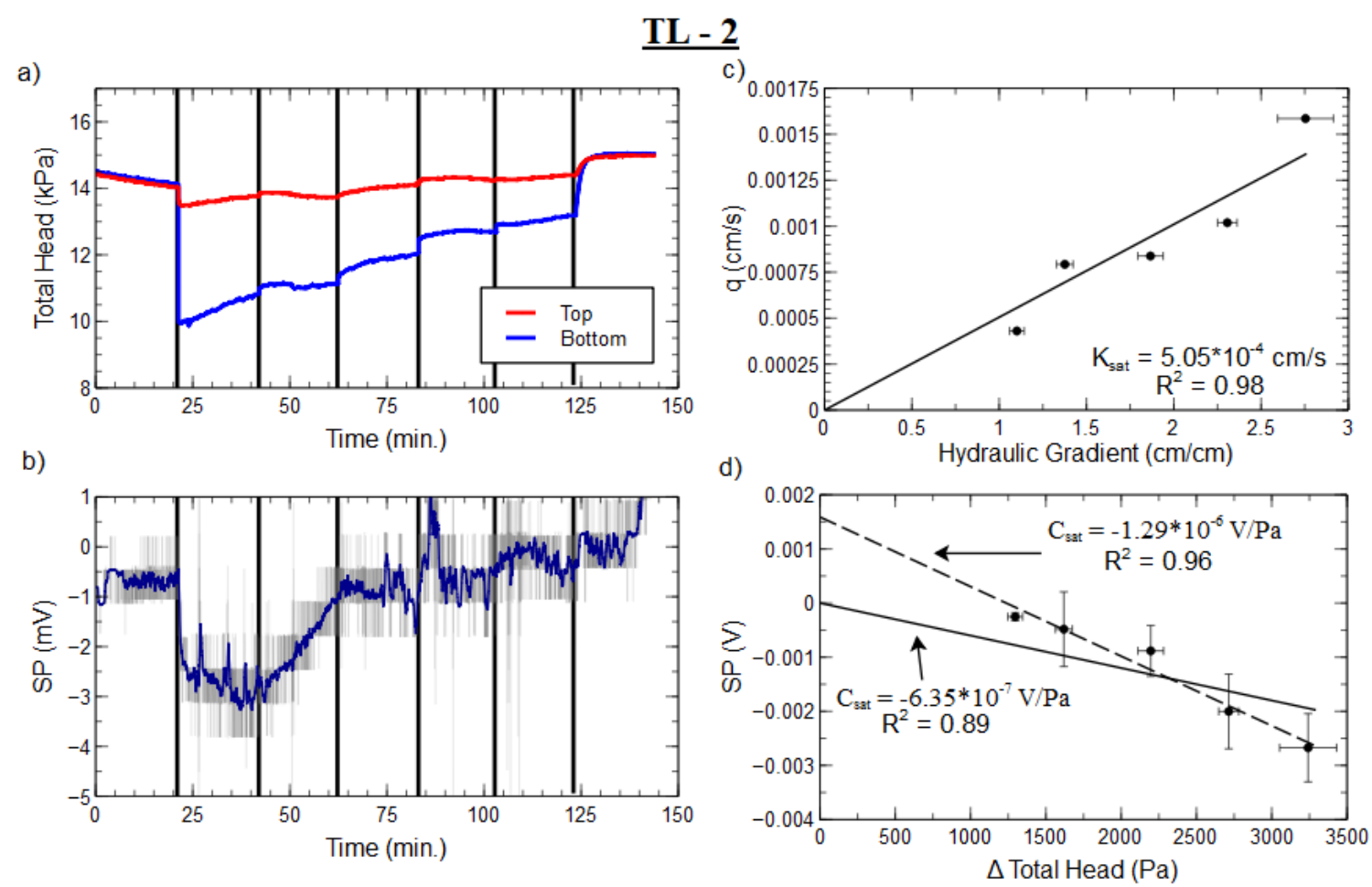

Figure 21 The saturated testing results for the sample taken $40 \mathrm{~cm}$ below the surface, TL - 2: a) total head (expressed as $\mathrm{kPa}$ ) measured from the two probes, b) the measured self-potential (voltage difference between the top probe and bottom probe), c) specific discharge versus applied hydraulic gradient, and d) self-potential versus change in total head. Different flow intervals are separated by the vertical black lines in a) and b). The data points in c) and d) represent the average value for each interval and the associated error bars indicate one standard deviation. In b) the grey line represents the raw data and the blue line is the 60 second moving average value. In d), a slope that does not pass through an origin is shown due to the improved fit. 
$\mathrm{TL}-1$ represents a sample taken near the ground surface. This sample demonstrated distinct hydraulic and electrical responses during the saturated test relative to TL -3 and TL -2 . In general, the flow rates achieved with this sample are very small, ranging between 0.0089 to $0.04 \mathrm{ml} \mathrm{s}^{-1}$, when compared to $\mathrm{TL}-2$ (which ranged from 0.019 to $0.07 \mathrm{ml} \mathrm{s}^{-1}$ ). Applying Darcy's law, the estimated $K_{\text {sat }}$ is $6.24 \times 10^{-7} \mathrm{~m} \mathrm{~s}^{-1}$. The SP signal (Figure 22b) during the test does not show a clear relation to changes in hydraulic gradient (Figure 22a). However, if the absolute voltage measured by each electrode is plotted (Figure 22c), the voltage values shows a clear correlation with the hydraulic gradient change. Despite this, the streaming potential coupling coefficient $C_{\text {sat }}$ is determined to be $1.21 \times 10^{-7} \mathrm{~V} \mathrm{~Pa}^{-1}$. 
$\underline{\text { TL }-1}$

a)

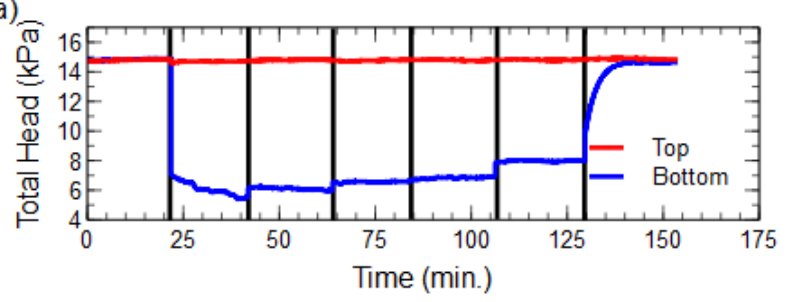

b)

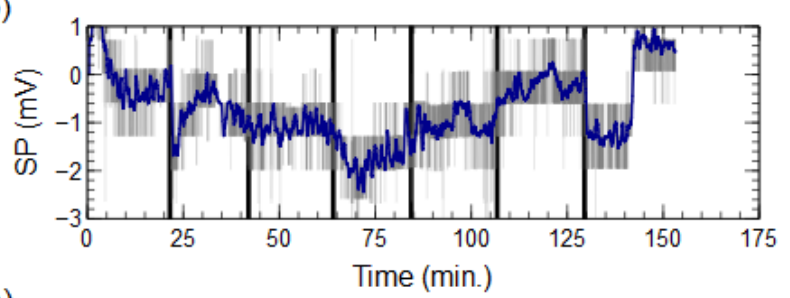

c)

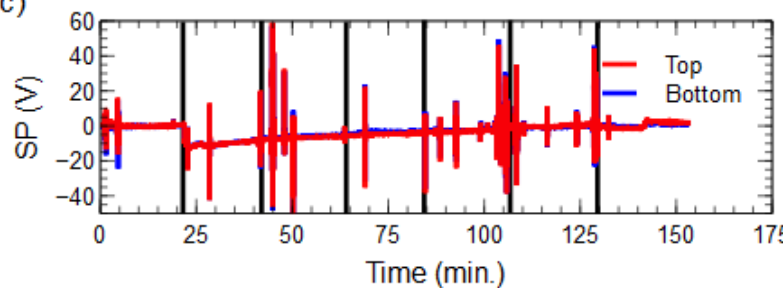

d)

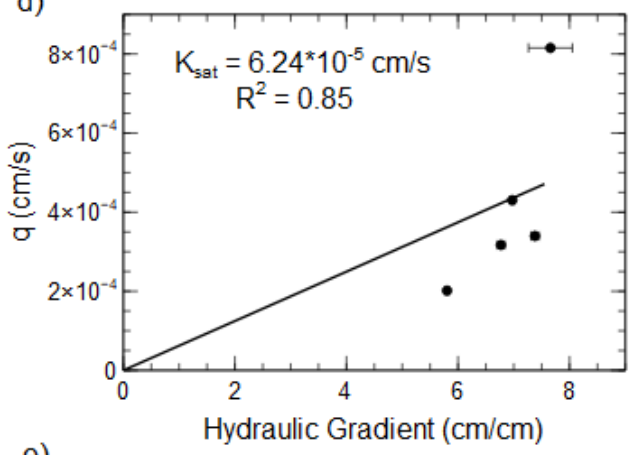

e)

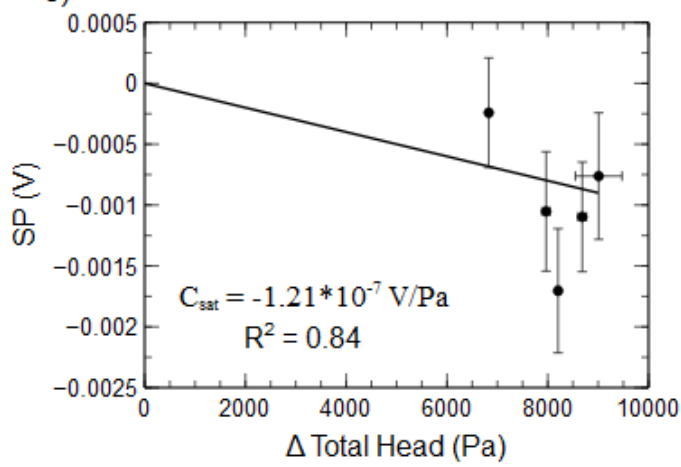

Figure 22 The saturated testing results for the sample taken $10 \mathrm{~cm}$ from the surface, TL - 1: a) total head (expressed as $\mathrm{kPa}$ ) measured from the two probes, b) the measured self-potential (voltage difference between the top probe and bottom probe),c) shows each electrodes $S P$ response relative to an external ground, $d$ ) specific discharge versus applied hydraulic gradient, and e) self-potential versus change in total head. Different flow intervals are separated by the vertical black lines in a), b), and c). The data points in d) and e) represent the average value for each interval and the associated error bars indicate one standard deviation. In b) the grey line represents the raw data and the blue line is the 60 second moving average value. Through observation of the electrode's absolute values in c), there is an observed SP signal change relative to changes in the hydraulic gradient that is not observed in b). With respect to the other soil samples, TL -1 has the lowest coefficient of determination observed for plots d) and e).

The saturated hydraulic conductivity $K_{\text {sat }}$ and saturated streaming potential coupling coefficient $C_{\text {sat }}$ of the four samples were summarized in Table 4. Other petrophysical properties such as porosity $\phi$, permeability $k$, dry density $\rho_{\text {samp }}$, real conductivity $\sigma^{\prime}$, imaginary conductivity $\sigma^{\prime \prime}$, formation factor $F$, and apparent formation factor $F_{a}$, are also shown in Table 4 and were measured using the same methods 
described in Chapter Three. For comparison, the results of the silica sand are also presented in the Table 4.

Table 4 Summary of the measured petrophysical properties of five for soil samples. The real electrical conductivity and imaginary conductivity were measured at a frequency of $0.077 \mathrm{~Hz}$. The formation factor $F$ was found using Equation 16 where the contribution for surface conductivity was accounted for. The apparent formation factor $\boldsymbol{F}_{a}$ does not account for surface conduction and is simply calculated as fluid conductivity $\sigma_{f}$ divided by the real electrical conductivity $\sigma^{\prime}$. The water conductivity $\sigma_{f}$ at which the complex conductivity was measured is also reported in the table.

\begin{tabular}{|c|c|c|c|c|c|}
\hline & \multicolumn{3}{|c|}{ Sample } & \multirow[b]{2}{*}{$\mathrm{TL}-3$} & \multirow[b]{2}{*}{$\mathrm{S}-1$} \\
\hline & $\mathrm{RS}-1$ & $\mathrm{TL}-1$ & $\mathrm{TL}-2$ & & \\
\hline$\phi$ & 0.45 & 0.43 & 0.45 & 0.42 & 0.47 \\
\hline$K_{\text {sat }}(\mathrm{m} / \mathrm{s})$ & $1.14 \times 10^{-3}$ & $6.24 \times 10^{-7}$ & $5.04 \times 10^{-6}$ & $3.06 \times 10^{-6}$ & $2.0 \times 10^{-3}$ \\
\hline$k\left(\mathrm{~m}^{2}\right)$ & $1.17 \times 10^{-10}$ & $1.21 \times 10^{-14}$ & $5.16 \times 10^{-13}$ & $3.13 \times 10^{-13}$ & $1.77 \times 10^{-10}$ \\
\hline $\begin{array}{l}\mathrm{D}_{75}, \mathrm{D}_{50}, \mathrm{D}_{25} \\
(\mathrm{~mm})\end{array}$ & $\begin{array}{l}0.59,0.48 \\
0.25\end{array}$ & $\begin{array}{l}1.2,0.51 \\
0.21\end{array}$ & $\begin{array}{l}1.7,0.68 \\
0.25\end{array}$ & $\begin{array}{l}1.75,0.7 \\
0.28\end{array}$ & $\begin{array}{l}0.53,0.42 \\
0.31\end{array}$ \\
\hline $\begin{array}{l}\rho_{\text {samp }} \\
\left(\mathrm{g} / \mathrm{cm}^{3}\right)\end{array}$ & 1.45 & 1.5 & 1.43 & 1.53 & 1.4 \\
\hline$\sigma^{\prime}\left(\sigma_{f}\right)(\mathrm{S} / \mathrm{m})$ & $\begin{array}{l}9.45 \times 10^{-4} \\
\left(1.92 \times 10^{-3}\right)\end{array}$ & $\begin{array}{l}6.68 \times 10^{-3} \\
\left(7.54 \times 10^{-3}\right)\end{array}$ & $\begin{array}{l}5.19 \times 10^{-3} \\
\left(8.15 \times 10^{-3}\right)\end{array}$ & $\begin{array}{l}3.22 \times 10^{-3} \\
\left(9.13 \times 10^{-3}\right)\end{array}$ & $\begin{array}{l}1.03 \times 10^{-3} \\
\left(3.65 \times 10^{-3}\right)\end{array}$ \\
\hline$\sigma^{\prime \prime}(\mathrm{S} / \mathrm{m})$ & $2.75 \times 10^{-5}$ & $6.29 \times 10^{-5}$ & $1.5 \times 10^{-4}$ & $1.26 \times 10^{-4}$ & $1.26 \times 10^{-5}$ \\
\hline$F$ & 2.86 & 1.25 & 2.21 & 4.66 & 4.03 \\
\hline$F_{a}$ & 2.03 & 1.29 & 1.57 & 2.84 & 4.57 \\
\hline$C_{\text {sat }}(V / P a)$ & $7.49 \times 10^{-6}$ & $1.21 \times 10^{-7}$ & $6.35 \times 10^{-7}$ & $2.06 \times 10^{-7}$ & $5.69 \times 10^{-6}$ \\
\hline
\end{tabular}

\section{Performance of Experimental Setup}

The developed novel experimental setup was found to be applicable to most of the soil samples tested. The best results came from coarser grained soils ( $\mathrm{S}-1, \mathrm{RS}-1$, and $\mathrm{TL}-3$ ), where both the SP signals and total head data show clear step-wise responses to 
the hydraulic gradient changes (Figure 11, 19, and 20). The corresponding flow rate and induced SP and total head difference for each of these samples showed linear correlation from which the saturated hydraulic conductivity and streaming potential coupling coefficient can be accurately calculated. The results of samples containing more clay minerals (i.e., $\mathrm{TL}-2$ and $\mathrm{TL}-1$ ), however, identified some limitations of the experimental setup. Although the total head response of sample TL-1 is still step-wise in response to the applied hydraulic gradient change (Figure 22a), the SP response did not show a clear trend (Figure 22b) and did not increase monotonically relative to increase in hydraulic gradient (Figure 22e). Moreover, the measurement error related to SP at each hydraulic gradient is very large $(\sim 1 \mathrm{mV})$ and is at the same order of the flow induced SP signals.

The relatively poor performance of sample TL-1 is due to the relatively higher content of clay minerals (i.e., illite, smectite, kaolinite, and mica) (Table 3). TL - 1 has the highest clay content by weight (44.3\%) relative to TL $-2(42.73 \%), \mathrm{TL}-3(39.21 \%)$, and RS - 1 (4.25\%). Moreover, TL -1 has the highest content of smectite (15.3\%) relative to the other samples studied (Table 3). It is well known that clay minerals, especially smectite, can significantly influence the hydraulic and electrical properties of a soil (Lambe \& Whitman, 1969). This statement is reflected in the quality of the experimental results. TL -3 , the coarsest grained of the field samples and thus lowest clay mineral content, has a coefficient of determination for SP and change in total head of 0.98 (Figure 20d). TL -2 , a finer material with more clay minerals, has a SP and change in total head coefficient of determination of only 0.89 (Figure 21 d). Finally, TL -1 , the 
sample with the highest clay mineral content, has a coefficient of determination of only 0.84 between SP and change in total head (Figure 22e).

The decrease in correlation between SP and change in total head with increasing clay minerals may be explained by the reduction in permeability of the soils. Clay minerals can significantly lower the hydraulic conductivity by decreasing the pore size of a sample and holding water via electrical forces (Dingman, 2015). Therefore, the maximum flow rate achievable for clay bearing samples during the saturated test under a given hydraulic gradient is lower relative to samples with little to no clay. As shown in Equation 9, if the other parameters stay the same, a small Darcy velocity will produce a low SP signal and thus the induced streaming potential will be smaller. Because the observed SP signal is relatively small $(<2 \mathrm{mV})$ for a slow flow rate $\left(<\sim 0.02 \mathrm{ml} \mathrm{s}^{-1}\right)$, the relative contribution of noise on the measured electrical signals may be significant enough that it becomes difficult to distinguish streaming-potential signal from the associated noise. To improve the distinction between SP and noise, increasing the probes spacing may provide a solution to this problem and could be an option for future experimental setup modification. Given the same streaming current, increasing the distance between the integrated hydrogeophysical probes will increase the difference in the observed streaming potential.

The relationship between pressure and the flow rate was relatively good for all tested samples. TL -1 had the smallest coefficient of determination, 0.85 , of all the tested samples. TL -3 , TL - 2, and RS - 1 had a very high $\mathrm{R}^{2}(>0.98)$. As seen in Figure $22 \mathrm{~d}, \mathrm{TL}-1$ has a single outlier that disrupts the linear nature of the points. This outlier is representative of the average pressure from the first flow rate interval and could be 
associated with experimental error. As seen in Figure 22a, the pressure at the bottom sensor does not reach equilibrium for the first interval. This speaks to the need to increase the observation time when testing clay bearing samples to ensure the flow in the medium reaches a steady state.

Although the associated difficulties measuring clay bearing soils leaves some room for improvement of the test setup, overall, the hydraulic conductivity and streaming potential coupling coefficient of most of the soil samples were accurately measured with low uncertainty. Soils $\mathrm{S}-1, \mathrm{RS}-1$, and $\mathrm{TL}-3$ all had nearly perfect linear relationship between both flow rate and change in hydraulic gradient and SP and change in total head. Additionally, calculation of the petrophysical properties of all soils (such as apparent formation factor and imaginary conductivity) were in the range of published literature values. Therefore, it is concluded that the experimental setup is applicable to coarse grained soils and with some modifications, it may become a preferred method for fine soils as well.

\section{Measured Soil Properties}

In this subsection, influences of texture (physical weathering) and mineralogy (chemical weathering) on the electrical and hydraulic properties of $\mathrm{CZ}$ soils are discussed based on the result of samples RS-1, TL-3, TL-2, and TL-1. The relative importance of physical and chemical weathering is analyzed.

Hydraulic conductivity

The hydraulic conductivity of soils is influenced by the porosity, tortuosity, and effective pore/grain size of the material (Carman, 1937). Since the porosity was not controlled in the experiment, it is not meaningful to directly compare the measured 
hydraulic conductivity, and therefore, the Kozeny-Carman (KC) equation (Equation 3) was used to guide the analysis. As shown in Figure 23, the $K-\phi$ curves are generated with the $\mathrm{KC}$ equation via different effective grain sizes (i.e., $d=1 \mathrm{~mm}, 0.1 \mathrm{~mm}$, and 0.01 $\mathrm{mm})$. In the $\mathrm{KC}$ equation, the tortuosity is assumed to be a function of porosity and thus, the curves in Figure 23 are influenced only by effective grain size (Carman, 1937). A comparison of measured data points with these curves reveal how the effective grain size is changing among these samples. As shown in Figure 23, the effective grain/pore size (i.e., $\left.d_{10}\right)$ varies considerably among the samples: $0.31 \mathrm{~mm}(\mathrm{~S}-1), 0.21 \mathrm{~mm}(\mathrm{RS}-1)$, $0.13 \mathrm{~mm}(\mathrm{TL}-3), 0.1 \mathrm{~mm}(\mathrm{TL}-2)$, and $0.09 \mathrm{~mm}(\mathrm{TL}-1)$. The increase in effective grain size with increasing depth speaks to the fact that material from the bedrock is continuously being physically/chemically weathered into finer particles with time. The effective grain/pore size of the samples TL - 3 and TL - 2 are at the same order; the sample near the ground surface ( $T L-1)$, which has experienced the most significant weathering processes, has the smallest effective grain/pore size, indicating a higher content of fine particles.

The predicted $d_{10}$ values for the $\mathrm{TL}-1, \mathrm{TL}-2$, and $\mathrm{TL}-3$ from the $\mathrm{KC}$ equation and measured hydraulic conductivity and porosity are an order of magnitude lower than the measured $d_{10}$ values (Figure 23). Conversely, the measured hydraulic conductivity of RS -1 and $\mathrm{S}-1$ seem to fit well within the predicted values of the $\mathrm{KC}$ equation when using the measured $d_{10}$. The discrepancy between the calculated effective grain/pore size and sieving determined $d_{10}$ may come from issues within the development of the model itself. The KC equation was developed for granular materials with gravel and sand sized particles (Carman, 1937). 
Hazen (1892) developed a formula to determine hydraulic conductivity which described the effective grain-size as $d_{10}$. Many studies, however, have recognized that there is no single grain size representative of the effective grain-size for all aquifers as it relates to the KC equation (e.g., Slater et al., 2014). This statement is further reflected by the results in Figure 23, where $d_{10}$ values are underestimated for the sandy loam regolith samples, but do well to predict the sand samples (RS -1 and $\mathrm{S}-1)$. The predicted effective grain-size is closer to $d_{2}$ for the regolith samples. Furthermore, previous studies have suggested the $\mathrm{KC}$ model in its original form does not apply to clay bearing samples (Al-Tabbaa and Wood, 1987, Bojana and Otoničar, 2007).

Relative to granular material, clays have unique properties that influence the behavior of water flow through a sample. Clays often have a high surface area relative to their mass (i.e., high specific surface area). The high surface area of the grains can significantly reduce the permeability by decreasing the porosity, increasing tortuosity, and blocking the pore throats (Carcione et al., 2019). Moreover, because of the high specific surface area, if the grains are oriented parallel to another, the tortuosity of the soil can be drastically increased and permeability decreased (Lambe \& Whitman, 1969). In addition to a high specific surface area, clays have a high ion exchange capacity which encourages the attraction of water molecules to the mineral surface (Lambe \& Whitman, 1969). Both these properties are unique to clays and are not accounted for in the KC equations original form. The results presented here demonstrate the inability for the $\mathrm{KC}$ equation to predict the hydraulic conductivity of the sandy loam samples and therefore suggests even a small amount of clay should be accounted for when using the $\mathrm{KC}$ equation to determine the hydraulic conductivity of soil samples. 


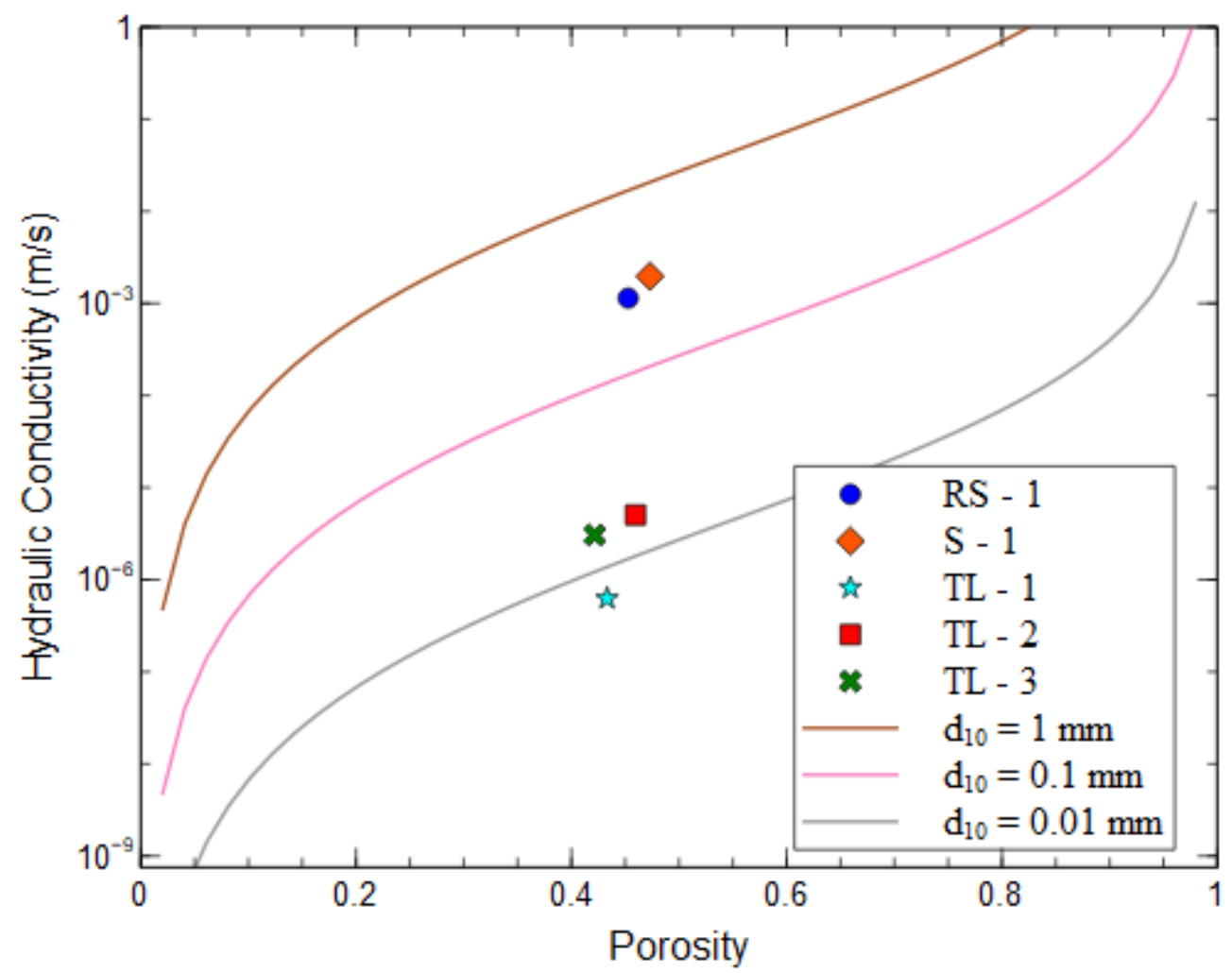

Figure 23 Measured hydraulic conductivity plotted against porosity. S - 1 represents the silica sand sample used to validate the experimental setup (see Chapter Three). The lines on the graph represent the Kozeny-Carman equation (Equation 3) with different effective grain/pore sizes $(1 \mathrm{~mm}, 0.1 \mathrm{~mm}$, and $0.01 \mathrm{~mm})$. The Kozeny-Carman equation does well to predict the measured $K$ relative to the $\mathrm{d}_{10}$ values for $\mathrm{RS}-1(0.21 \mathrm{~mm})$ and $S-1(0.31 \mathrm{~mm})$. The measured hydraulic conductivity values for $T L-1, T L-2$, and $T L-3$, which have $d_{10}$ values equal to $0.09 \mathrm{~mm}, 0.1 \mathrm{~mm}$, and $0.13 \mathrm{~mm}$ respectively, are underestimated relative to the values of the Kozeny-Carman equation.

\section{$\underline{\text { Electrical Properties }}$}

The role of soil composition predominantly affects the electrical conductivity results. For example, the bulk electrical conductivity increases with decreasing depth even though the fluid conductivity is similar for each sample (Table 4). The increase in bulk electrical conductivity with decreasing depth is most likely a response to increasing clay content with decreasing depth. RS -1 and $\mathrm{S}-1$ have almost no clay content and have a bulk electrical conductivity of $9.45 \times 10^{-4} \mathrm{~S} / \mathrm{m}$ and $1.03 \times 10^{-3} \mathrm{~S} / \mathrm{m}$ respectively. As 
clay content progressively increases in the Treeline samples, so does the bulk electrical conductivity. Starting with TL -3 at $3.22 \times 10^{-3} \mathrm{~S} / \mathrm{m}$ and ending with TL -1 at $6.68 \times 10^{-3}$ $\mathrm{S} / \mathrm{m}$ (Table 4). These results are on par with the expected results for sandy loam soils (Katsube et al., 2003).

Both real and imaginary conductivity values were used in calculating the formation factor (Equation 16). To interpret the calculated formation factor, measured values were plotted against porosity and compared to predicted values from Archie's Law (Equation 15) (Figure 24). The measured formation factor for RS - 1, S - 1, and TL - 3 are within the expected cementation factor (1.3 to 2.3) for unconsolidated sands (Figure 24) (Salem \& Chilingarian, 1999). The soil samples containing the most clay minerals (i.e., TL -1 and $\mathrm{TL}-2$ ) do not fall within the theoretical formation factor values. In theory, increasing clay content should increase the cementation factor [this is due to the platy shape of clay minerals (Salem \& Chilingarian, 1999)] and associated formation factor (Equation 15), however, this is not the case (Figure 24). The error most likely stems from the surface conductivity associated with soil samples containing clays. An attempt was made to correct the surface conductivity with measured imaginary conductivity values via Equation 16, but the attempted correction seems to fall short in improving the calculated formation factor. These results suggest Equation 16 cannot be used to correct the influence of surface conduction for samples in this study.

To further assess the role of surface conductivity, a constant cementation factor of 1.4 (estimated value from $\mathrm{RS}-1$ ) is used to estimate the formation factor $F$ for all regolith samples based on their respective porosity values (Equation 15). The results of 
the calculated $F$ values can be seen in Table 5. Based on the new $F$ values, the surface conduction $\sigma_{s}$ can be estimated based on the following equation (Archie, 1942):

$$
\sigma_{s}=\sigma^{\prime}-\frac{\sigma_{f}}{F}
$$

In Table 5, it can be seen that surface conductivity is highest near the surface (TL -1) and decreases as you move down the stratigraphic column. The decrease in surface conductivity is a reflection of the decrease in clay minerals with depth. TL -1 , which has the highest clay content of the samples, has the highest surface conduction contribution and RS - 1, which has almost no clay, has the lowest surface conduction.

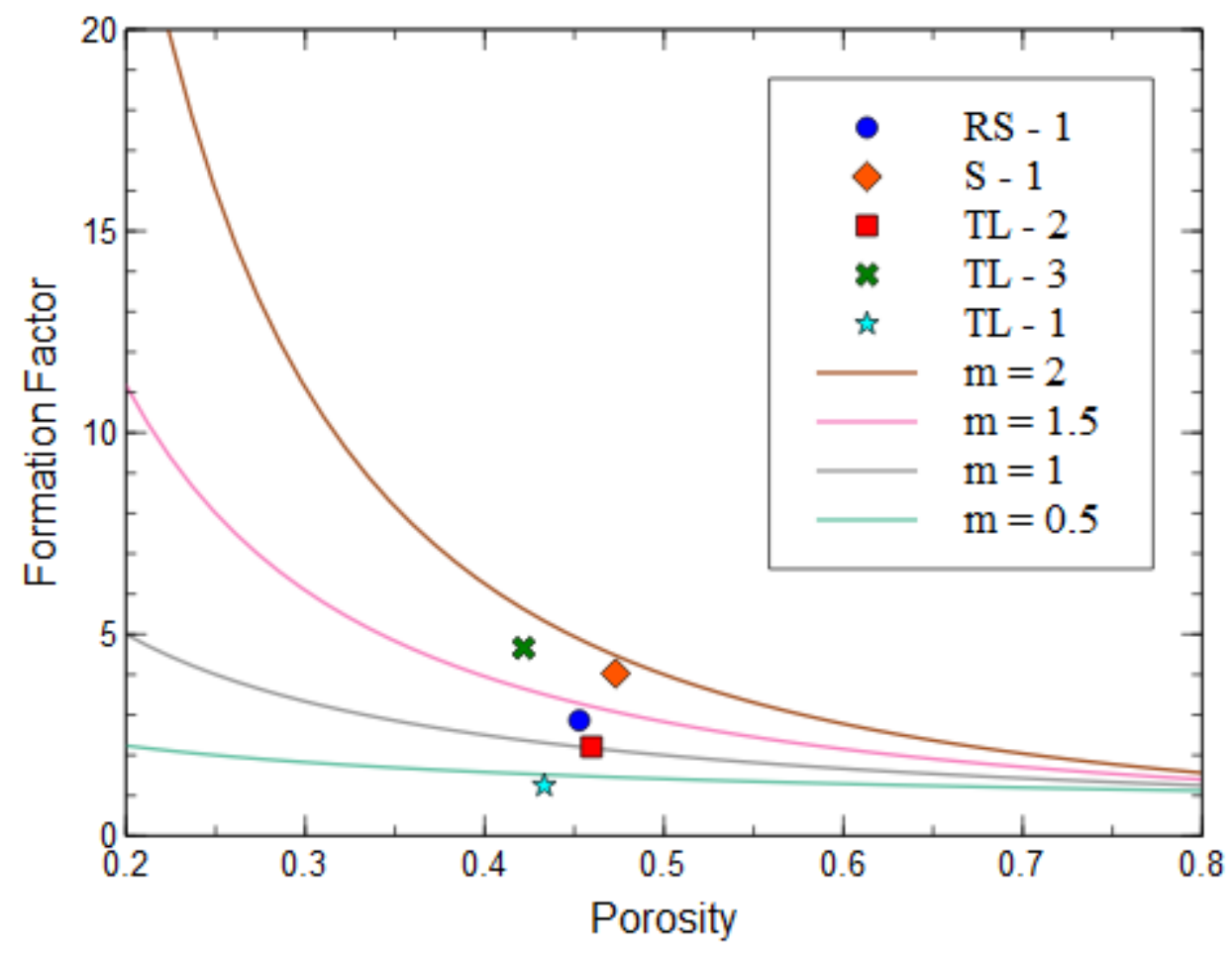

Figure 24 Formation factor plotted relative to porosity. The formation factor can be predicted from porosity and a cementation factor $(m)$ as demonstrated in Archie's Law (Equation 15). Lines represent the predicted formation factor as a function of porosity, with a constant cementation factor. Expected $\boldsymbol{m}$ for unconsolidated soils range from 1.3 to 2.3 . TL -1 and TL -2 fall below the minimum expected value. This is not completely unexpected since Archie's Law is developed to interpret samples made up of predominantly clean sands (Glover et al., 2000). TL -1 and TL -2 are made up of more silt/clay then the other samples and may not be applicable to Archie's Law. 
Table 5 Calculated formation factor $F$ values based on Archie's law (Equation 15) with a constant cementation factor $m$ (1.4). Using Equation 17, the surface conduction $\sigma_{s}$ was calculated.

\begin{tabular}{|c|c|c|c|c|}
\hline & \multicolumn{4}{|l|}{ Sample } \\
\hline & RS - 1 & $\mathrm{TL}-1$ & $\mathrm{TL}-2$ & $\mathrm{TL}-3$ \\
\hline$\phi$ & 0.45 & 0.42 & 0.45 & 0.43 \\
\hline$F$ & 2.87 & 3.05 & 2.87 & 3.14 \\
\hline$\sigma_{s}(\mathrm{~S} / \mathrm{m})$ & $2.77 \times 10^{-4}$ & $4.20 \times 10^{-3}$ & $2.35 \times 10^{-3}$ & $3.15 \times 10^{-4}$ \\
\hline
\end{tabular}

Streaming Potential Coupling Coefficient

Upon initial observation, there seems to be a clear relationship between the permeability of the sample and the coupling coefficient (Figure 25). As the permeability of the sample increases, there is a proportional increase in the coupling coefficient. It is well understood, however, that the coupling coefficient is not only influenced by the physical properties of the sample, but also the electrical properties of the sample (i.e., zeta potential and formation factor) and pore fluid (i.e., dielectric permittivity and electrical conductivity) (see Equation 12). To further evaluate the coupling coefficient dependence on permeability, relative to the electrical properties, the following equation is used (Jouniaux \& Pozzi, 1995):

$$
C_{s a t}=\frac{\varepsilon \zeta}{\eta\left(\sigma_{f}+\frac{\Sigma_{s} \sqrt{c}}{\sqrt{k} \sqrt{F}}\right)}
$$

where $\varepsilon=80 \varepsilon_{0}\left(\varepsilon_{0}=8.84 \times 10^{-12} \mathrm{~F} \mathrm{~m}^{-1}\right)$ is the dielectric constant of pore water, $\Sigma_{s}$ is the specific surface conductance (S), and $c$ is a factor determined by the actual pore shape (0.5 for circular pores) (Wyllie \& Spangler, 1952). The specific surface conductance $\Sigma_{s}$ is 
the "excess" surface conductivity at the grain surface by comparison with that of the bulk water (Revil \& Glover, 1997). Specific surface conductance values for both clay and sand samples are typically found at an order of magnitude of $10^{-9} \mathrm{~S}$ (e.g., Jouniaux \& Pozzi, 1995; Revil et al., 1999). When interpreting the samples in this study, $\Sigma_{s}$ is assumed to equal $4 \times 10^{-9} \mathrm{~S}$, which is equivalent to measured values for a quartz sand (Revil et al., 1999).

Using Equation 18, the streaming potential coupling coefficient's dependence on permeability is investigated (Figure 25). Although the measured streaming potential coupling coefficient appears to be proportional to the permeability of the sample, the model suggests the zeta potential $\zeta$ is responsible for determining the magnitude of the streaming potential coupling coefficient. This statement is supported in theory by the Helmoltz-Smoluchowski relation (Equation 12), which only considers one soil property (zeta potential) when calculating the streaming coupling potential coefficient.

To further evaluate the dependence of the streaming potential coupling coefficient on the zeta potential, the following equation from Revil et al. (1999) is used:

$$
C_{s a t}=\frac{\varepsilon \zeta}{\eta\left(\sigma_{f}+\frac{2 \Sigma_{s}}{\Lambda}\right)}
$$

where the mean pore radius $\Lambda=d /[3(F-1)] ; d$ is the mean grain diameter. The formation factor $F$ used to find $\Lambda$ comes from Table 5 . The results of the analysis can be seen in Figure 26.

The results in Figure 25 and 26 suggest the zeta potential plays a significant role in determining the magnitude of the streaming potential coupling coefficient. The zeta potential for both $\mathrm{RS}-1$ and $\mathrm{S}-1, \sim 19$ and $\sim 27 \mathrm{mV}$ respectively, is greater than the 
values of the regolith samples $(\sim 1$ to $\sim 9 \mathrm{mV})$. The difference in zeta potential reflects the mineralogical makeup of the soil samples. More specifically, the zeta potential values are a reflection of the sample's cation exchange capacity (CEC) and associated EDL

(Cherian \& Arnepalli, 2015). A relatively thick EDL is indicative of a relatively large zeta potential (more negative) (Yukselen \& Kaya, 2003). Following the Gouy-Chapman model for the EDL, it can be inferred that an increase in concentration and/or valence ions decreases the thickness of the EDL; thereby lowering the magnitude of zeta potential (becomes less negative) (Cherian \& Arnepalli, 2015). By definition, the CEC is the quantity of counter ions in the zone adjacent to the charged surface that can be exchanged for other cations (West \& Stewart, 1995). Therefore, a sample with a high CEC, which has a high concentration of ions, will have a relatively thin EDL, and low zeta potential. The CEC is expressed as milliequivalents of charge per $100 \mathrm{~g}$ (meq./100 g) of dry soil. Smectite has a very high CEC at $80-150$ meq./100 g, followed by illite with $15-40$ meq./100 g, and kaolinite at 1-15 meg./100 g (Arabi, 1986). Moreover, a sand with very little organics, can be expected to have a CEC of $<3$ meq./100 g (CUCE, 2007).

TL -1 has the lowest predicted zeta potential value (Figure 26) and highest concentration of high CEC minerals (smectite and illite) (Table 3). Conversely, the samples with little or no clay $(\mathrm{RS}-1$ and $\mathrm{S}-1)$, and therefore lowest CEC, have the highest zeta potential. TL -2 and TL -3 both have values that fall between the TL -1 and the sand samples. This pattern of relatively smaller zeta potentials for the clay bearing regolith samples is in line with previous work (e.g., Revil et al., 1999). Although the mineralogical composition and resulting zeta potential seem to determine the magnitude of streaming potential coupling coefficient values, when considering samples 
of the same mineralogical makeup, it may be important to consider the sample's permeability. Revisiting Figure 25, if a consistent zeta potential is considered, it is apparent that the resulting streaming potential coupling coefficient is dependent on the permeability of the sample. Therefore, if multiple samples with the same, or very similar, mineralogical makeup are being evaluated, it may be appropriate to consider only the permeability of the sample when evaluating the streaming potential coupling coefficient.

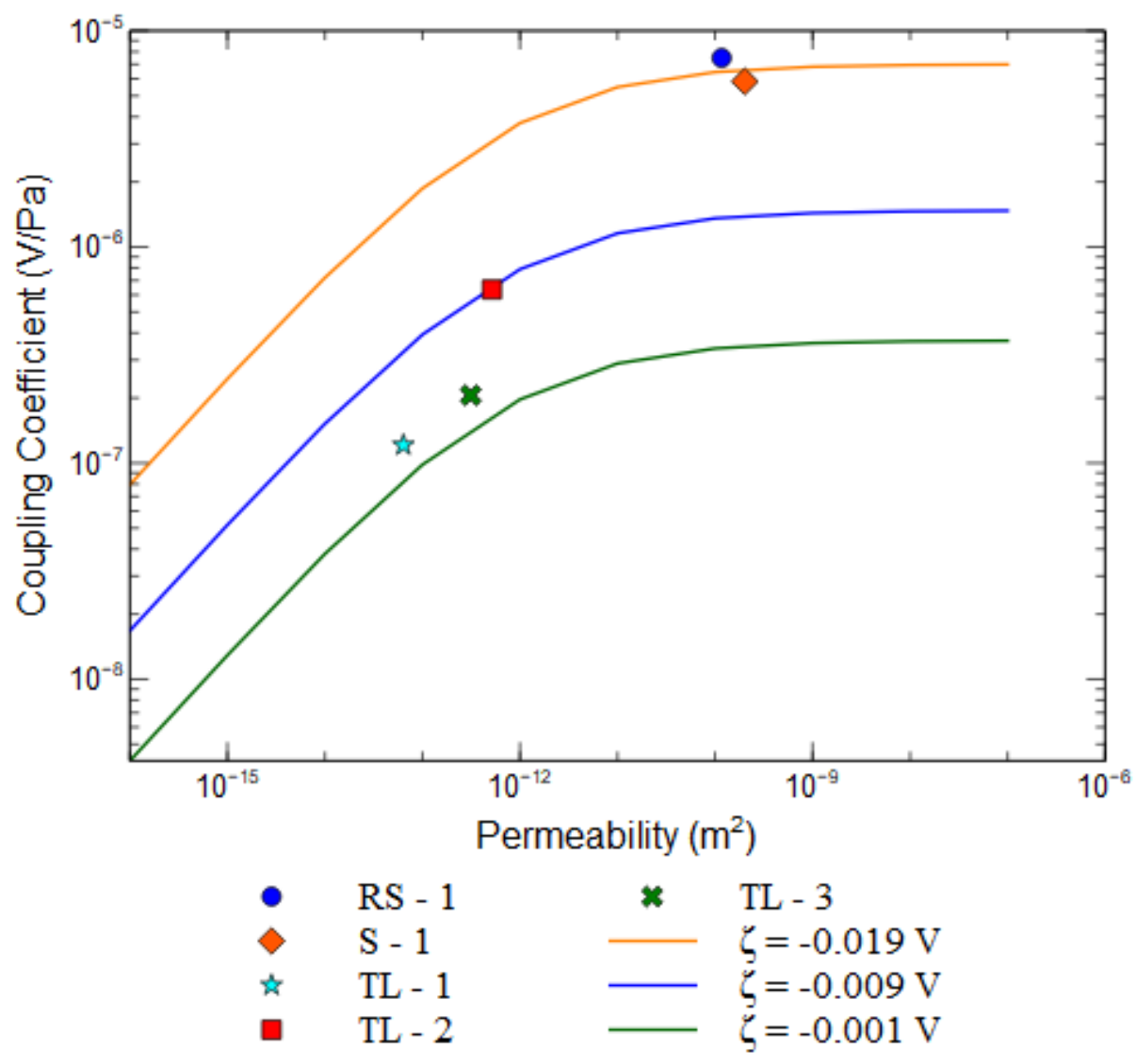

Figure 25 Saturated Streaming potential coupling coefficient $\boldsymbol{C}_{\text {sat }}$ plotted relative to the permeability $k$. The lines represent the predicted permeability using Equation 18) with the zeta potentials $-0.019 \mathrm{~V}$ (orange), $-0.009 \mathrm{~V}$ (blue), and $-0.001 \mathrm{~V}$ (green).

The fluid conductivity $\sigma_{f}$ is assumed constant at $1.92 \times 10^{-3} \mathrm{~S} / \mathrm{m}$, a reasonable assumption considered the relatively small variation in fluid conductivity between samples (Table 4). Moreover, the formation factor $F$ is assumed constant at 2.87 based on the lack of variability between the samples (Table 5). Based on the plotted functions, the zeta potential plays a significant role in the magnitude of coupling coefficient values. Coupling coefficient values are reported as absolute values. 

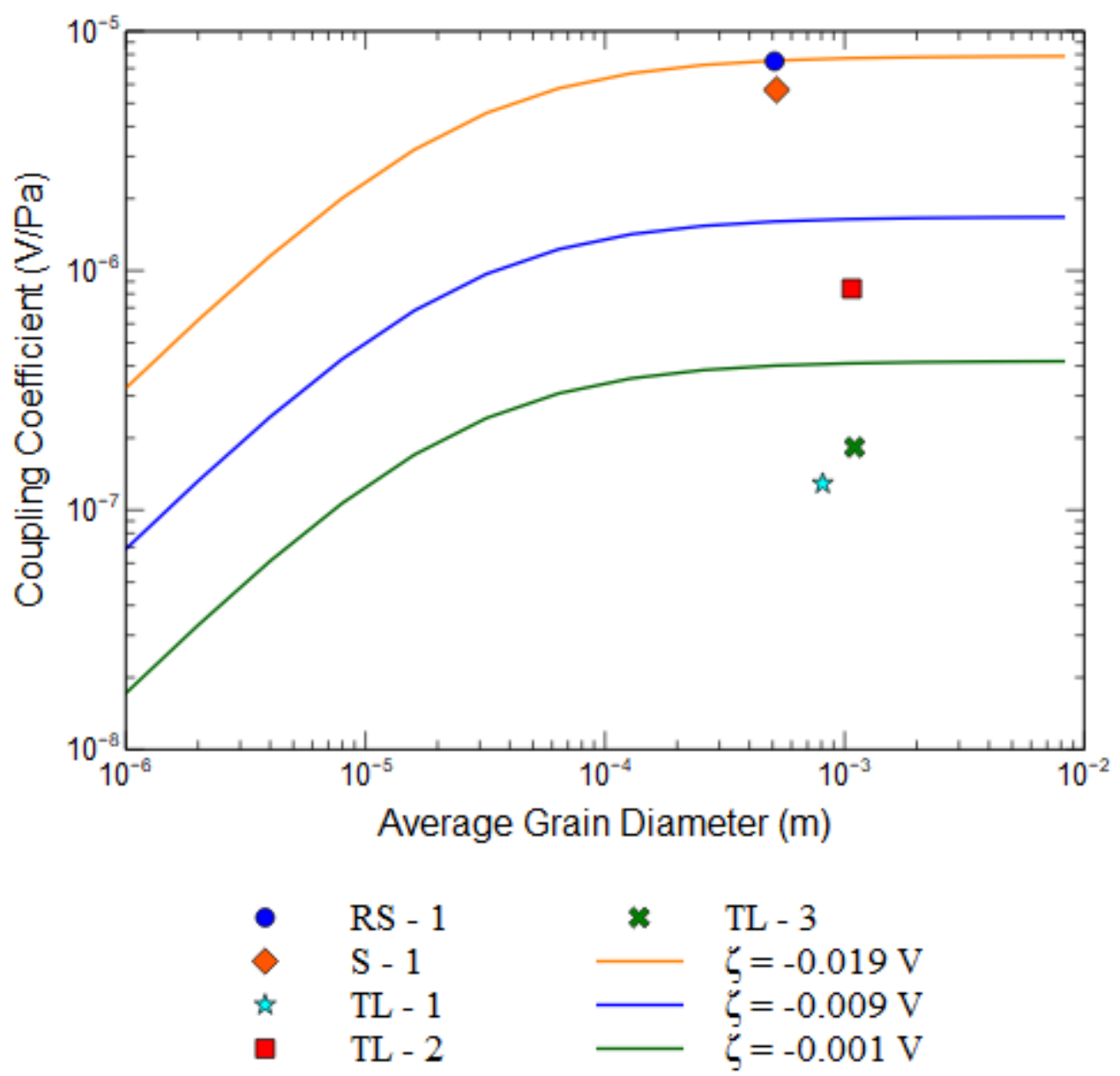

Figure 26 Saturated Streaming potential coupling coefficient $C_{\text {sat }}$ plotted with average grain diameter using Equation 19. The fluid conductivity $\sigma_{f}$ is assumed constant at $1.92 \times 10^{-3} \mathrm{~S} / \mathrm{m}$, a reasonable assumption considered the relatively small variation in fluid conductivity between samples (Table 4). Moreover, the formation factor $F$ is assumed constant at $\mathbf{2 . 8 7}$ based on the lack of variability between the samples (Table 5).With relatively similar average grain diameters, it is apparent that the zeta potential has a significant impact on the streaming potential coupling coefficient values. The predicted zeta potentials seem to be a reflection of the mineralogy. TL -1 has the highest clay content (i.e., highest CEC) and lowest predicted zeta potential. $R S-1$ and $S-1$ have the lowest clay content (i.e., lowest CEC) and highest predicted zeta potentials. Coupling coefficient values are reported as absolute values.

\section{Summary}

The main petrophysical properties of the regolith soils are summarized in Figure

27. RS - 1 is included in Figure 27, due to its lack of fines and mineralogical

composition, to serve as a representative sample of the intact bedrock. Thus, the y-axis in 
Figure 27 can be regarded as depth. Based on the results of the test, soils sampled only 30 $\mathrm{cm}$ apart show significant variations in their associated properties. The results presented in Figure 27 reflect the change in mineralogy with depth induced by chemical/physical weathering. The samples all show a general fining upward sequence from the bedrock as indicated by the $d_{10}$ value. The surface conductivity $\sigma_{\text {surf }}$ reflects a proportional increase in response to the overall increase in clay minerals in the fining upward stratigraphic sequence. This increase in clay content is also reflected in the grain size distribution (Figure 18) and XRD analysis (Table 3). As previously discussed, the apparent formation factor $F_{a}$ values reflect the mineralogical makeup of each sample. Values for TL -3 and $\mathrm{RS}-1$ are within the expected range of theoretical values, but TL -2 and TL -1 are significantly less than expected (Figure 24). Again, this is an influence of the associated increase in surface conductivity resulting from an increase in clay content. Moreover, the influence of clays is further seen in the streaming potential coupling coefficient and zeta potential values. For both values, there is again a proportional response to clay content. Although TL -3 and TL -2 don't represent a perfect linear response to the increase in clay content, the overall trend is that of one mirrored by the change in mineralogical makeup of the samples. The variations in the electrical and physical properties of the soil samples suggest that the regolith is not homogenous, and consideration of the soil mineralogy should be taken when trying to characterize water flux in the field using hydrogeophysical methods. 


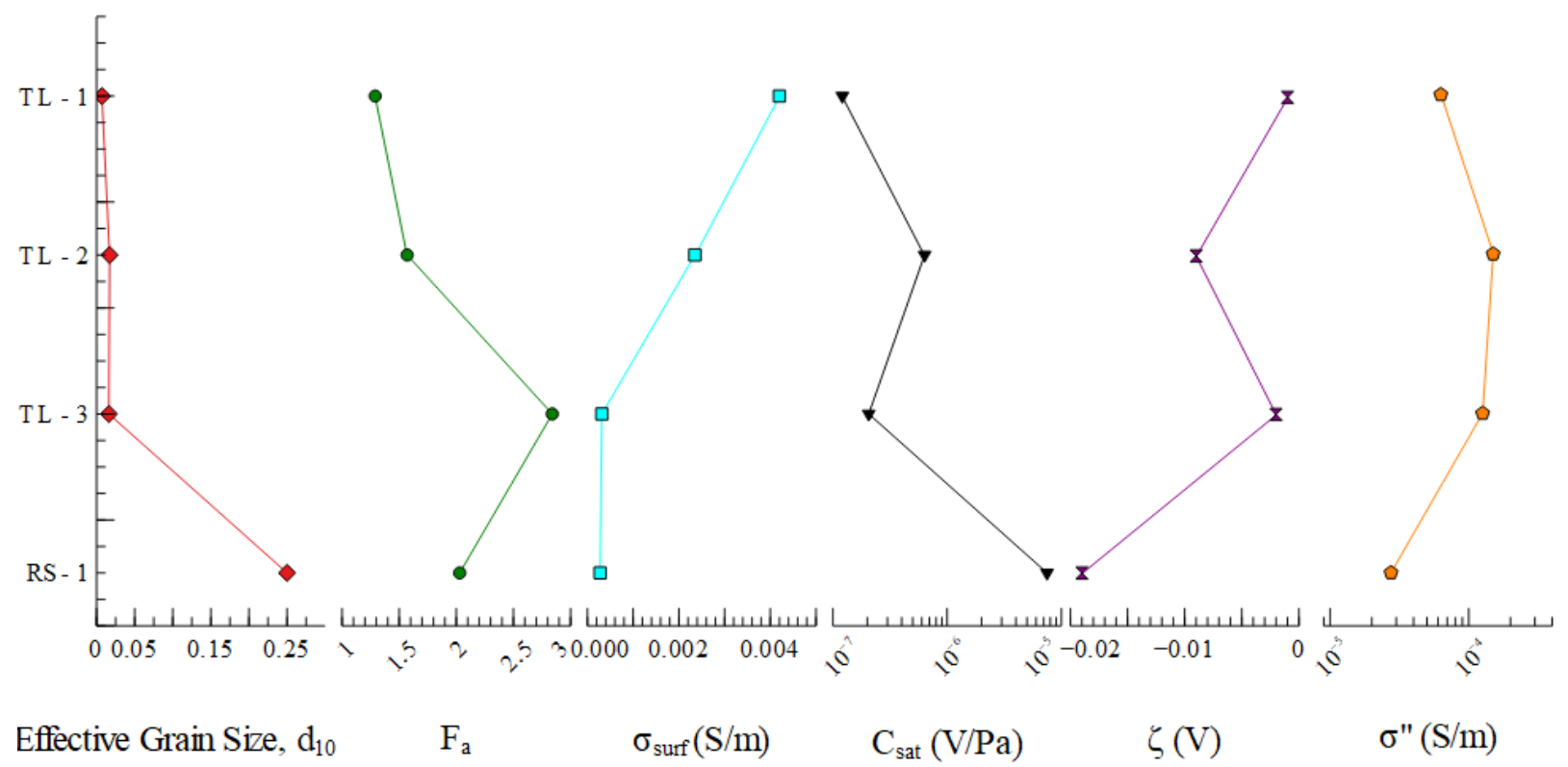

Figure 27 The distribution of petrophysical properties with depth for the regolith samples. $\mathrm{RS}-1$ is included to be a representative sample of the bedrock. The effective grain size and electrical properties (i.e., $F_{a}, \sigma_{s u r f}, C_{s a t}, \zeta$, and $\sigma^{\prime \prime}$ ) reflect the fining upward sequence and increase in clay mineral content with decreasing soil depth. 


\section{CHAPTER SIX: UNSATURATED TEST}

Through a simple manipulation of the saturated test setup, the unsaturated test can be performed for the same soil sample tested in the saturated experiment. The SP and pressure response during unsaturated testing can be observed with the same hydrogeophysical probes from the previously mentioned saturated test. The time-series data from unsaturated testing can be used to estimate the unsaturated electrical and hydraulic properties of a given sample. In this chapter, the usefulness of the test-setup and integrated hydrogeophysical probe to measure unsaturated soil properties is evaluated. The interpretation of the unsaturated data is aided by using COMSOL Multiphysics 5.6, which numerically simulates the drainage process based on input saturated and unsaturated soil properties. The drainage experiment was carried out for all the regolith samples $(\mathrm{TL}-1, \mathrm{TL}-2$, and $\mathrm{TL}-3)$ and $\mathrm{RS}-1$.

\section{Experimental Procedure}

Once saturated testing is complete, the experimental test setup can be rearranged to preform drainage tests. Before the drainage test, the connection between the upper constant head reservoir and soil column is removed (Figure 28). During configuration of the unsaturated test setup, the valve near the outlet is closed so the sample remains saturated. The valve near the inlet (top of the soil column) is opened and the water in the soil sample is subjected to atmosphere pressure. Setting this initial pressure condition ensures the sample will enter an unsaturated state as soon as the drainage begins. Additionally, the lower constant head reservoir is placed about a meter below the bottom 
of the soil column. This negative hydraulic gradient (relative to the base of the soil column) will be applied to the bottom of the soil column once the valve at the outlet is opened. A scale and water collection vessel are placed at the outlet of the lower reservoir (Figure 28). The scale is connected to a computer and records the mass of water in the water collection vessel every one second. Before drainage begins, measurements are made while the sample is at a hydrostatic state with the water level at the surface of the soil sample. After the hydrostatic period is over, the valve at the bottom of the soil column is opened and the water in the soil column will drain due to the applied negative hydraulic gradient. In general, this drainage process will last several hours. Data acquisition will take place for a period of at least four hours. 


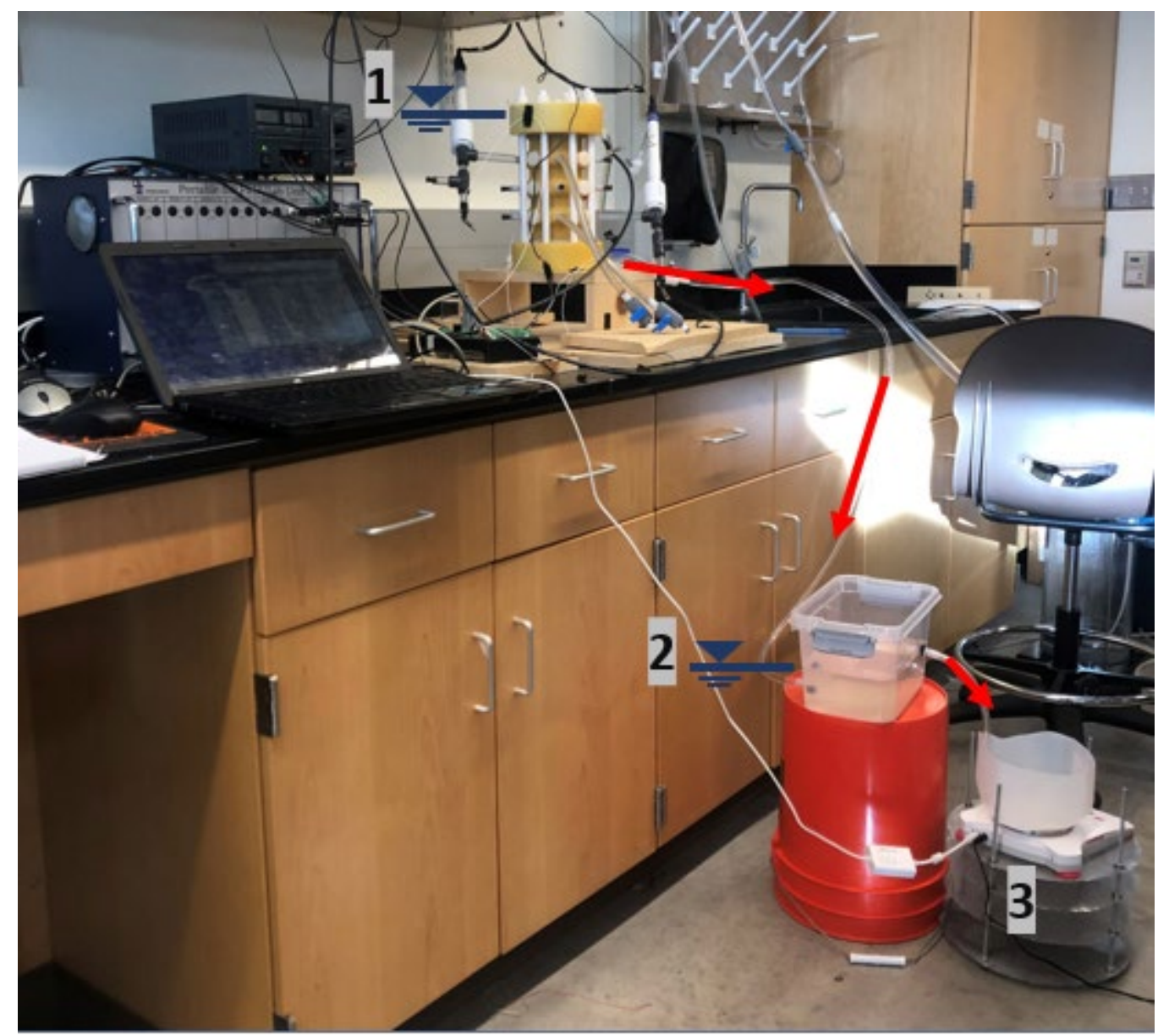

Figure 28 The experimental setup for unsaturated testing. (1) represents the height of the water level during the pre-drainage hydrostatic period. Once drainage commences, water flows from the soil column to the lower constant head reservoir (2). From the lower constant head reservoir, water flows into the container atop the scale (3). The weight of water in the container is recorded every second. The rate at which water is draining from the soil column can be calculated based on weight in the container for a given time.

\section{Hydraulic and Electrical Modeling of the Unsaturated Response}

To interpret unsaturated measurements from the drained tests, a commercial finite element software (COMSOL Multiphysics 5.6) was used to model the 1-D unsaturated water flow and streaming potential generation in each soil sample. By adjusting the input soil properties to match the calculated soil water pressure and SP responses to the measurement, the hydraulic and electrical properties of the samples can be estimated. In this study, the parameter adjustment is performed via a trial and error process. COMSOL 
Multiphysics solves the Richards equation to model the hydraulic response of the soil sample during the unsaturated test. The Richards equation for 1-D unsaturated flow in soils is written as follows:

$$
\frac{\partial \theta}{\partial t}-\nabla \cdot K \nabla h-\frac{\partial K}{\partial z}=0
$$

where $K$ is the unsaturated hydraulic conductivity as function of pore-water pressure head $h$ and $z$ is the vertical coordinate (Richards, 1931).

The volumetric water content $\theta$ is function of pore water pressure head, known as the soil water retention curve $\theta(h)$ and the hydraulic conductivity $K$ is a function of volumetric water content known as the hydraulic conductivity function $K(\theta)$. In this study, the Brooks-Corey model (Equation 4) is used to model $\theta(h)$. Moreover, the Brooks-Corey model can be adjusted to express $K(\theta)$ analytically (Brooks and Corey, 1964):

$$
K(\theta)=(\Theta)^{2 \lambda+3} K_{\text {sat }}
$$

where $\Theta$ is the effective saturation (Equation 5) and $\lambda$ is a fitting parameter.

The governing equation used in COMSOL to determine the streaming potential $V$ distribution in unsaturated soils has been previously discussed (see Equation 9). In order to solve the streaming potential, the unsaturated soil conductivity $\sigma$ and unsaturated streaming potential coupling coefficient $C$ need to be related to the hydrologic state (i.e., saturation) of the soil sample. In this study, the following constitutive models are used in the simulation:

$$
\sigma=\frac{\sigma_{f}}{F} S_{w}^{n_{a}}+\sigma_{s}
$$

and 


$$
C=\frac{C_{s a t}}{S_{w}} \frac{K}{K_{s a t}} \frac{\sigma_{s a t}}{\sigma}
$$

where $n_{a}$ is the Archie's saturation exponent.

The initial boundary conditions of the model are set to match those of the experimental drainage test. The petrophysical properties of each soil sample (i.e., porosity, saturated hydraulic conductivity, and the saturated coupling coefficient) and the fluid conductivity are determined from the saturated experiment and used as the input parameters for the model. The formation factor $F$ of each soil is calculated using Archie's Law (Equation 15) with a constant cementation factor $m$ (1.4). An initial set of BrooksCorey parameters $\left(\lambda\right.$ and $\left.\psi_{b}\right)$, based on published literature values, are used as a starting point for testing. Similarly, the parameter related to the electrical properties of unsaturated soil's $n_{a}$ (Equation 22) is also initially assumed based on published literature values. After inputting the boundary conditions, physical properties, and Brooks-Corey parameters, the SP signal, change in total head, and cumulative outflow is modeled over the entirety of the drainage period. After each simulation, the Brooks-Corey parameters are reevaluated through a visual interpretation to determine the quality of fit for the modeled results relative to the experimental results. If necessary, the initial Brooks-Corey parameters are adjusted, and the model is executed again. This process is repeated until the input parameters are representative of the experimental signal produced.

\section{Results}

The unsaturated response was modelled for all the regolith samples and RS - 1 with COMSOL Multiphysics. Table 6 lists major petrophysical properties, the estimated Brooks-Corey parameters, and $n_{a}$ values used to model the drained response for all samples. The modeled and experimental change in total head, SP signal, and cumulative 
outflow are summarized in Figure 29 to 32. The modeled and measured response of cumulative outflow for RS - 1 are in good agreement (Figure 29). The modeled and experimental SP signal were congruent throughout the entire drainage process, indicating the probe's ability to measure SP over a variably saturated medium (Figure 29).

The results of the drained response for the regolith samples showed some variations in the viability of the setup to observe a soil's drained response. The measured and modeled SP signal and cumulative outflow data for TL-3 were in relatively good agreement (Figure 30b and 30c). The change in total head, however, was underestimated in the modeled response (Figure 30). Conversely, the modeled change in total head response was overestimated for $\mathrm{TL}-2$ (Figure $31 \mathrm{a}$ ). For $\mathrm{TL}-2$ and $\mathrm{TL}-1$, the observed SP response remains within the same magnitude of the modeled response, but there is a significant fluctuations within the measured SP signal (Figure $31 \mathrm{~b}$ and $32 \mathrm{~b}$ ). The modeled and measured change in total head, however, are in relatively good agreement for $\mathrm{TL}-1$ (Figure 32a). 
a)

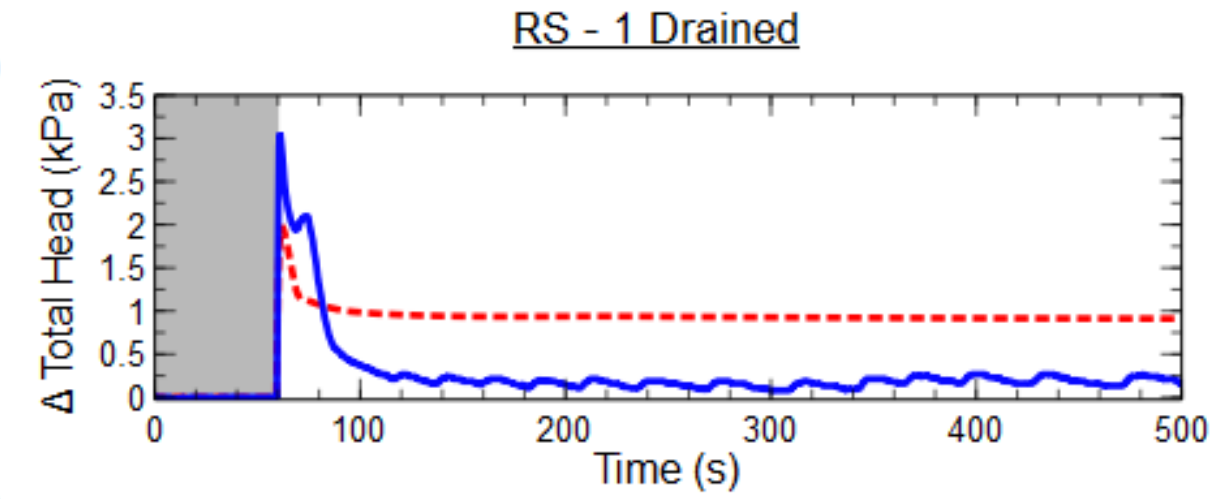

b)

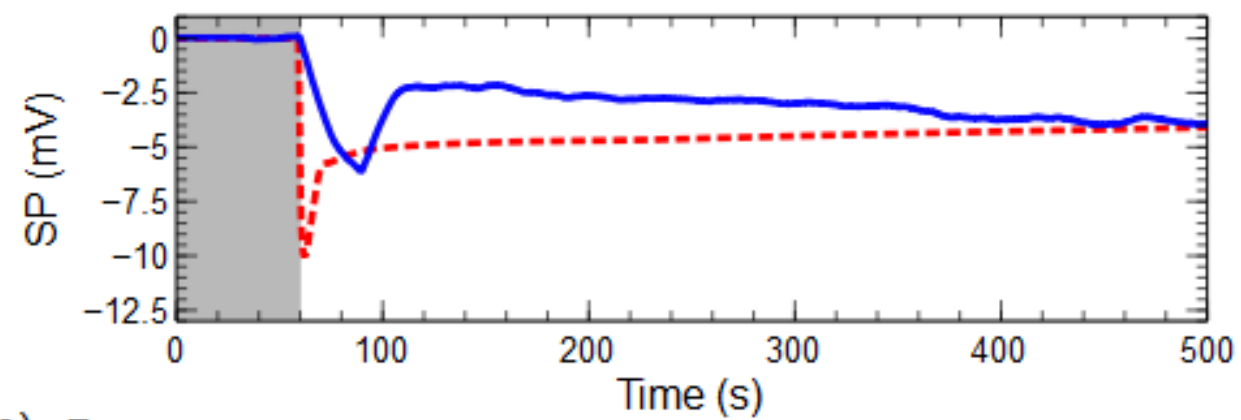

c)

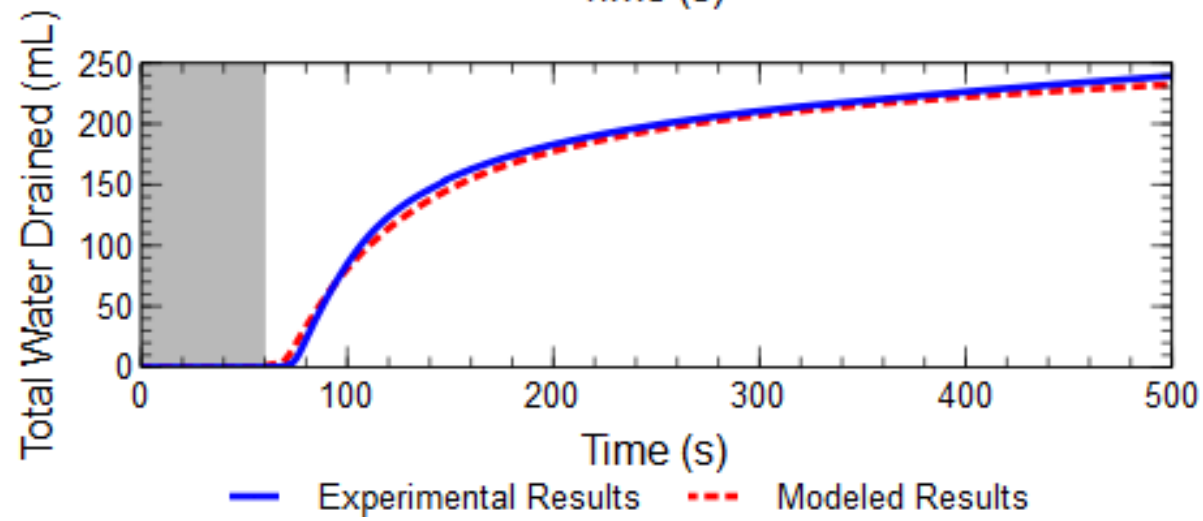

Figure 29 The measured and modeled electrical and hydraulic responses during the drainage process for $\mathrm{RS} \mathbf{- 1}$. The shaded area represents the measured response at a hydrostatic state. (a) is the total head difference between the two probes. The overall measured trend is in good agreement with the modeled signal. The measured

pressure starts to approach zero at 120s. The modeled pressure, however, consolidates at about one kilopascal, indicating some hydraulic gradient still inducing fluid flow. (b) and (c) represents the SP response and the total volume of drained water. The measured SP signal is a 60 - period moving average of the raw signal. Both (b) and (c) are show promising results for the proposed method to measure the drained response in sand samples. 
a)

\section{$\underline{\text { TL }-3 \text { Drained }}$}

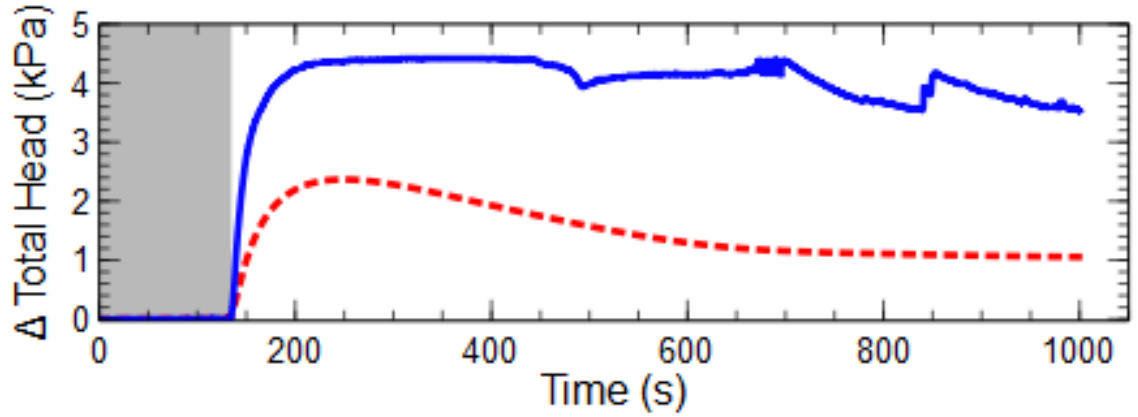

b)

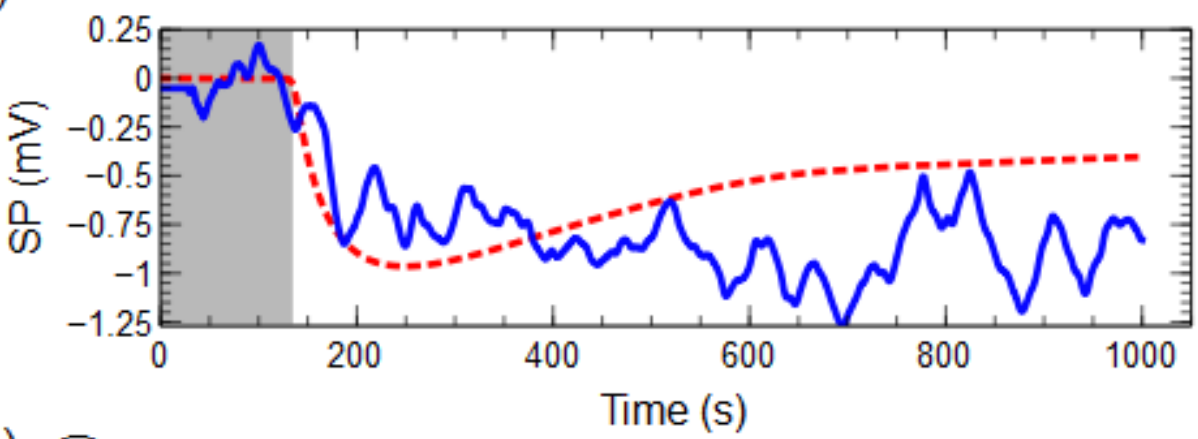

c)

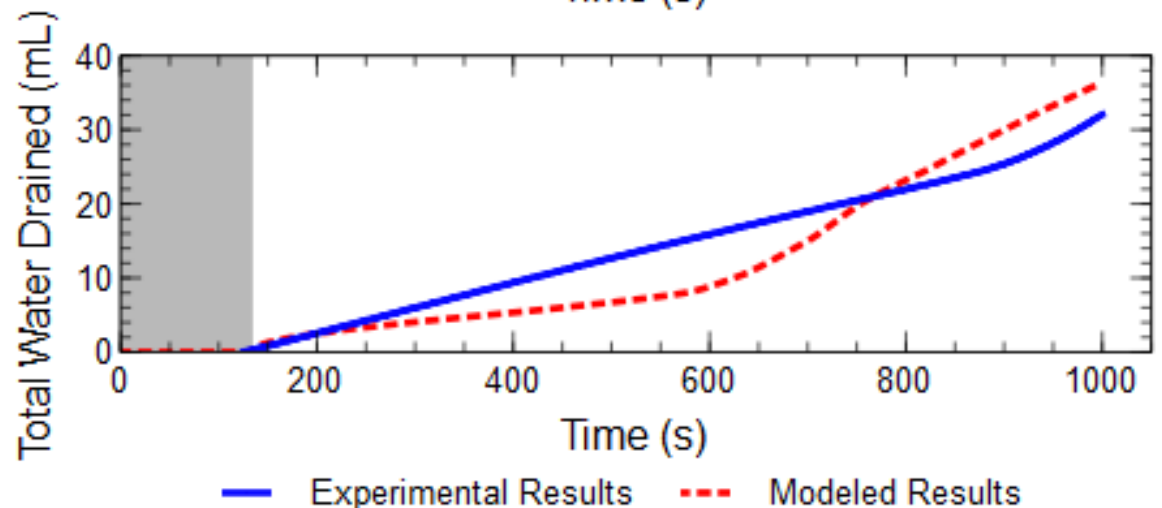

Figure 30 The measured and modeled electrical and hydraulic responses during the drainage process for $T L-3$. The shaded area represents the measured response at a hydrostatic state. (a) is the total head difference between the two probes. Although the two signals show the same trend, the magnitude between the measured and modeled results are significantly different. (b) and (c) represents the SP response and the total volume of drained water. The measured SP signal is a 60 period moving average of the raw signal. The measured and experimental SP signal both show a similar trend, but the measured signal is associated with some obvious noise. (c) represents a good relationship between the modeled and experimental cumulative flow response. 
a)

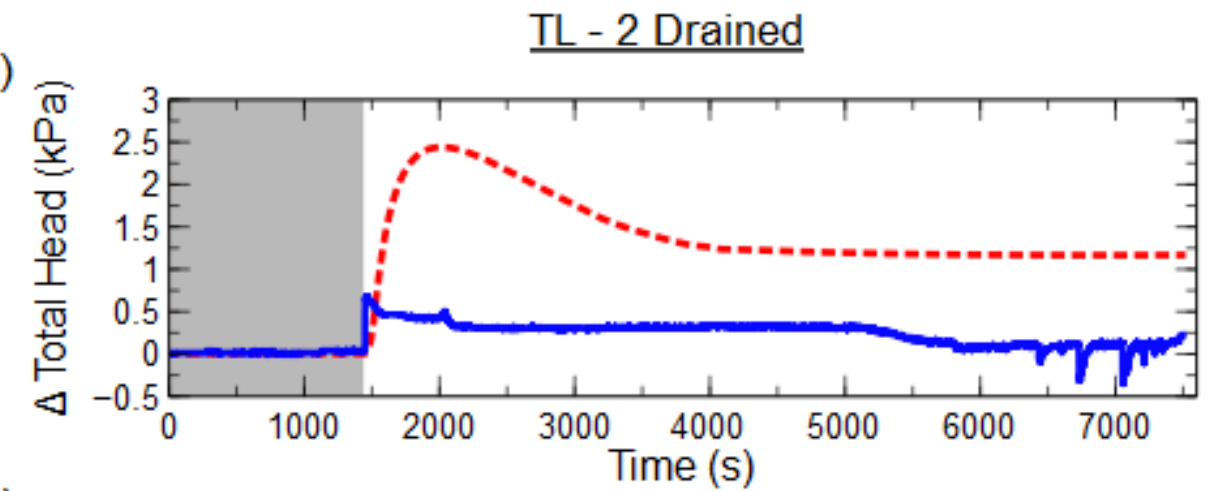

b)

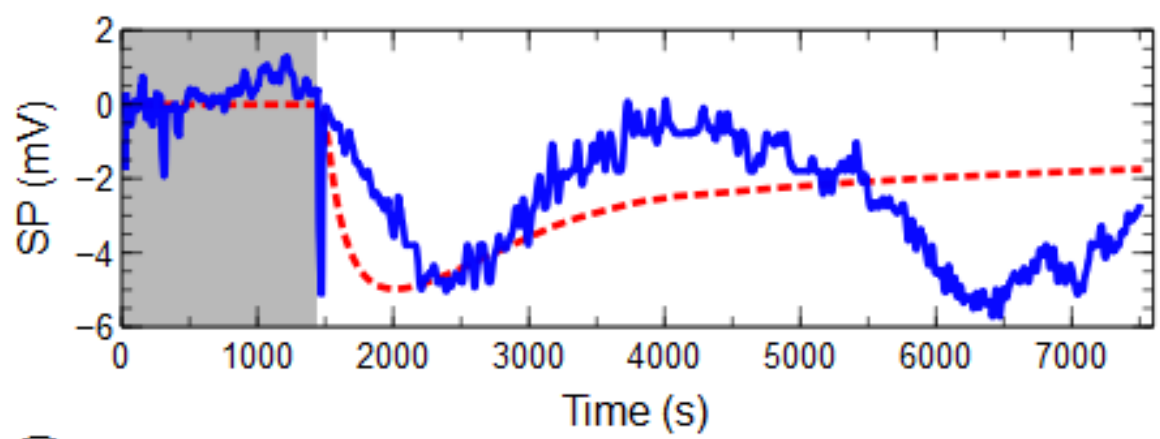

c)

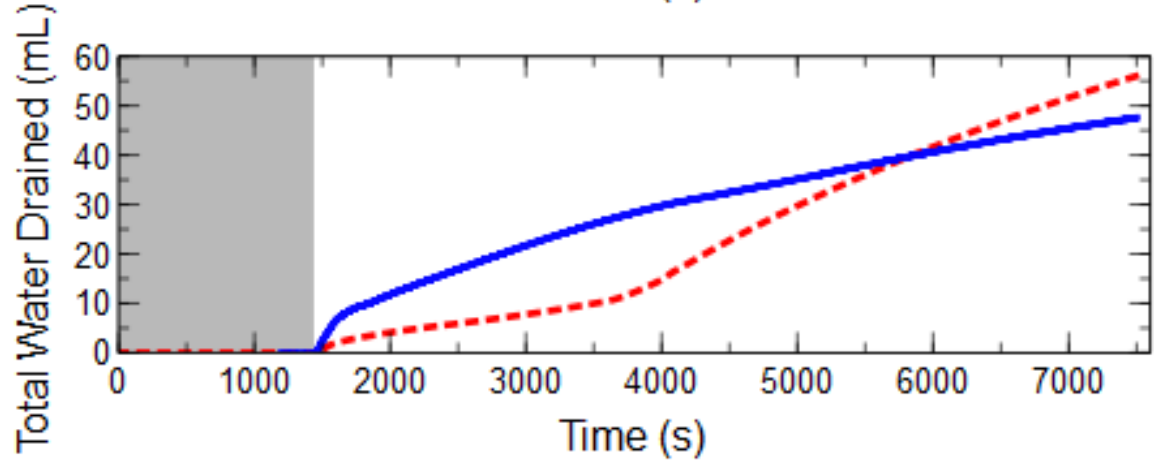

Figure 31 The measured and modeled electrical and hydraulic responses during the drainage process for $T L-2$. The shaded area represents the measured response at a hydrostatic state. (a) is the total head difference between the two probes. Like

TL -3 , the two signals show a parallel trend, but the magnitude between the measured and modeled results are significantly different. (b) shows the SP response.

The measured SP signal is a 60 - period moving average of the raw signal. The experimental signal for the first $\sim 5500$ s of testing is similar to the modeled response. After this point, experimental SP signal increases. This response is not associated with an observed hydraulic gradient increase, indicating it is most likely a result of some external influence. (c) represents an agreeable relationship between the modeled and experimental cumulative outflow response. 
a)

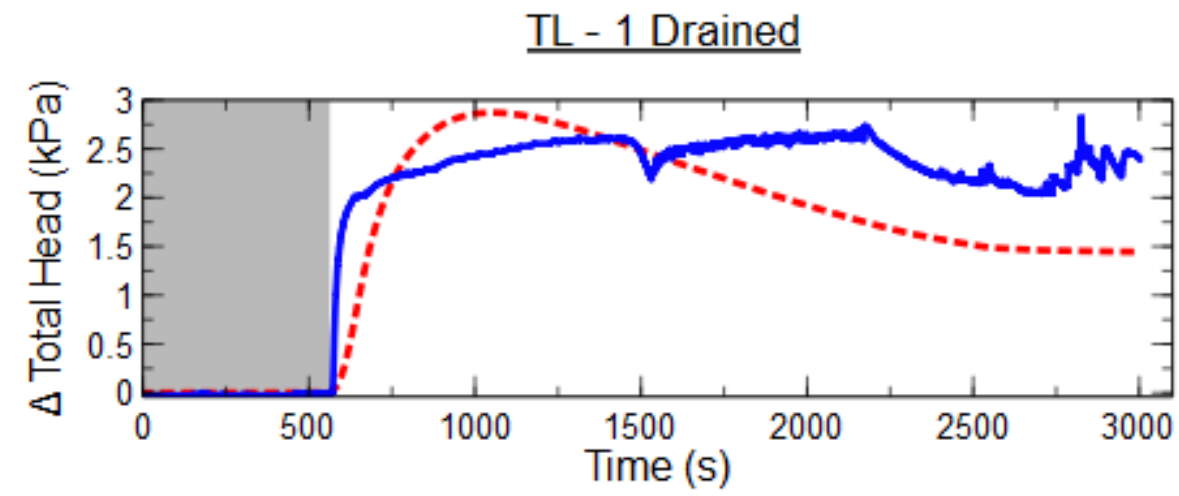

b)

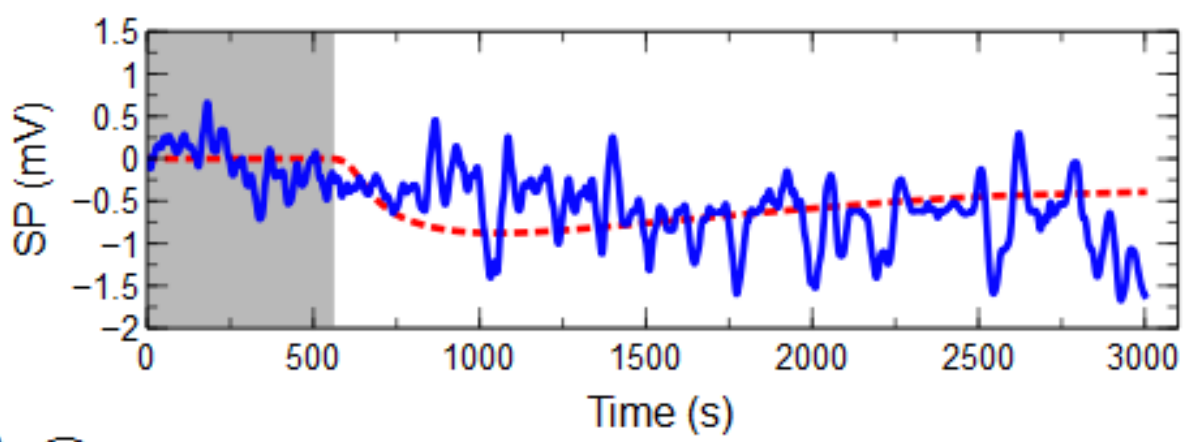

c)

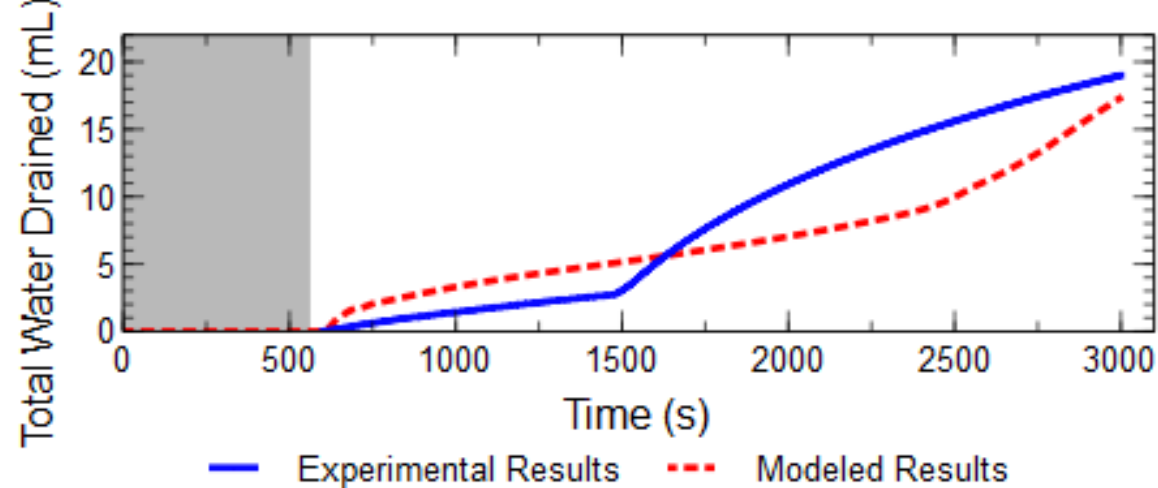

Figure 32 The measured and modeled electrical and hydraulic responses during the drainage process for $T L-1$. The shaded area represents the measured response at a hydrostatic state. (a) is the total head difference between the two probes. For

this sample, there is again a similar signal produced by the modeled and experimental measurements. (b) shows the SP response. The measured SP signal is a 60 - period moving average of the raw signal. The experimental signal seems to follow the same trend as the modeled results, but the associated noise with the experimental signal make it difficult to make any definitive conclusions about response. (c) shows the total volume of water drained and again, both signals are in good agreement. 
Table 6: The Brooks-Corey parameters and electrical properties of each soil used to model the drainage process in COMSOL. For reference, published BrooksCorey values of a sand (Del Monte Sand), to compare with the sand sample RS - 1, and a sandy loam (Columbia Sandy Loam), to compare with the sandy loam samples $T L-1, T L-2$, and $T L-3$, have been included in the table.

\begin{tabular}{|c|c|c|c|c|c|c|}
\hline & \multicolumn{6}{|l|}{ Sample } \\
\hline & $\mathrm{RS}-1$ & $\mathrm{TL}-1$ & $\mathrm{TL}-2$ & $\mathrm{TL}-3$ & $\begin{array}{l}\text { Del Monte } \\
\text { Sand* }\end{array}$ & $\begin{array}{l}\text { Columbia } \\
\text { Sandy } \\
\text { Loam* }\end{array}$ \\
\hline$\phi$ & 0.45 & 0.43 & 0.46 & 0.42 & 0.36 & 0.50 \\
\hline$K_{\text {sat }}(\mathrm{m} / \mathrm{s})$ & $8.0 \times 10^{-4}$ & $5.00 \times 10^{-6}$ & $4.00 \times 10^{-6}$ & $2.00 \times 10^{-5}$ & $8.00 \times 10^{-2}$ & $8.1 \times 10^{-6}$ \\
\hline$-\psi_{b}(\mathrm{~m})$ & 0.15 & 0.25 & 0.2 & 0.2 & 0.112 & 0.85 \\
\hline$\lambda$ & 3.5 & 0.5 & 0.8 & 1.4 & 2.5 & 1.6 \\
\hline$C_{\text {sat }}(V / P a)$ & $-5.0 \times 10^{-6}$ & $-3.00 \times 10^{-7}$ & $-2.00 \times 10^{-6}$ & $-4.00 \times 10^{-7}$ & - & - \\
\hline$n_{a}$ & 2.2 & 2.5 & 2.5 & 2.5 & - & - \\
\hline
\end{tabular}

*From Lappala et al., 1983.

\section{Discussion}

The results of the drainage experiments are only intended to serve a qualitative purpose; therefore, no significant interpretations can be made from the soil samples themselves. Additionally, the drainage response presented here represent only the period in which significant drainage took place. As seen in the associated drainage results for TL -3 and TL - 1, the change in total head in the results presented do not return to zero after drainage (Figure 30a and 32b), which indicates some drainage is still taking place. The rate of drainage at this point, however, did not exceed the rate at which water evaporates from the water collection vessel. Excluding the results in which drainage is insignificant make modeling and interpretation more straightforward, and therefore, only the point of significant drainage is modeled, presented, and discussed here. 
With that said, however, the results of the drainage experiments encourage the use of the experimental setup and integrated hydrogeophysical probe to interpret the unsaturated properties of a given soil sample. Moreover, the test method seems best suited for coarse grained material because the drainage process is relatively short. From a visual comparison of the modeled versus experimental results, RS - 1 showed the best match between the modelled and measured unsaturated response. All three responses (change in total head, SP, and cumulative outflow) were in good agreement with the modeled results (Figure 29). The quality of results for the sand sample support previous statements from the saturated analysis regarding the experimental setup and integrated hydrogeophysical probe's usefulness to make hydrological measurements in sand samples.

The response between modeled and experimental results becomes less congruent for the finer grained regolith soil samples. The input parameters were first evaluated based on the quality of fit of the modeled signal relative to the measured response for the cumulative drained water. Therefore, all the regolith soil samples modeled and experimental cumulative drained results are in relatively good agreement with one another. The cumulative outflow is mainly controlled by the hydraulic conductivity of the soil. Thus, the results indicate the estimation of hydraulic conductivity of the soil are relatively accurate.

For $\mathrm{TL}-3$, there is some discrepancies between the modeled pressure and experimental pressure (Figure 30a). Although the cumulative water drained results are in good agreement, the measured change in total head is significantly greater than the modeled. This discrepancy most likely stems from an inaccurate parameter defining the 
shape of the water retention curve (i.e., $\lambda$ ). At a given water content, the pressure required to drain water from a sample is characterized by the shape of its respective SWRC. In this case, the parameter chosen for TL -3 underestimates the pressure required to move a given amount of water through the sample during drainage. This error may be further exacerbated by the effort made to match the modeled cumulative water drained to the measured. To do so, the input saturated hydraulic conductivity for the modeled response was increased by an order of magnitude from the measured value $\left(3.06 \times 10^{-6} \mathrm{~m} \mathrm{~s}^{-1}\right.$ to $2.00 \times 10^{-5} \mathrm{~m} \mathrm{~s}^{-1}$ ). This increase in $K_{\text {sat }}$ results in a lower hydraulic gradient to move the same amount of water as the experimental response (Equation 1). As a result, the overall magnitude of modeled change in total head is lower than the measured response. The correlation between experimental and modeled SP, however, remains in relatively good correlation for TL -3 .

A similar discrepancy between modeled and experimental change in total head in seen in TL - 2 (Figure 31a). In this instance, however, the modeled response overestimates the change in total head relative to the measured response. No significant changes were made for the input parameters relative to the measured soil parameters from the saturated test. Further statistical evaluation of the input parameters is necessary to determine if the relationship between results can be improved by changing the petrophysical properties of the sample or the Brooks-Corey parameters input into the model. Additionally, it is difficult to make any definitive interpretations for the SP response relative to the water being drained for this sample. Doing so, however, is beyond the scope of this study. The initial modeled and measured SP response to drainage is good, but the correlation between the measured and modeled response is less 
apparent as the drainage test progresses (Figure 31b). The modeled response approaches zero after an initial dip while the measured response begins an almost cyclical cycle, peaking near $0 \mathrm{mV}$ at $4000 \mathrm{~s}$, then returning to $-6 \mathrm{mV}$ at $6500 \mathrm{~s}$, and finally approaching 0 $\mathrm{mV}$ again.

Conversely, the soil response for TL -1 is relatively well matched with the magnitude of modeled values for all three responses. In order to improve the relationship between modeled and experimental results, the $K$ value was increased by an order of magnitude from the measured value $\left(6.24 \times 10^{-7} \mathrm{~m} \mathrm{~s}^{-1}\right.$ to $\left.5.00 \times 10^{-6} \mathrm{~m} \mathrm{~s}^{-1}\right)$. While the magnitude of the measured response correlates to the modeled response, it is hard to make an interpretation for the measured SP response. The SP response does not demonstrate any clear correlation to the drained water (Figure 32b). The overall magnitude of the SP signal is relatively small and is hard to parse out from the associated electrical potential noise. As for mentioned, the quality of SP response observed for slow moving water may be improved by increasing the electrode spacing. See Chapter Five; Performance of Experimental Setup.

Regardless of the quality of correlation between the measured and modeled response, the estimated water retention curve parameters for RS- 1 and the regolith soil samples are within the expected range when compared to published sand and sandy loam parameters (Table 6). To visualize the results of the input Brooks-Corey parameters, the SWRC and the unsaturated hydraulic conductivity vs negative pressure head have been plotted (Figure 33). The shape of the curves in Figure 33 are representative of the grainsize distribution for each sample. For example, the SWRC for RS -1, a sand sample, has almost vertical lines near saturation $(\Theta=1)$ and at complete drainage $(\Theta=0)$, but has a 
shape closer to horizontal between these two points (Figure 33a). The shape of the curve is reflective of a low clay content, which inhibits its ability to hold water. Observations from the SWRC suggest RS-1 can begin draining at soil water pressure head of about 0.1 $\mathrm{m}$ and then reach an effective saturation $\Theta$ near zero at a soil water pressure head of about $1 \mathrm{~m}$. The relatively small range of values indicate the relative ease at which $\mathrm{RS}-1$ can drain water. The ability for RS - 1 to drain water is further reflected in the rate at which its unsaturated hydraulic conductivity decreases with increasing pressure (Figure 33b). Unsaturated hydraulic conductivity is a function of water content (Equation 17), and because RS - 1 can only hold water at relatively small tension values, the unsaturated hydraulic conductivity decreases relatively quickly for RS -1 . Furthermore, the RS -1 SWRC takes on a similar shape as the Del Monte Sand, which suggests the interpretation of SWRC parameters from the drainage response did well to characterize RS -1 . This suggests it is appropriate to use the experimental setup to interpret the unsaturated hydraulic properties of sands.

The Treeline samples, which are classified as sandy loam (Figure 18), cover a larger range of soil water pressure values during their drainage process (Figure 33a). This is indicative of an increased clay mineral content, which improves the soils ability to hold water. To initiate drainage, the regolith samples require a higher air-entry pressure relative to the sand samples. TL -1 , which has the highest clay mineral content, has the highest air-entry pressure $(0.25 \mathrm{~m})$ of the regolith samples (Table 6). Moreover, the shape of each samples curve is reflective of the clay mineral content in each sample. As clay mineral content increases, the gradient of each samples respective SWRC increases. For example, TL -3 , the deepest of the three samples, has a gradual, gently sloping curve 
reflective of low a clay mineral content (Figure 33a). Conversely TL -1 , sampled near the surface and containing the most clay minerals, has the steepest curve and shows water drainage taken place over a large range of soil water pressure head values (Figure 33a). The regolith samples all take on a similar shape to the Columbia Sandy Loam, but the Columbia Sandy Loam starts drainage (i.e., point at which $\Theta$ becomes less than 1) at a higher soil tension. This is indicative of the Columbia Sandy Loam's higher soil air-entry pressure relative to the regolith samples (Table 6). Also, because the sandy loam samples are able to hold water over a greater range of soil water pressure head values, the rate at which the unsaturated hydraulic conductivity values decrease with increasing tension is lower than the sand samples (Figure 33b).

Furthermore, the impact of the Brooks-Corey parameters is reflected in the shape and position of each sample. As previously mentioned, the soil air-entry pressure head $\psi_{b}$ determines the point at which drainage begins, and therefore, the position of the curve on the graph is determined by this parameter. The overall shape of the SWRC is representative of the pore-size distribution index $\lambda$, with larger $\lambda$ values indicating a mostly horizontal curve. As seen in Table 6 , the largest $\lambda$ values are associated with RS 1 and the Del Monte Sand, 3.5 and 2.5 respectively. Both respective curves for these samples are mostly horizontal with near vertical lines at saturation and complete drainage. Furthermore, $\lambda$ become progressively larger as regolith samples become progressively coarser with depth $(0.5$ for $\mathrm{TL}-1,0.8$ for $\mathrm{TL}-2$, and 1.4 for $\mathrm{TL}-3)$. This is again reflected by the shape of the curves for regolith samples where $\mathrm{TL}-3$ has slightly increased gradient relative to the sand samples and $\mathrm{TL}-1$ has the steepest slope relative to all the sampled soils. 
a)

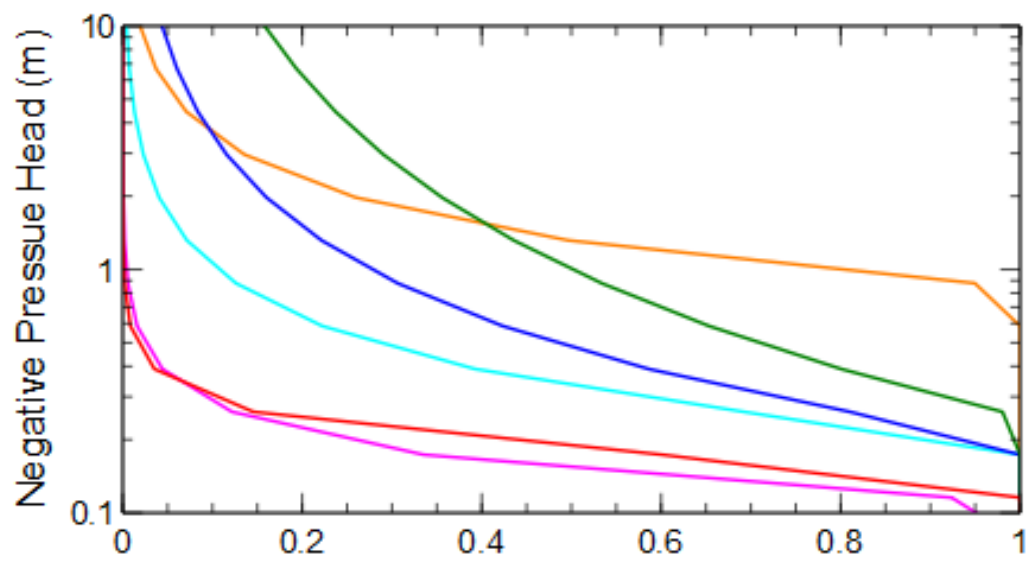

b)

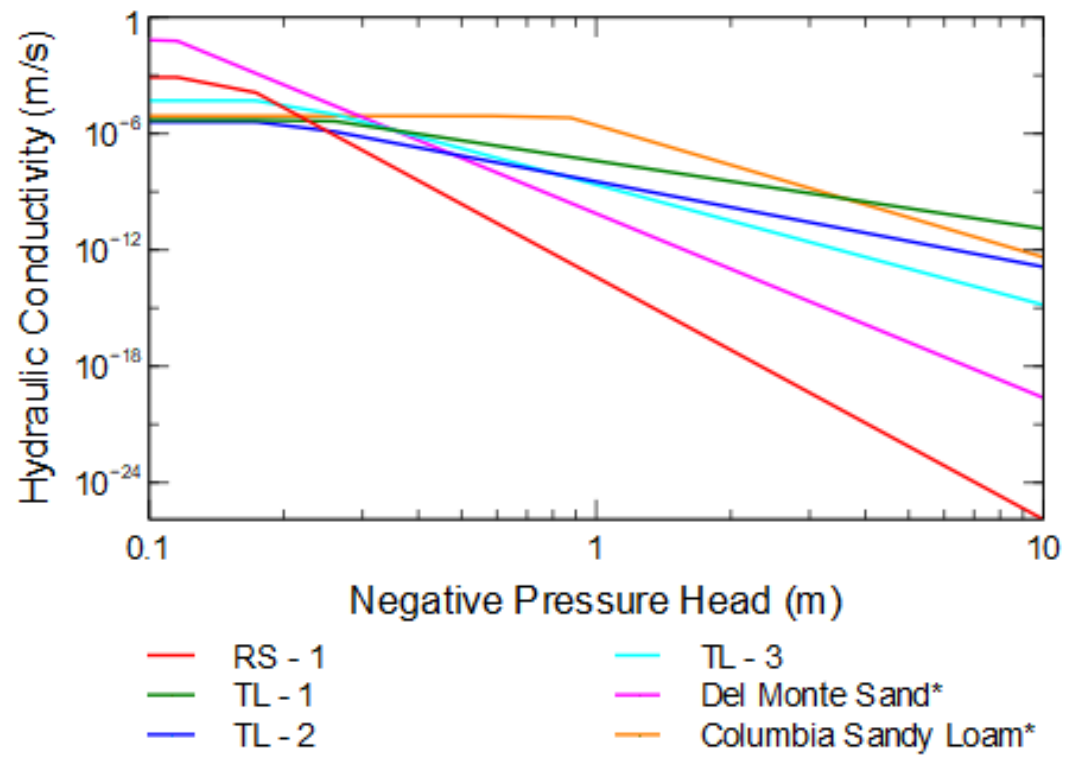

Figure 33 (a) represents the soil water pressure (tension) versus the effective saturation. Both the sand samples (RS-1 and Del Monte Sand), red and pink lines, are in good agreement with one another. The regolith samples have a similar shape to their sandy loam counterpart (the Columbia Sandy Loam), but they have a lower air-entry pressure head $\left(\psi_{b}\right)$ relative to the Columbia Sandy Loam, and therefore, become unsaturated $(\Theta<1)$ at a lower pressure head. The air-entry pressure head

values, however, seem to reflect their relative grainsize distribution. The sand samples have the lowest air-entry pressure head, while the sandy-loam samples have the highest. (b) represents the change in unsaturated hydraulic conductivity with increasing pressure head. Here, the sand samples show a steep decrease in hydraulic conductivity with increasing pressure, while the sandy loam samples have a more gradual change in hydraulic conductivity with increasing pressure. *Samples are from Lappala et al., 1983.

Ultimately, efficiency of finding and the quality of the unsaturated parameters would be improved by taking a more reliable approach than trial and error to fit the 
modeled results of COMSOL to the measured response. Such a process may include developing a computational program to find the best fit parameters via a nonlinear inversion process. This effort, however, is beyond the scope of this study, and a visual interpretation was sufficient to draw conclusions about the ability of this experimental setup and integrated hydrogeophysical probe to measure the drainage response for a given soil. Like the saturated test, the coarser materials showed the best results with regards to the experimental setup. One can make clear interpretations from the measured change in total head and SP response for the sand sample. Additionally, the correlation between the measured and modeled response was more than sufficient for the sand samples. Similar to the saturated tests, the ability to make interpretations about the SP data becomes less straightforward as the soils become finer grained. Again, the quality of the observed SP response for fine soils may be improved by increasing the probe spacing. Moreover, an inversion-based parameter estimation, rather than trial and error fitting, may improve the quality of fit between the measured and modeled drainage responses. 


\section{CHAPTER SEVEN: CONCLUSION}

Characterizing water flux within the $\mathrm{CZ}$ is a difficult process. Both the structural heterogeneity of the subsurface and the complex interactions taking place between biological, chemical, and physical processes make groundwater flow highly variable and difficult to characterize. In this study, it is demonstrated that there is a strong correlation between saturated water flow and SP signals in CZ soils. Moreover, there is also a clear $\mathrm{SP}$ response induced by the unsaturated water flow in $\mathrm{CZ}$ soils. This strong correlation between both unsaturated and saturated water flow and SP signals encourages the use of SP in future hydrological investigations of the CZ. When measurements of the SP signal are combined with other hydraulic measurements, such as soil moisture and water pressure, it is possible to accurately and completely describe the water movement in the subsurface. The concept of simultaneous monitoring of SP and hydraulic variables is an improved method for hydraulic characterization of the $\mathrm{CZ}$ relative to traditional methods. The integration of electrical and hydraulic data could make quantifying water movement in the $\mathrm{CZ}$ more straightforward and less ambiguous.

The novel experimental setup and hydrogeophysical probe performed well in determining the hydrological and electrical properties of coarse-grained geological sediments. The measured electrical response (i.e., SP due to change in pressure) and hydraulic response (i.e., specific discharge due to change in hydraulic gradient) showed an almost perfect linear response, in line with the theoretical expectations, for relatively coarse grained samples $\mathrm{S}-1, \mathrm{RS}-1$, and $\mathrm{TL}-3$. Because these samples closely 
matched the theoretical response for both the saturated streaming potential coupling coefficient and saturated hydraulic conductivity, there is little uncertainty in the ability for this experimental setup to measure the electrical and hydrological properties of coarse-grained sediments. The measured response for soils with a greater quantity of clay minerals (TL -2 and TL -1$)$, however, identified some limitations of the experimental setup. TL -2 showed a sufficient response for specific discharge relative to changes in hydraulic gradient with a $\mathrm{R}^{2}$ of 0.98 , but had a SP response relative to change in total head $\mathrm{R}^{2}$ value of only 0.89 (when the line of best fit passes through the origin). Furthermore, TL -1 , the sample with the highest clay mineral content, had the lowest $\mathrm{R}^{2}$ values for the specific discharge relative to change in hydraulic gradient (0.85) and SP response relative to change in pressure $(0.84)$.

In order to improve the quality of results when evaluating clay-bearing samples with the current experimental setup, two changes are suggested. First, to improve the relationship between specific discharge and change in hydraulic gradient for clay bearing sediments, it is suggested that when the hydraulic gradient is changed, the wait time before making measurements is increased. The clay-bearing samples take a longer time to reach a steady-state and prematurely making measurements before equilibrium can give erroneous results. Second, to improve the relationship between the SP signal and change in total head, it is suggested that the probes spacing is increased. For clay-bearing samples, the water moves relatively slow, and therefore, the resulting SP signal is relatively low. The relative contribution of noise associated with SP measurements may be significant such that it becomes difficult to distinguish the streaming-potential signal from the associated noise. Given a same streaming current, increasing the distance 
between the integrated hydrogeophysical probes will increase the difference in the observed streaming potential. Although the experimental setup leaves room for some improvement, the hydraulic conductivity and streaming potential coupling coefficient of most of the soil samples were accurately measured with little ambiguity and the calculated petrophysical properties of all soils were within the range of published literature values. Ultimately, it is determined that the experimental setup is applicable to coarse grained soils and with some modifications, may become a preferred method for clay-bearing soils as well.

The measured properties of the regolith samples demonstrate the vertical heterogeneity and extent of chemical weathering for soils within the critical zone. The increase in effective grain size with increasing depth speaks to the fact that material from the bedrock is continuously being physically/chemically weathered into finer particles with time. Moreover, the increasing presence of clay minerals indicates an increase in the degree of chemical weathering for samples further from the bedrock. The resulting increasing clay mineral content plays a significant role in the hydrological and electrical properties of the subsurface. The associated increase in clay minerals as a sample becomes farther removed from the bedrock is matched by a proportional decrease in saturated hydraulic conductivity, permeability, streaming potential coupling coefficient, and increase in surface conduction. Moreover, it was determined that the zeta potential at the mineral-water interface (i.e., mineralogical influence), not permeability (i.e., textural influence), determines the magnitude of the streaming potential coupling coefficient of the soils studied here. These results highlight the significant effect of mineralogy (specifically clay mineral content) on the hydraulic and electrical properties of CZ soils. 
Furthermore, when evaluating $\mathrm{CZ}$ soil samples through existing models, it is important to select a model that considers the effects of clay minerals, even if the clay mineral content is minor. Through demonstration of the Kozeny-Carmen equation, it was determined that simply using the effective grain-size (e.g., $\left.d_{10}\right)$, may lead to a significant underestimation of hydraulic conductivity for samples with only small amounts of clay sized particles (i.e., $<10 \%$ ). Additionally, when evaluating the electrical properties of clay-bearing samples, such as the formation factor, it is important to choose a model that appropriately accounts for the surface conduction associated with clay minerals. The model selected for the samples used in this study fell short of correcting the associated surface conduction associated with the samples containing clay minerals.

Finally, the results of the drainage experiments encourage the use of the experimental setup and integrated hydrogeophysical probe to determine the unsaturated properties of a given soil sample. The experimental setup demonstrated some difficulties in characterizing samples with higher clay mineral content, but again, the quality of measured response may be improved by increasing the probe spacing. Regardless of the quality of correlation between the measured and modeled response, the estimated soil water retention curve parameters for RS-1 and the regolith soil samples were within the expected range of theoretical values. The quality of parameters obtained for the unsaturated tests indicate the ability of the test setup to obtain useful information regarding the unsaturated properties of the subsurface. Future work may include developing a computer program that uses nonlinear inversion to determine the unsaturated soil properties that create the best fit modeled response relative to the measured response. 


\section{REFERENCES}

Abbas, M., Jardani, A., Soueid Ahmed, A., Revil, A., Brigaud, L., Bégassat, P., \& Dupont, J. P. (2017). Redox potential distribution of an organic-rich contaminated site obtained by the inversion of self-potential data. Journal of Hydrology, 554, 111-127. https://doi.org/10.1016/j.jhydrol.2017.08.053

Abdulsamad, F., Florsch, N., Schmutz, M., Camerlynck, C., \& Ummisco, U. M. I. (2016). Assessing the high frequency behavior of non-polarizable electrodes for spectral induced polarization measurements. Jounal of Applied Geophysics, 135, 449-455.

Aishlin, P., Thoma, M., and Barrash, W. (2013). Installation, maintenance, and offset calculation for tensionmeters at the Boise Hydrogeophysical Research Site. (Technical Report BSU CGISS 13-02, pp. 1-25). Boise, ID: Boise State University

Allègre, V., Jouniaux, L., Lehmann, F., \& Sailhac, P. (2010). Streaming potential dependence on water-content in Fontainebleau sand. Geophysical Journal International, 182(3), 1248-1266. https://doi.org/10.1111/j.1365246X.2010.04716.x

Allègre, V., Maineult, A., Lehmann, F., Lopes, F., \& Zamora, M. (2014). Self-potential response to drainage-imbibition cycles. Geophysical Journal International, 197(3), 1410-1424. https://doi.org/10.1093/gji/ggu055

Al-Tabbaa, A. and Wood, D. (1987). Some measurements of the permeability of kaolin, Geotechnique, 37, 499-503.

Anderson, S. P., von Blankenburg, F., and White, A. F. (2007). Physical and chemical controls on the critical zone. Elements, 3, 315-319. 
Anderson, S.P., Anderson, R.S., Hinckley, E.S., Kelly, P., \& Blum, A. (2011). Exploring weathering and regolith transport controls on critical zone development with models and natural experiments. Applied Geochemistry, 26, S3-S5. https://doi.org/10.1016/j.apgeochem.2011.03.014

Arabi, M. (1986). Fabric and strength of clays stabilized with lime, (Dissertation). Wales, UK: The Polytechnic of Wales.

Archie, G.E. (1942). The electrical resistivity log as an aid in determining some reservoir characteristics. Petroleum Transactions of the AIME, 146, 54-62.

Avena, M.J. \& De Pauli, C.P. (1998). Proton adsorption and electrokinetics of an Argentinean Montmorillonite. Journal of Colloid and Interface Science, 202, 195-204.

Bear, J. (1972). Dynamics of fluids in porous media, New York, NY: American Elsevier Publishing Company.

Benson, C. \& Gribb, M. (1997). Measuring unsaturated hydraulic conductivity in the laboratory and the field. Geotechnical Special Publication, 68, 113-168.

Blake, G.R. (2008). Particle density. In Chesworth W. (Eds), Encyclopedia of Soil Science Series. Dordrecht: Springer. https://doi.org/10.1007/978-1-4020-3995$9+406$

Bojana, D. \& Otoničar, M. (2007). Evaluation of permeability of saturated clays based on their physical properties. Geologija, 50, 487-495.

Bolève, A., Revil, A., Janod, F., Mattiuzzo, J. L., \& Fry, J. J. (2009). Preferential fluid flow pathways in embankment dams imaged by self-potential tomography. Near Surface Geophysics, 7(5-6), 447-462. https://doi.org/10.3997/18730604.2009012

Börner, F. D., Schopper, J. R., \& Weller, A. (1996). Evaluation of transport and storage properties in the soil and groundwater zone from induced polarization measurements. Geophysical Prospecting, 44, 583-602. 
Brantley, L. B., Goldhaber, M. B., \& Ragnarsdottir, K. V. (2007). Crossing disciplines and scales to understand the critical zone. Elements, 3(5), 307-314. https://doi.org/10.2113/gselements.3.5.307

Brickmore, B. (2019). RockjockML [Computer Software]. Retrieved from http://geology.byu.edu/bickmorewiki/?q=content/rockjockml

Brooks, R.H. \& Corey, A.T. (1964). Hydraulic properties of porous media, in Hydrology Paper No. 3, Colorado State University, Fort Collins, Colorado.

Breede, K., Kemna, A., Esser, O., Zimmermann, E., Vereecken, H., \& Huisman, J.A. (2012). Spectral induced polarization measurements on variably saturated sandclay mixtures. Near Surface Geophysics, 10(6), 479-489.

Carcione, J.M., Gei, D., Yu, T., \& Ba, J. (2019). Effect of Clay and Mineralogy on Permeability. Pure Applied Geophysics. 176, 2581-2594. https://doi.org/10.1007/s00024-019-02117-3

Carman, P. C. (1937). Fluid flow through granular beds. Transactions of the Institution of Chemical Engineers, 15, 150-166.

Cherian, C. \& Arnepalli, D. (2015). A critical appraisal of the role of lcay mineralogy in lime stabilization. International Journal of Geosynthetics and Ground Engineering, 1, 1-20. https://doi.org/10.1007/s40891-015-0009-3

Chidichimo, F., Biase, M. De, Rizzo, E., Masi, S., \& Straface, S. (2015). Hydrodynamic parameters estimation from self-potential data in a controlled full-scale site. Journal of Hydrology, 522, 572-581. https://doi.org/10.1016/j.jhydrol.2015.01.022

Chiorean, V. F. (2017). Determination of matric suction and saturation degree for unsaturated soils, comparative study - numerical method versus analytical method. IOP Conference Series: Materials Science and Engineering, 245(3). https://doi.org/10.1088/1757-899X/245/3/032074

Clayton, J.L. (1974). Clay mineralogy of soils in the Idaho Batholith. GSA Bulletin, 85 (2), 229-232. 
Cornell University Cooperative Extension (CUCE). (2007). Cation exchange capacity (CEC). agronomy fact sheet series \#22. Department of Crop and Soil Sciences, College of Agriculture and Life Sciences, Cornell University.

Corwin, R. (1990). The self-potential method for environmental and engineering applications. Geotechnical and Environmental Geophysics, 1, 127-143.

Crespy, A., Bolève, A., \& Revil, A. (2007). Influence of the Dukhin and Reynolds numbers on the apparent zeta potential of granular porous media. Journal of Colloid and Interface Science, 305(1), 188-194. https://doi.org/10.1016/j.jcis.2006.09.038

Dahlin, T., Leroux, V., \& Nissen, J. (2002). Measuring techniques in induced polarisation imaging. Journal of Applied Geophysics, 50(3), 279-298. https://doi.org/10.1016/S0926-9851(02)00148-9

Darnet, M., \& Marquis, G. (2004). Modelling streaming potential (SP) signals induced by water movement in the vadose zone. Journal of Hydrology, 285(1-4), 114-124. https://doi.org/10.1016/j.jhydrol.2003.08.010

Deer, W.A., Howie, R.A., \& Zussman, J. (2013). $3^{\text {rd }}$ ed. An Introduction to the RockForming Minerals, London: Minerlogical Society of Great Britain and Ireland. https://doi.org/10.1180/DHZ

Dingman, L. S. (2015). Physical Hydrology, Long Grove, Illinois: Waveland Press, Inc.

Doussan, C., Jouniaux, L., and Thony, J. L. (2002). Variations of self-potential and unsaturated water flow with time in sandy loam and clay loam soils. Journal of Hydrology, 267(3-4), 173-185. https://doi.org/10.1016/S0022-1694(02)00148-8

Eberl, D. (2003). User guide to RockJock - a program for determining quantitative mineralogy from $x$-ray diffraction data (Open-File Report 2003-78). USGS.

Eggleton, R. A. (Ed.). (2001). The Regolith Glossary: Surficial Geology, Soils and Landscapes. Floreat Park, Western Australia: Cooperative Research Centre for Landscape Environments and Mineral Exploration. 
Fullhart, A.T., Kelleners, T.J., Chandler, D.G., McNamara, J.P., \& Seyfried, M.S. (2018). Water flow modeling with dry bulk density optimization to determine hydraulic properties in mountain soils. Soil Science Society of America Journal, 82(1), 3144. https://doi.org/10.2136/sssaj2017.06.0196

Garba, M. A., Vialle, S., Madadi, M., Gurevich, B., \& Lebedev, M. (2019). Electrical formation factor of clean sand from laboratory measurements and digital rock physics. Solid Earth Discuss, 10(5), 1505-1517. https://doi.org/10.5194/se-2018133

Glover, P. W. J., Hole, M. J., \& Pous, J. (2000). A modified Archie's law for two conducting phases. Earth Planet Science Letters, 180(3-4), 369-383.

Gray D. M., \& Granger, R. J. (1986). In situ measurement of moisture and salt movement in freezing soils. Canadian Journal of Earth Science, 23, 696-704.

Haghverdi, A., Öztürk, H.S., \& Durner, W. (2018). Measurement and estimation of the soil water retention curve using the evaporation method and the pseudo continuous pedotransfer function. Journal of Hydrology, 563. 251-259. https://doi.org/10.1016/j.jhydrol.2018.06.007

Hazen, A. (1892). Some physical properties of sands and gravels, with special reference to their use in filtration. Boston, MA: Massachusetts State Board of Health.

Hu, K., Jougnot, D., Huang, Q., Looms, M. C., \& Linde, N. (2020). Advancing quantitative understanding of self-potential signatures in the critical zone through long-term monitoring. Journal of Hydrology, 585, 1-17. https://doi.org/10.1016/j.jhydrol.2020.124771

Iwata, Y., \& Hirota, T. (2005). Monitoring over-winter soil water dynamics in a freezing and snow-covered environment using a thermally insulated tensiometer. Hydrological Processes, 19(15), 3013-3019. https://doi.org/10.1002/hyp.5813

Jaafar, M. Z., Vinogradov, J., \& Jackson, M. D. (2009). Measurement of streaming potential coupling coefficient in sandstones saturated with high salinity $\mathrm{NaCl}$ brine. Geophysical Research Letters, 36(21), 1-6. https://doi.org/10.1029/2009GL040549 
Jang, A., Lee, J., Bhadri, P., Kumar, S., Timmons, W., Beyette, F., et al. (2005).

Miniaturized redox potential probe for in-situ environmental monitoring. Environmental Science and Technology, 39 (16), 6191-6197. https://doi.org/10.1021/es050377a

Jardani, A., Dupont, J. P., \& Revil, A. (2006). Self-potential signals associated with preferential groundwater flow pathways in sinkholes. Journal of Geophysical Research: Solid Earth, 111(9), 1-13. https://doi.org/10.1029/2005JB004231

Jardani, A., Revil, A., \& Dupont, J. P. (2013). Stochastic joint inversion of hydrogeophysical data for salt tracer test monitoring and hydraulic conductivity imaging. Advances in Water Resources, 52, 62-77. https://doi.org/10.1016/j.advwatres.2012.08.005

Johnson, K.M., Lewis, R.S., Bennett, E.H., and Kiilsgaard, T.H. (1988). Cretaceous and Tertiary intrusive rocks of south-central Idaho. In P.K. Link, P.K. \& W.R. Hackett (Eds.), Guidebook to the Geology of Central and Southern Idaho (Bulletin 27, pp. 55-86). Idaho Geologic Survey.

Jougnot, D., Ghorbani, A., Revil, A., Leroy, P., \& Cosenza, P. (2010). Spectral induced polarization of partially saturated clay-rocks: A mechanistic approach. Geophysical Journal International, 180(1), 210-224. https://doi.org/10.1111/j.1365-246X.2009.04426.x

Jougnot, D., Linde, N., Haarder, E. B., \& Looms, M. C. (2015). Monitoring of saline tracer movement with vertically distributed self-potential measurements at the HOBE agricultural test site, Voulund, Denmark. Journal of Hydrology, 521, 314327. https://doi.org/10.1016/j.jhydrol.2014.11.041

Jouniaux, L. \& Pozzi, J. P. (1995). Permeability dependence of streaming potential in rocks for various fluid conductivities. Geophysical Research Letters, 22, 485-488.

Katsube, T., Klassen, R.A., Das, Y., Ernst, R., Calvert, T., Cross, G., et al. (2003). Prediction and validation of soil electromagnetic characteristics for application in landmine detection. Proceedings of SPIE - The International Society for Optical Engineering, 5089, 1219-1230. https://doi.org/10.1117/12.486983. 
Kelleners, T.J., Chandler, D.G., McNamara, J.P., Gribb, M.M., \& Seyfried, M.S. (2009). Modeling the water and energy balance of vegetated areas with snow accumulation. Vadose Zone Journal, 8, 1013-1030. https://doi.org/10.2136/vzj2008.0183

King, E.M., Valley, J.W. (2000). The source, magmatic contamination, and alteration of the Idaho batholith. Contributions to Mineralogy and Petrology, 142, 72-88. https://doi.org/10.1007/s004100100278

Lambe, T. W., \& Whitman, R. V. (Eds.). (1969). Soil mechanics. New York, NY: John Wiley.

Lappala, E.G., Healy, R.W., \& Weeks, E.P., (1983). Documentation of the computer program VS2D to solve the equations of fluid flow in variably saturated porous media. Water-Resources Investigations (Report 83-4099, pp. 184). U.S.G.S.

Leung, A. K., Garg, A., \& Ng, C. W. W. (2015). Effects of plant roots on soil-water retention and induced suction in vegetated soil. Engineering Geology, 193, 183197. https://doi.org/10.1016/j.enggeo.2015.04.017

Lo, W. C., Yang, C. C., Hsu, S. Y., Chen, C. H., Yeh, C. L., \& Hilpert, M. (2017), The dynamic response of the water retention curve in unsaturated soils during drainage to acoustic excitations. Water Resource Research, 53, 712- 725. https://doi.org/10.1002/2016WR018833

Mariappan, S., Bin, F., \& Huat, L. (2009). Matric suction and slope engineering, Paper presented in $3^{\text {rd }}$ Geotechnical and Ecological Environmental Management for Global Sustainability, Japan-Malaysia Symposium on Geohazards and Geoenvironmental Engineering, Kyoto, Japan.

Mboh, C. M., Huisman, J. A., Zimmermann, E., \& Vereecken, H. (2012). Coupled hydrogeophysical inversion of streaming potential signals for unsaturated soil hydraulic properties. Vadose Zone Journal, 11(2), 1-14. https://doi.org/10.2136/vzj2011.0115 
McNamara, J. P., Chandler, D. G., Seyfried, M., \& Achet, S. (2005). Soil moisture states, lateral flow, and streamflow generation in a semi-arid, snowmelt-driven catchment. Hydrological Processes, 19, 4023-4038.

Migoń, P. (2013). Weathering mantles and long-term landform evolution. In J. Shroder \& G.A. (Eds.), Treatise on Geomorphology (Vol. 4, pp. 127 - 144). San Diego, CA: Academic Press.

Miller, C., Routh, P., Brosten, T., \& McNamara, J. (2008). Application of time-lapse ERT imaging to watershed characterization. Geophysics, 73(3), 1-46. https://doi.org/10.1190/1.2907156

Mitchell, J.K. \& Soga, K. (Eds.). (2005). Fundamentals of soil behavior (Vol. 3). New York, NY: John Wiley \& Sons

Ng, C. W. W., \& Pang, Y. W. (2000). Experimental investigations of the soil-water characteristics of a volcanic soil. Canadian Geotechnical Journal, 37(6), 12521264. https://doi.org/10.1139/t00-056

Niu, Q., \& Zhang, C. (2018). Physical explanation of Archie's porosity exponent in granular materials: A process-based, pore-scale numerical study. Geophysical Research Letters, 45, 1870- 1877. https://doi.org/10.1002/2017GL076751

Nordsiek, S., Diamantopoulos, E., Hördt, A., \& Durner, W. (2016). Relationships between soil hydraulic parameters and induced polarization spectra. Near Surface Geophysics, 14(1), 23-37. https://doi.org/10.3997/1873-0604.2015050

National Research Council (NRC) (2001): Basic research opportunities in earth science. Washington DC.: The National Academy Press.

Odom, I. E. (1984). Smectite clay minerals: properties and uses, Philosophical Transactions of the Royal Society of London. Series A, Mathematical and Physical Sciences, 311(1517), 391-409 http://doi.org/10.1098/rsta.1984.0036

Pope, G. (2015). Regolith and Weathering (Rock and Decay) in the critical zone. In J. Giardino \& C. Houser (Eds.), Developments in Earth Surface Processes (Vol. 19). New York, NY: Elsevier. https://doi.org/10.1016/B978-0-444-63369-9.00004-5 
Rawls, W.J., Pachepsky, Y.A., Ritchie, J.C., Sobecki, T.M., \& Bloodworth, H. (2003). Effect of soil organic carbon on soil water retention, Geoderma, 116 (1), 61-76.

Revil, A., Ahmed, A. S., \& Jardani, A. (2017a). Self-potential: A Non-intrusive Ground Water Flow Sensor. Journal of Environmental and Engineering Geophysics, 22(3), 235-247. https://doi.org/10.2113/JEEG22.3.235

Revil, A., Coperey, A., Shao, Z., Florsch, N., Fabricius, I. L., Deng, et al. (2017b). Complex conductivity of soils. Water Resources Research, 53(8), 7121-7147. https://doi.org/10.1002/2017WR020655

Revil, A., Florsch, N., \& Camerlynck, C. (2014). Spectral induced polarization porosimetry. Geophysical Journal International, 198(2), 1016-1033. https://doi.org/10.1093/gji/ggu180

Revil, A. \& Glover, P. W. J. (1997) Theory of ionic surface electrical conduction in porous media, Physical Review B, 55, 1757-1773. https://doi.org/10.1103/PhysRevB.55.1757

Revil, A., Karaoulis, M., Johnson, T., \& Kemna, A. (2012). Review: Some lowfrequency electrical methods for subsurface characterization and monitoring in hydrogeology. Hydrogeology Journal, 20(4), 617-658. https://doi.org/10.1007/s10040-011-0819-x

Revil, A., Schwaeger, H., Cathles, L. M., \& Manhardt, P. D. (1999). Streaming potential in porous media: 2. Theory and application to geothermal systems, Journal of Geophysical Research, 104( B9), 20033-20048. https://doi.org/10.1029/1999JB900090

Richards, L. A. (1931). Capillary conduction of liquids through porous mediums, Physics, 1(5), $318-333$.

Rizzo, E., Suski, B., Revil, A., Straface, S., \& Troisi, S. (2004), Self-potential signals associated with pumping tests experiments, Journal of Geophysical Research, 109(B10203), 1-14. https://doi.org/10.1029/2004JB003049 
Robinson, J., Slater, L., Weller, A., Keating, K., Robinson, T., Rose, C., \& Parker, B. (2018). On Permeability Prediction From Complex Conductivity Measurements Using Polarization Magnitude and Relaxation Time. Water Resources Research, 54(5), 3436-3452. https://doi.org/10.1002/2017WR022034

Robinson, J. L., Slater, L. D., \& Schafer, K. V. R. (2012). Evidence for spatial variablity in hydraulic redistrivution within an oak-pine forest from resistivity imaging. Journal of Hydrology, 430-431, 69-79. https://doi.org/10.1016/j.jhydrol.2012.02.002

Salem, H. S., \& Chilingarian, G. V. (1999). The cementation factor of Archie's equation for shaly sandstone reservoirs. Journal of Petroleum Science and Engineering, 23(2), 83-93. https://doi.org/10.1016/S0920-4105(99)00009-1

Schwartz, F.W. and Zhang, H. (Eds.). (2003). Fundamentals of Groundwater, New York, NY: John Wiley \& Sons.

Shaw, R.J., Coughlan, K.J., \& Bell, L.C. (1998). Root zone sodicity. In Sumner, M.E. \& Naidu, R. (Eds.), Sodic soils: Distribution, properties, management, and environmental consequences (pp. 95-106). New York, NY: Oxford University Press.

Shwetha, P. \& Varija, K. (2015). Soil water retention curve from saturated hydraulic conductivity for sandy loam and loamy sand textured soils. Aquatic Procedia, 4, 1142-1149. https://doi.org/10.1016/j.aqpro.2015.02.145

Sill, W. R. (1983). Self-potential modeling from primary flows. Geophysics, 48, 76-86. https://doi.org/10.1190/1.1441409

Slater, L., Barrash, W., Montrey, J., and Binley, A. (2014). Electrical-hydraulic relationships obserbed for unconsolidated sediments in the presence of a cobble framework. Water Resources Research, 50, 1-20.

Smoluchowski, M. (1905). Zur theorie der elektrischen kataphorese und der oberflächenleitung. Physikalische Zeitschrift, 6, 529-536. 
Straface, S., Chidichimo, F., Rizzo, E., Riva, M., Barrash, W. A. Revil, et al. (2011). Joint inversion of steady-state hydrologic and self-potential data for 3D hydraulic conductivity distribution at the Boise Hydrogeophysical Research Site, Journal of Hydrology, 1-4, 115-128. https://doi.org/10.1016/j.jhydrol.2011.07.013

van Genuchten, M. T. (1980). A closed-form equation for predicting the hydraulic conductivity of unsaturated soils. Soil Science Society of America Journal, 44(5), 892-898. https://doi.org/10.2136/sssaj1980.03615995004400050002x

Voytek, E. B., Barnard, H. R., Jougnot, D., \& Singha, K. (2019). Transpiration- and precipitation-induced subsurface water flow observed using the self-potential method. Hydrological Processes, 33(13), 1784-1801. https://doi.org/10.1002/hyp.13453

Walker, J., Willgoose, G., and Kalma, J. (2004). In situ measurement of soil moisture: A comparison of techniques. Journal of Hydrology, 293(1), 85-99. https://doi.org/10.1016/j.jhydrol.2004.01.008

Wang, T., Franz, T.E., Yue, W., Szilagyi, J., Zlotnik, V.A., You, J., et al. (2016). Feasibility analysis of using inverse modeling for estimating natural groundwater recharge from a large-scale soil moisture monitoring network. Journal of Hydrology, 533, 250-265.

Watlet, A., Kaufmann, O., Triantafyllou, A., Poulain, A., Chambers, J. E., Meldrum, P. I. et al. (2018). Imaging groundwater infiltration dynamics in the karst vadose zone with long-term ERT monitoring. Hydrology and Earth System Sciences, 22, 1563-1592. https://doi.org/10.5194/hess-22-1563-2018, 2018.

Weller, A., Slater, L., \& Nordsiek, S. (2013). On the relationship between induced polarization and surface conductivity: implications for petrophysical interpretation of electrical measurements. Geophysics, 78, D315-D325.

West, L.J. \& Stewart, D.I. (1995). Effect of zeta potential on soil electrokinesis. Geoenvironment. ASCE Special Publication, 46, 1535 -1549. 
White, A.F. \& Blum, A.E. (1995). Effect of climate on chemical weathering in watersheds. Geochimica et Cosmochimica Acta, 59(9), 1729-1747. https://doi.org/10.1016/0016-7037(95)00078-E

Williams, C. J. (2005). Characterization of the spatial and temporal controls on soil moisture and streamflow generation in a semi-arid headwater catchment, (Master's thesis). Boise, ID: Boise State University.

Wyllie, M.R.J. \& Spangler, M.B. (1952). Application of electrical resistivity measurements to problem of fluid flow in porous media, AAPG Bulletin, 36(2), 359-403.

Yenko, M. K. (2003). Hydrometric and geochemical evidence of streamflow sources in the upper Dry Creek Experimental Watershed, southwestern Idaho, (Master's thesis). Boise, ID: Boise State University.

Younes, A., Zaouali, J., Lehmann, F., \& Fahs, M. (2018). Sensitivity and identifiability of hydraulic and geophysical parameters from streaming potential signals in unsaturated porous media. Hydrology and Earth System Sciences, 22(7), 35613574. https://doi.org/10.5194/hess-22-3561-2018

Yukselen, Y. \& Kaya, A. (2003). Zeta potential of kaolinite in the presence of alkali, alkaline earth and hydrolysable metal ions. Water, Air, and Soil Pollution, 145, 155-168. 